Portland State University

PDXScholar

1995

Performance Appraisal in Organizational Cultural Context

Unoda C. Moyo

Portland State University

Follow this and additional works at: https://pdxscholar.library.pdx.edu/open_access_etds

Part of the Organizational Behavior and Theory Commons Let us know how access to this document benefits you.

Recommended Citation

Moyo, Unoda C., "Performance Appraisal in Organizational Cultural Context" (1995). Dissertations and Theses. Paper 1155.

https://doi.org/10.15760/etd.1154

This Dissertation is brought to you for free and open access. It has been accepted for inclusion in Dissertations and Theses by an authorized administrator of PDXScholar. Please contact us if we can make this document more accessible: pdxscholar@pdx.edu. 


\title{
PERFORMANCE APPRAISAL \\ IN \\ ORGANIZATIONAL CULTURAL CONTEXT
}

by

UNODA CURRICULUM MOYO

A Dissertation Submitted in Partial Fulfillment of the Requirements for the Degree of

\author{
DOCTOR OF PHILOSOPHY \\ IN \\ PUBLIC ADMINISTRATION AND POLICY
}

PORTLAND STATE UNIVERSITY

1995 
UMI Number : 9542389

UMI Microform 9542389

Copyright 1995, by UMI Company. All rights reserved.

This microform edition is protected against unauthorized copying under Title 17, United States Code.

\section{UMI}

300 North zeeb Road

Ann Arbor, MI 48103 


\section{DISSERTATION APPROVAL}

The abstract and dissertation of Unoda Curriculum Moyo for the Doctor of Philosophy in Public Administration and Policy was presented May 3, 1995 and accepted by the dissertation committee and the doctoral program.

APPROVALS :

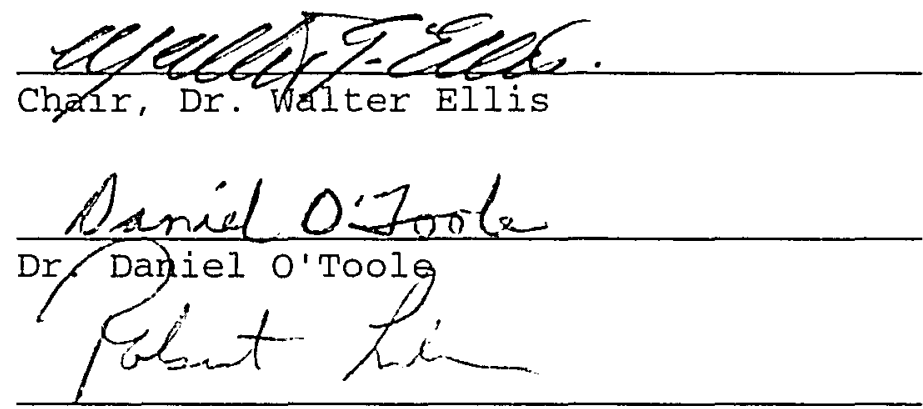

Dr. Robert Liebman

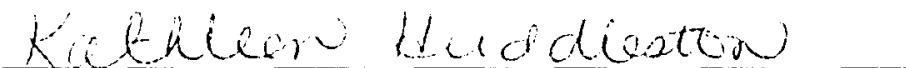
Dr. Kathleen Huddleston

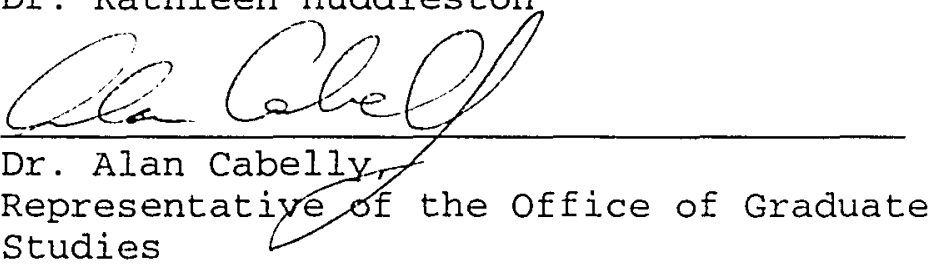

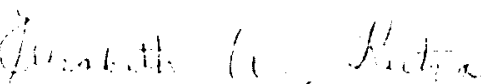
Elizabeth A. Kutza/, Coordinator, Ph.D. Program in Public Administration and Policy

ACCEPTED FOR PORTLAND STATE UNIVERSITY bY the LIBRARY

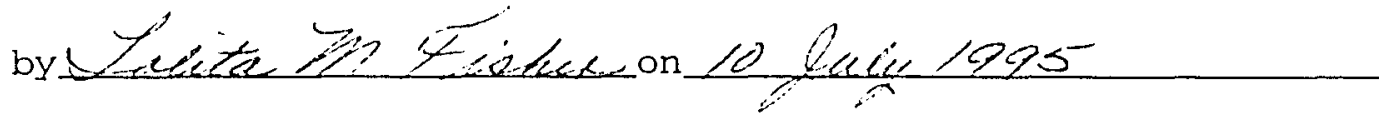




\begin{abstract}
An abstract of the dissertation of Unoda Curriculum Moyo for the Doctor of Philosophy in Public Administration and Policy presented May 3, 1995.

Title: Performance Appraisal in Organizational Cultural Context
\end{abstract}

This study examined the relationship between an organization's culture and its performance appraisal (PA) system and process. The initial phase of this study involved examining an organization's culture and the properties of its performance appraisal system from organizational archival information. Information derived from this phase of the study was later utilized to formulate interview questions, guide the search for the organizational culture survey instrument, and to construct the performance appraisal perceptions measuring instrument. This latter instrument is a quantitative measure that was later employed in testing the primary hypothesis that stated the performance appraisal process had a positive effect on organizational culture.

The results of the hypotheses testing revealed that the PA process, in terms of individual member perceptions 
thereof, had a significant positive effect on the selected organizational cultural elements. Further analysis of the data revealed that members of the organization that had been recently appraised had statistically stronger positive perceptions towards the PA process and, therefore, stronger inclination towards the espoused cultural values.

These findings make a strong case for using the performance appraisal process for the purpose of not only evaluating individual performance for various administrative goals, but for other goals related to creating, maintaining, and perpetuating the desired organizational culture. This suggests that organizational leadership (through its management), when designing its PA system should pay attention to the value system, or the culture, it wants to prevail in its organization and include this information along with other relevant performance measures into the PA structure. Such a policy can lead to the existence of an appropriate culture for that organization if, as the results of this study show, the managers and supervisors at all levels timely perform such appraisals for all their subordinates.

Performance appraisal, which itself is often considered a structural element designed for organizational control, has the potential to have as much impact on an 
organization's culture as any other mode of communication. In that regard, this study takes a step towards looking at PA as one more criteria to be examined during organizational cultural studies and organizational intervention. 


\section{ACKNOWLEDGEMENT}

This work is dedicated to Evelyne A. Kashi who persevered with me during this challenging time. Your patience and love are greatly appreciated. I would not have made it without your support $A B$. Thank you. 
Table of Contents

\section{Acknowledgement3}

\section{Abstruct}

List of Figures.......................

List of Tables........................ VI

\section{Chapter 1}

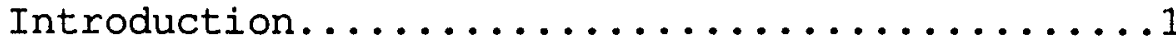

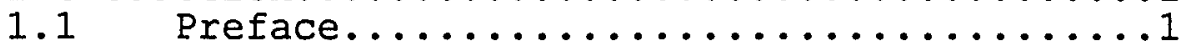

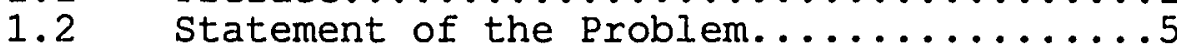

1.3 Research Purpose and Scope...........8

\section{Chapter 2}

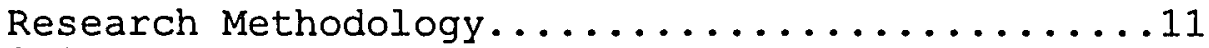

2.1 Choice of Methodology................11

2.2 OCTAPACE: Survey of Organizational Ethos.12

2.3 The Performance Appraisal Perception

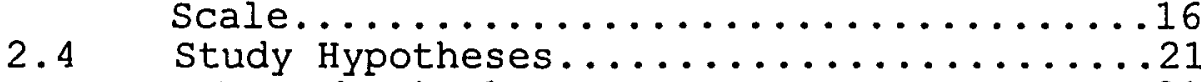

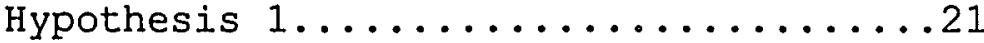

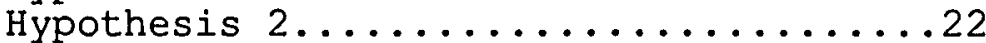

Hypothesis $3 \ldots \ldots \ldots \ldots \ldots \ldots \ldots . \ldots \ldots 22$

Hypothesis $4 \ldots \ldots \ldots \ldots \ldots \ldots . \ldots \ldots 23$

Hypothesis $5 \ldots \ldots \ldots \ldots \ldots \ldots \ldots . \ldots \ldots 23$

Hypothesis $6 \ldots \ldots \ldots \ldots \ldots \ldots . \ldots \ldots 23$

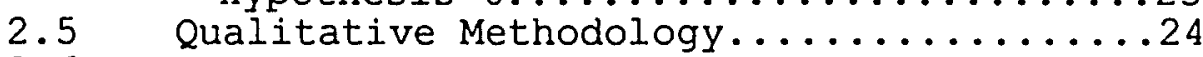

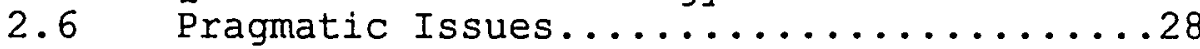

2.6.1 Gaining Entry into Organizations.........29

2.6.2 Control over Individual Participation....30

2.6.3 Designing and Pre-testing the Survey

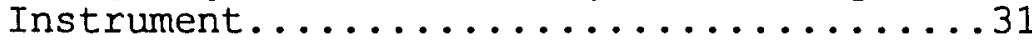

\section{Chapter 3}

Organization Theory and the

Organizational Culture Perspective..........34

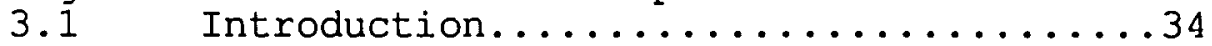

3.2 The Emergence of the Organizational

Culture Perspective..............38

Chapter 4

Understanding the Performance Appraisal

Process........................48

4.1 Introduction.................48

4.2 Performance Appraisal Literature Review..49

4.3 Performance Appraisal at Ecology Agency..55 
Chapter 5

Ecology Agency Culture...............663

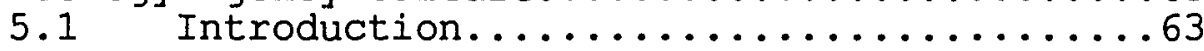

5.2 The Anatomy of a Techno-Pollegal Culture. 67

5.3 History of Ecology Agency............72

5.4 Current Ecology Agency Organizational

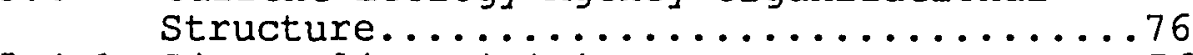

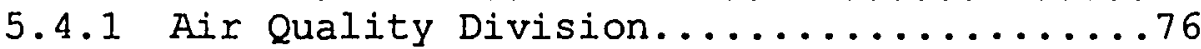

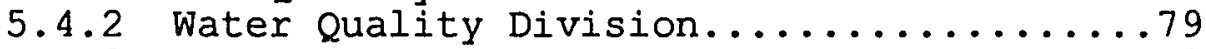

5.4.3 Waste Management and Cleanup Division...882

5.4 .4 Regional Divisions...............85

5.4 .5 Management Services Division...........86

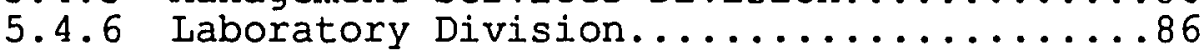

5.4 .7 summary...................... 91

5.5 Societal Cultural Influence..........94

5.6 Nature of the Business Cultural

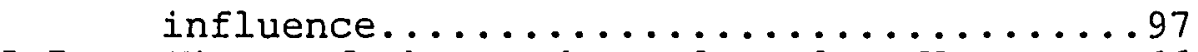

5.7 Views of the Leader Cultural Influence...111

5.8 Summary of the Cultural Influences......104

Chapter 6

Results from Quantitative Inquiry..........114

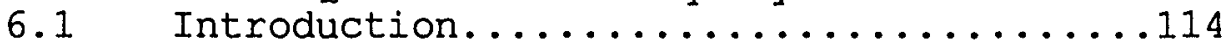

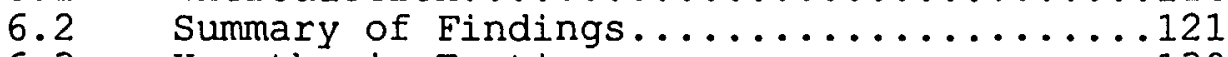

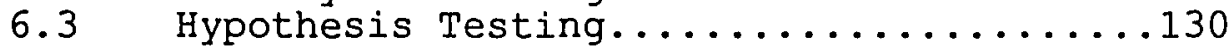

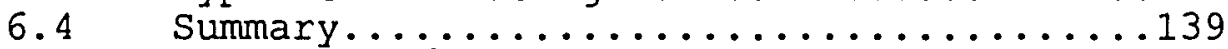

Chapter 7

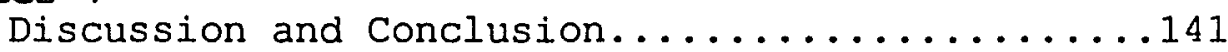

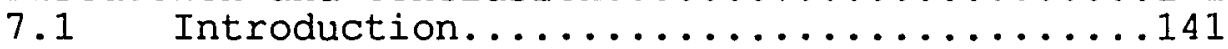

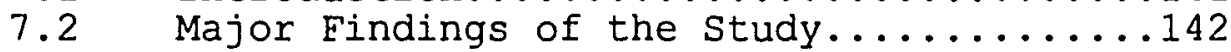

7.3 Contributions of the study..........147

7.4 Study Limitations and Suggestions

for Future Research................148

References ............................. 154

Appendices

1 Factor Analysis and the Construction of the PA Perception Scale

la Performance Appraisal Perception Questionnaire and PA Perception Scale Scoring sheet

1b Organizational Culture Survey and Scoring Sheet

1c Introductory Letter and Informed Consent Form

1d Interview Questions For Organizational Members

2 Complete Ecology Agency performance Appraisal System Dimensions With Brief Definitions 
Figure

List of Figures

1.1 Performance Appraisal in Larger

Organizational Context...........6

1.2 Schein's Three Levels of Culture

2.1 and their Interaction.............

2.1 Ecology Agency Organizational Chart...26

5.1 The Culture Triangle............65

5.2 Structure of the Techno-Pollegal

5. Culture in the Early Years..........71

5.3 Structure of the Techno-Pollegal

Culture today..................71

Air Quality Division

5.5 Water Quality Division

5. Organizational Chart.............80

5.6 Waste Management and Cleanup

5.7 Eastern Region Division

Organizational Chart.............87

5.8 Northwest Region Division

Organizational Chart.............88

5.9 Western Region Division

Organizational Chart............89

5.10 Management Services Division

Organizational Chart.............90

5.11 Laboratory Division

Organizational Chart..............92

5.12 Divisional Orientation in the Techno-Pollegal Culture............93

5.13 The Environmental Policy Making

5.14 Ecology Ägency organizational Chart

Before Reorganization.............106

5.15 Ecology Agency Culture in Terms of Three Levels of Culture and their

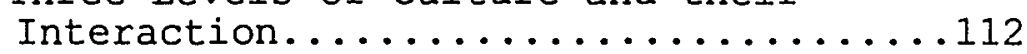




\section{List of Tables}

Table

Page

2.1 Norms of the OCTARACE Profile.........15

6.1 Demographic Profile of EA Respondents..120

6.2 Mean Organizational Scores on PA and

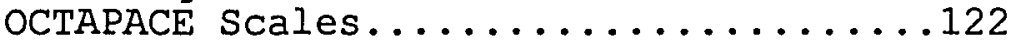

6.3 Mean Management Scores on PA and OCTAPACE Scales..................123

6.4 Mean Non-Management Scores on PA and OCTAPACE Scales.................123

6.5 Mean Scores for Division Administrators on $\mathrm{PA}$ and OCTAPACE Scales.......................124

6.6 Mean Non-Management Scores on PA and OCTAPACE Scales by Division............124127

6.7 Mean Non-Management Scores on PA and oCTAPACE Scales by Gender..........128

6.8 Mean Non-Management Scores on PA and OCTAPACE Scales by Education..........129

6.9 Mean Non-Management Scores on PA and OCTAPACE Scales by Region...........130

6.10 PA Perceptions on Openness...........132

6.11 PA Perceptions on Trust............132

6.12 PA Perceptions on Collaboration........133

6.13 PA Perceptions on Confrontation........133

6.14 ANOVA by Date of last Performance Appraisal.............136

6.15 ANOVA by Length of Service..........137

6.16 Frequency Table of Length of Service by Date of Last Appraisal.......139 


\section{Chapter 1}

\section{Introduction}

\subsection{Preface}

Human resource management (HRM) and organizational or corporate culture are concepts that made their way into management literature at about the same time as a result of similar socio-economic developments. These developments began to be felt in the mid-to-late seventies and eventually took a hold in the eighties and became soundly established in the nineties. HRM and organizational culture concepts, although related, have been largely dealt with in isolation from each other, although some authors have anticipated and suggested the likely relationship (Walton, 1991; Townley, 1989; Quinn Mills and Balbaky, 1985; Von Glinow, 1988). Most of these anticipations and suggestions owed their credence, in large part, to their recognition of the complex role these concepts play in most complex organizations. Performance appraisal (PA) is perhaps the most important HRM support system utilized by most organizations. Its influence can be more extensive in the cognitive processes of an organizational member than any single management system. For this reason, this HRM system may, in fact, play a role in maintaining and perpetuating an 
organization's culture. The extent to which the PA system is appropriately designed, implemented, and evaluated may result in the successful or unsuccessful

institutionalization of appropriate organizational culture. Appropriate cultures, variously defined as strong cultures (Deal \& Kennedy, 1982), integrated cultures (Von Glinow, 1988), well defined cultures (Kotter \& Heskett, 1992), strategically appropriate cultures (Schwartz \& Davis, 1981), and a combination thereof (see Akin \& Hopelain, 1986; Peters \& Waterman, 1982; Bolman \& Deal, 1984; Barney, 1986; Dyer, 1986) have been linked to greater organizational effectiveness.

To date, most of the literature dealing with the subject of organizational culture has focused on four related themes: Socialization; Storytelling; Managing culture and relationship between business strategy and organizational culture and; research methodology (Denison, 1990). These themes will be further explored in the chapter dealing with organizational culture. To these themes, this study sought to add a fifth theme: Performance Appraisal as a culture affecting phenomenon.

Organizational culture is a product of three main influences: Societal culture; Nature of the organization's business and; The views and values of founders or leaders 
(Schein, 1992). This istudy sought to explore and test the last influence in terms of an organization's performance appraisal process. In other words, it sought to examine the possibility that organizational leadership may be communicating the organizational values through the performance appraisal process.

The larger societal culture shapes the culture an organization adopts (Pfeiffer \& Salancik, 1978; Lawrence \& Lorsch, 1967). This has been shown in a number of studies about multinational corporations and international managers (see especially Hofstede, 1984; 1981; 1980; 1980 Summer; and Laurent, 1983). The nature of an organization's business has an impact on its organizational culture due, in part, to the nature of the business environment which, to a significant extent, dictates how organizations in that environment ought to operate and what sort of individuals get drawn to that environment. For example, we generally expect people who work in banks to be markedly different from those who work in manufacturing in terms of their dress and views of what is important for success (see Becker, Geer, Hughes, \& Stauss, 1961; Whyte, 1956; Kets de Vries \& Miller, 1986).

Views of the founders or leaders have a strong impact on what the organizational membership believes and how it 
behaves (see Iacoca, 1984; Carlzon, 1987) because they are, in most cases, a source of direction and inspiration (Schein, 1983; Leavitt, 1986; Bennis \& Nanus, 1985; Bennis, 1984). In governmental agencies such as the Ecology Agency, political leaders have a profound impact on how individual agencies operate ${ }^{1}$.

Most organizational culture literature, particularly Schein (1992), has tended to focus on this latter cultural influence, particularly in manufacturing and high-tech industries, as the primary ingredient of organizational culture creation and maintenance. This assertion follows from the widely acceptable notion that people, in general, have an inherent tendency to emulate their superiors [Bates, 1984; O'Reilly, 1991; Schein, 1983 (Summer), 1984, 1992; Sergiovanni, 1984; Tichy \& Devanna, 1986; Smith \& Peterson, 1988; Taylor, 1984; Tichy \& Ulrich, 1984, see also Milgram, 1974] .

However, little attention is paid to the tools or the actual process that leaders use to convey or instill

\footnotetext{
${ }^{1}$ In this document, organizational leadership refers to the agency director and the eight Division administrators. However, the political leadership in the form of the governor, the Environmental Commission, and other elected officials represent another layer of leadership which has some impact on the overall scope of activities of individual state agencies. The Director, who is a political appointee embodies the critical values of the agency. As will be shown later, the influence of the director alone is obvious and deliberate.
} 
cultural values. This study tries to answer the question of how values are conveyed by examining whether or not the PA process can be thought of as an acculturation tool? In other words, how important is it for organizational leaders, in their effort to successfully disseminate their values to the rest of their followers, to take into account their organizations' PA process, as a potential cultural affecting mechanism?

\subsection{Statement of the Problem}

What role does the PA play in affecting the culture of a complex organization? Does the PA system in a complex organization affect the nature of that organization's culture in such a way that if that organization desires to create/strengthen/change its culture, the PA system has to be appropriately adjusted to facilitate the desired situation?

The assumption was that organizations use their PA systems as information gathering and information disseminating mechanisms. Figure 1.1 on the next page illustrates the potential information flow in terms of the relationship between $\mathrm{PA}$ and organizational goals. In this model, the PA process is viewed in terms of individual position descriptions that are a result of job categories 
Figure 1.1 Performance Appraisal In Larger Organizational Context

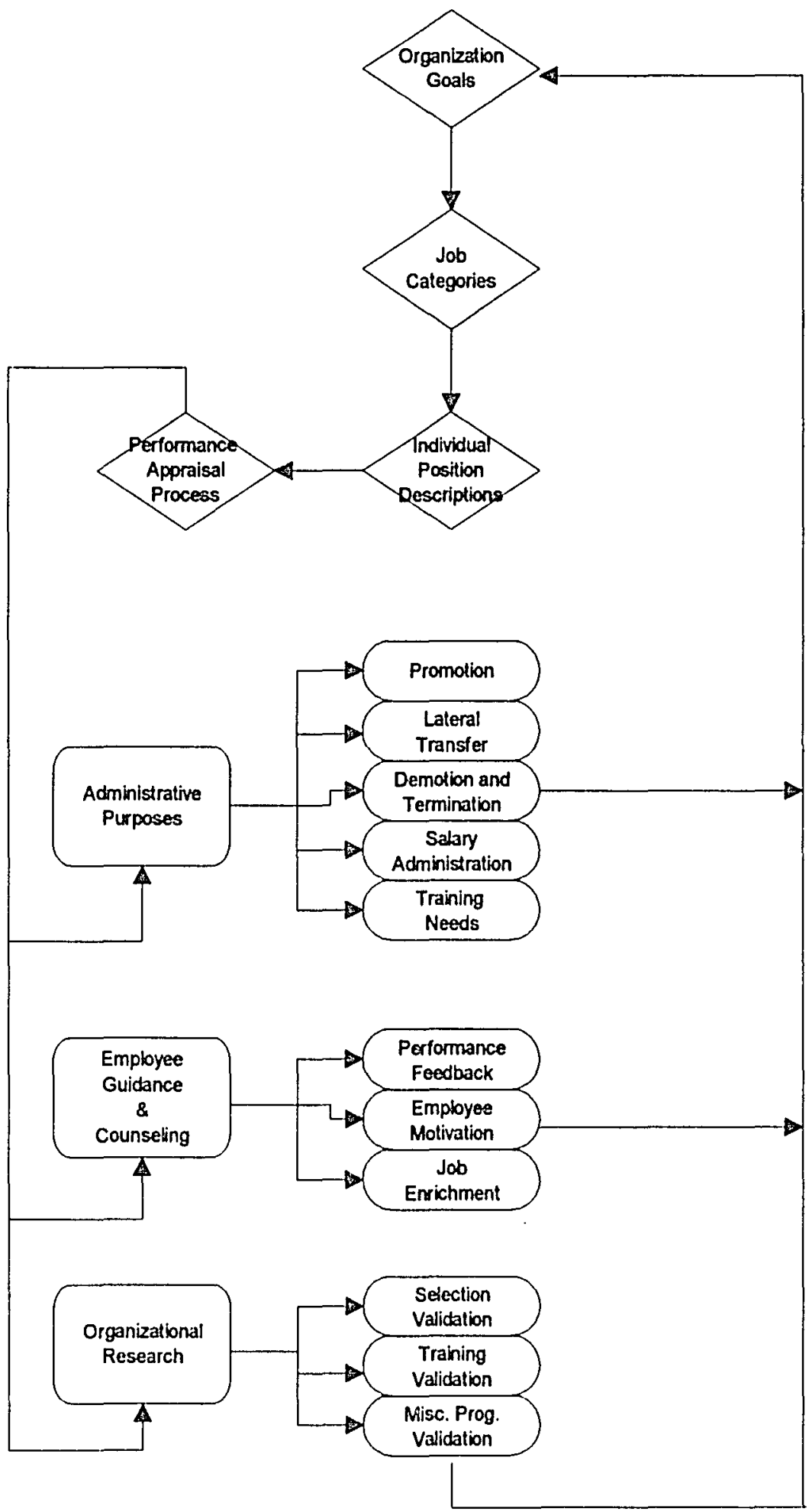


that are designed to carry out overall organizational goals. In this context, PA functions fall into three categories: Administrative, Guidance \& Counseling, and Organizational Research. These three areas are further broken down into distinct sub-functions.

The administrative purposes include information gathering with respect to decisions regarding demotions and terminations, promotions, lateral transfers, salary administration, and identification of training needs. Guidance and counseling purposes are designed to help the employee by providing him or her with feedback and motivation through job enrichment.

Organizational research purposes include gathering information to evaluate and validate various organization programs such as selection procedures, training programs, and other programs that organizations periodically conduct such as performance improvement seminars.

But, does this potential flow of information, in any way, affect the culture of the organization? This question forms the basis for this research. The purpose and scope of this study is discussed below. 


\subsection{Research Purpose and scope}

The purpose of this study was to understand the linkage between the PA process and the organizational culture. To my knowledge, it is the first detailed study of an organization's PA system within the organizational cultural context.

The linkage was researched in the following manner: Initially, an attempt was made to uncover the organizational culture at all three of Schein's (1992, p. 14) levels (see figure 1.2 on the next page, and the methodology section in the next chapter for details). From this, the elements of the operating cultures were exposed in an attempt to answer the questions; What is Agency X's way of doing things? What is valued? What does it take for an individual to get ahead? How did it come to this? Who are/were the inspirational leader(s)? What are/were their values? Is what is apparent also the espoused values? Are people in different divisions and functional sections saying the same things, around key issues, in terms of values and norms?

Next, the study looked at the PA system by asking: What elements of the PA system reflect the culture? What are they? Who does these functions? Who designs them? Is there a consideration of values and behaviors apparent in the system? Are managers encouraged and trained to do PA 
Figure 1.2 Schein's Three Levels of organizational Culture and Their Interaction

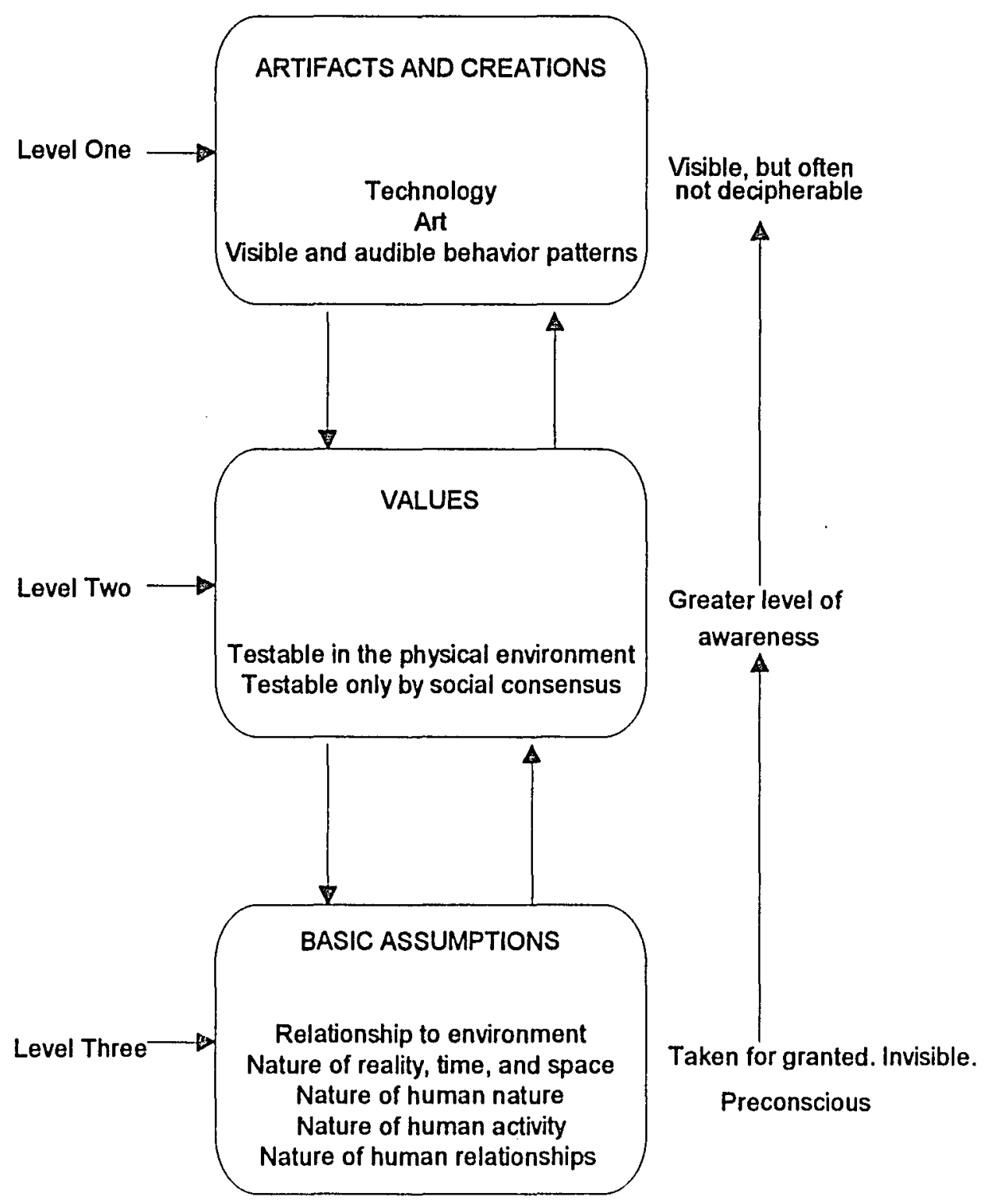

Source: Schein (1992), p. 14 
functions? What is the general attitude of managers towards the system. What are the uses of PA? Do most personnel decisions hinge on the PA results? What are some of the problems associated with PA? The next step after answering these questions was to see if a link between an organization's culture and the PA systems existed by seeking answers to the following questions: Is there a mention of key organizational culture elements in the PA system discussions? Does organizational leadership look at the PA systems as an information gathering and disseminating mechanism? How do they express this? Are there reoccurring themes about the organizational culture that can be attributable to the PA system? How about vice versa? What are those in each case? Is there a pattern about them? Do organizational members look at the PA system as a source of information about what to do in order to get ahead? Does it seem clear to them what the PA system is for? How do they feel about their past experiences with it? Are there marked differences, on this and other key points, as one goes from one division to another or from functional section to another, about this? How is that evident?

The research methodology in the next chapter outlines the process followed in this research. 


\section{Chapter 2}

\section{Research Methodology}

\subsection{Choice of Methodology}

The study of organizational culture is often problematic due to the fact that there is no consensual operational definition of the phenomenon, and hence no consensual research methodology. Qualitative methodologies, which are primarily subjective in nature, have been widely advocated by most researchers in this area (see cook \& Campbell, 1979, for a detailed discussion on this). The reason for such advocacy stems largely from the way most of the researchers in the field of organizational research operationalize organizational culture.

If organizational culture is operationalized in terms of basic assumptions, values, and philosophies (as most researchers do), then qualitative methods are appropriate because in such studies no values, or dimensions thereof, are identified a priori to actual research. If, on the other hand, organizational culture is operationalized in terms of predetermined normative behavior dimensions, then quantitative methods are appropriate (see ott, 1989, for a detailed discussion on this point).

This study operationalized the concept of organizational culture in terms of Schein's (1992) 
definition. This called for a qualitative study. Furthermore, this study sought to isolate and test some normative cultural issues, particularly those that would be later related to the PA process. In this case, a quantitative methodology was called for. For the former case, detailed interviews, observations, and archival data were utilized, as advocated by Barley (1983), Gregory (1983), and others. For the latter case, two attitudinal surveys were utilized. The discussion below explains the nature of these surveys and the hypotheses extrapolated and tested from them. Following that discussion will be a discussion on the qualitative methodology and procedures also employed in this study.

\subsection{OCTAPACE: Survey of Organizational Ethos}

Organizational culture elements can be isolated to include ethics, values, beliefs, attitudes, norms, and ethos. Ethics generally refer to normative aspects or what is socially desirable. Values, beliefs, attitudes, and norms are interrelated. Interactions between beliefs and values result in attitude formation (beliefs $\mathrm{x}$ values $=$ attitudes) and then produce norms. When these become "institutionalized" (accumulated and 
integrated), the result is a social phenomenon (Pareek, 1994). This social phenomenon can be characterized and evaluated in terms of the operating dominant assumptions shared by the group- ethos. The ethos, then, are the fundamental character or spirit of culture.

In this study the focus was on the PA system's relationship to the culture in which it operates. The preliminary preparation for this study involved looking into the assumptions upon which the PA system at the Ecology Agency (EA) was based. More details on that process will be discussed in the qualitative methodology section at the end of this chapter. For now, it will suffice to say that the EA's PA system assumptions included organizational disposition, at least on the part of top management, towards using the system for employee feedback within a coaching environment. These elements were designed to give the system a higher degree of fairness and acceptability (system integrity). Internal management philosophy documents, particularly the Executive Department's Performance Management System Reference Manual, support that conclusion. 
Issues dealing with rules governing superiorsubordinate interaction are central to the EA's espoused value system. Such manager/superiorsubordinate issues can be summarized in terms of overall organizational, divisional, or sectional interaction ethos. Openness, Collaboration, Confrontation, and Trust are the key espoused values leadership at the State and Agency levels take for granted in their philosophy, and believe ought to operate throughout the agency. Pareek's (1994) OCTAPACE profile contains these elements or dimensions that measure these espoused values. The following are Pareek's four dimensions on his eight dimension scale and their definitions: Openness, Confrontation, Trust, and Collaboration. Their definitions are as follows:

1. Openness: Spontaneous expression of feelings and thoughts and sharing of those without defensiveness.

2. Confrontation: Facing- not shying away fromproblems; deeper analysis of interpersonal problems; taking on challenges.

3. Trust: Maintaining confidentiality of information shared by others and not misusing it; a sense of assurance that others will help when needed and will honor mutual obligations and commitments.

4. Collaboration: Giving help to, and asking for help from, others; team spirit; working 
together (individuals and groups) to solve problems.

Based on studies of the OCTAPACE Profile so far,

table 2.1 below shows the high and low scoring norms on the four dimensions. The possible range of scores is 5 to 20 .

High scores indicate strong belief in the values and, thus, strong organizational ethos. Low scores, on the other hand, indicate weak aspects of the ethos in the organization.

Table 2.1 Norms for the octapACE Profile

Low High

1. Openness

13

17

2. Confrontation

10

16

3. Trust

10

16

7. Collaboration

13

17

This study proceeded while taking into account the assumptions held by top management at the state and the EA, and also largely from literature in this field (which, apparently, top management consulted in developing their philosophy), that team oriented organizations had to have strong ethos in primarily those four dimensions. Linking these four dimensions to the PA system became the major part of this study. 
It was necessary, in accomplishing this objective, to develop a PA scale that could be used for this linkage purpose. The section below describes that instrument.

\subsection{The Performance Appraisal Perception Scale}

The performance appraisal perception scale (PA Scale) was designed specifically for this study. Four dimensions were constructed from information gathered qualitatively. Two dimensions of Coaching Environment and Performance Feedback were uncovered first (see select paragraphs from organizational literature below). Most successful PA systems, as already discussed, are utilized for those two purposes (see also Mohrman, Jr., Resnick-West \& Lawler, III., 1990, IIgen, Fisher, \& Taylor, 1979). The EA leadership also expects their managers to use the system for those purposes. PA systems that have those dimensions emphasized are also considered by most users to be fair and to have integrity. Fairness and system Integrity became the other dimensions that completed the PA scale.

Feedback about the effectiveness, or lack thereof, of an individual's behavior on the job has long been recognized as essential for learning and for motivation 
in performance-oriented organizations (Ilgen,Fisher, \& Taylor, 1979). The Executive Department's Performance Management Reference Manual states that the performance management system approach, of which PA is a key component, benefits the employee because...

...it identifies, recognizes, rewards, and promotes desirable performance. This is a meaningful planning and feedback mechanism, which provides a fair and open method of performance appraisal and an incentive for all employees to do their best. It also clearly defines and identifies performance that requires

improvement....

In addition to the feedback dimension, the executive department's performance management manual spells out the organizational philosophy with regard to the necessity of a coaching environment. It states... ...Performance management should be viewed as a way to effectively communicate with employees regarding performance. Work expectations are clearly defined and mutually discussed. Encouragement and coaching of employees is emphasized with managers/supervisors practicing active listening. Individual performance is routinely measured, which eliminates performance evaluation "surprises"....(C) haracteristic of effective supervisors is the importance they attach to coaching and developing employees....

(W) hen supervisors coach employees well, they build not only the employee's skill level but also motivate them to higher standards. Effective coaching strengthens working relationships between the supervisor and the employee and is an effective method of enhancing individual performance...

(C) oaching is an on-going effort by the supervisor to assist employees in developing their full potential by correcting poor performance, teaching new skills, and enhancing 
the performance of already skilled employees. This is done by providing direction, encouragement, and specific feedback to employees regarding both their strengths (what they do well) and areas of their, performance that need improvement....

Feedback within a coaching environment clearly represents the central feature of the performance management system at all state agencies, including the EA. PA is the central component of that system. Individual agency goals are said to be tied to that system. The management philosophy, as articulated in the Executive Department Performance Management Manual further states that...

A performance management approach to compensation more effectively spends the state's salary dollars. It identifies and measures individual, group, and organization goals and objectives. This planning, Eeedback, and goal linkage results in a more efficient organization, and promotes maximum comritment by employees to objectives (performance results) that are critical to the success of individual agencies and to the state as a whole.

This study sought to test the degree to which organizational members at the EA perceive the performance management system's performance appraisal component by measuring their perceptions over Feedback, Coaching Environment, Fairness of the system (Fairness), and System Integrity. 
With those four dimensions in mind, four sets of five statements (to be consistent with the OCTAPACE scale) were developed. The goal was to develop statements that would capture, best describe, or define each of the dimensions. For each statement, a respondent would be asked to respond by assigning a number opposite each statement as follows:

$$
\begin{aligned}
& 4=\text { Strongly Agree } \\
& 3=\text { Somewhat Agree } \\
& 2=\text { Somewhat Disagree } \\
& 1=\text { Strongly Disagree }
\end{aligned}
$$

The responses did not contain a neutral response in order to avoid central tendency. Upon completing the twenty statements, a pre-test of the instrument was conducted using thirty subjects from the EA and a group of twenty-four high school teachers from a greater Portland high school.

Following the pre-test, some statements were revised for clarity using the input from the subjects. Preliminary factor analysis was also performed using the pre-test results from each group of respondents with each statement representing a variable ${ }^{2}$. Factor

\footnotetext{
${ }^{2}$ The rule of thumb in performing factor analysis is that for each variable there must be three cases. In that case, there should have been at least sixty cases to go with the twenty variables on the scale. The results of this analysis were not
} 
analysis was necessary to ensure that each statement assigned to each factor was highly correlated with all other statements designed to measure that factor. Appendix 1 shows the resulting factor loadings and discusses briefly the eventual factor alignments. The PA Scale measures perceptions individual organizational members have with respect to the issues raised. It does not claim to represent reality or the truth. However, in issues related to PA, as will be discussed in chapter 4, an individual's perception over the system can be more important than reality. Collectively, what organizational members perceive as reality may, in fact, be more important than actual reality, particularly in matters of organizational intervention. With this in mind, the study proceeded to test the impact the aggregate $P A$ perceptions have on the four organizational ethos.

stable enough to be discussed here since it was not possible to find sixty willing respondents at either the high school or the Ecology Agency. The actual analysis was then performed in the course of the study after the first one hundred and sixty surveys were received. The analysis of that process is in appendix 1 . 


\subsection{Study Hypotheses}

The PA process in this segment of the study is operationalized in terms of the perceptions discussed above. In this vein, the hypotheses to be tested sought to establish if these PA perceptions had an effect on the organizational culture. And organizational culture was operationalized in terms of the four OCTAPACE dimensions. Using regression (multiple and bivariate), operations were run to test if there was a statistically significant (effect) positive relationship between individual PA scale items and individual OCTAPACE dimensions (bivariate linear regressions). Further operations were run to test if all PA Scale dimensions had an impact on each of the four OCTAPACE dimensions (multiple linear regressions). In each of these operations, the PA scale dimensions represented independent variables and the OCTAPACE dimensions represented the dependent variables. The hypotheses to be tested were extended as follows:

\section{Hypothesis 1}

Each of the four PA perception dimensions of Fairness, Coaching, Feedback, and System Integrity will have a positive effect on Openness.

The breakdown is as follows:

1.1 Coaching will have a positive effect on Openness. 
1.2 Feedback will have a positive effect on Openness

1.3 System Integrity will have a positive effect on Openness

1.4 Fairness will have a positive effect on Openness.

\section{Hypothesis 2}

Each of the four PA perception dimensions of Fairness, Coaching, Feedback, and System Integrity will have a positive effect on Trust.

The breakdown is as follows:

2.1 Coaching will have a positive effect on Trust.

2.2 Feedback will have a positive effect on Trust.

2.3 Fairness will have a positive effect on Trust.

2.4 System Integrity will have a positive effect on Trust.

\section{Hypothesis 3}

Each of the four PA perception dimensions of Fairness, Coaching, Feedback, and System Integrity will have a positive effect on collaboration.

The breakdown is as follows:

3.1 Coaching will have a positive effect on Collaboration.

3.2 Feedback will have a positive effect on collaboration.

3.3 Fairness will have a positive effect on collaboration.

3.4 System Integrity will have a positive effect on Collaboration. 


\section{Hypothesis 4}

Each of the four PA perception dimensions of Fairness, Coaching, Feedback, and System Integrity will have a positive effect on Confrontation.

The breakdown is as follows:

4.1 Coaching will have a positive effect on Confrontation.

4.2 Feedback will have a positive effect on Confrontation.

4.3 Fairness will have a positive effect on Confrontation.

4.4 System Integrity will have a positive effect on Confrontation.

These relationships and their significance will be further discussed in chapter 6 . In addition to the above hypotheses, this study also sought to determine if mean differences existed in the sample on the PA scale by recency of last appraisal and length of service in the organization.

\section{Hypothesis 5}

Recency of last appraisal will have positive

effect on each of the dimensions on the PA scale.

\section{Hypothesis 6 \\ Length of service in the organization will have an effect on each of the dimensions on the PA scale.}

These hypothesized effects in the latter two hypotheses will be analyzed using Analysis of Variance (ANOVA). The 
purpose of this operation will be to determine if there is a significant difference in means among groups with respect to the dimensions on the PA scale.

The information that went into choosing the items to include in the PA scale, as already discussed, and the choice of the OCTAPACE scale, was derived through qualitative methodology. The section below discusses those methodologies.

\subsection{Qualitative Methodology}

Both primary and secondary sources were utilized for this research. Primary information was generated from interviews with management staff (five managers were not available), including the acting director, and a sample ( $N=$ $60)$ of non-management staff members of the organization. Secondary data included all relevant written information about the agency from sources such as the State's Revised Statutes, Newspapers, Annual Reports, Trade Journals, and internal communication materials (memos and printed electronic mail messages). The written information dated back to the beginning of the organization, and most of it was provided by the Public Affairs and HR departments. The Ecology Agency has over seven-hundred members divided into eight divisions and a separate public affairs 
section whose manager reports directly to the director (see Figure 2.1 for the EA Organization Chart on the next Page). Each division has a division administrator (DA) who reports directly to the director. Each division also has section managers who report to the DAs and are responsible for managing anywhere from six to twenty staff members. By many standards, this is a flat organization. There are three sections in the whole agency that have sub-sections with sub-section managers of a lower classification than section managers.

working from the organizational chart, all DAs ( $\mathrm{N}=8$ ) and most managers $(N=60)$ were interviewed from prepared questions (see appendix 1d). During the first few interviews the sequence of the questions was followed. After the tenth interview, interviews started with a question that seemed to address a particular issue of interest to the subject at that moment. This proved to be the best approach because interviews began to feel like simple conversations, and the subjects looked relaxed and were willing to share more information.

The interviews lasted as. little as forty-five minutes and as much as two hours. Much depended on how much the subject or informant had to say. Those individuals who had been with the organization the longest tended to have 
Figure 2.1 Ecology Agency Organizational Chart

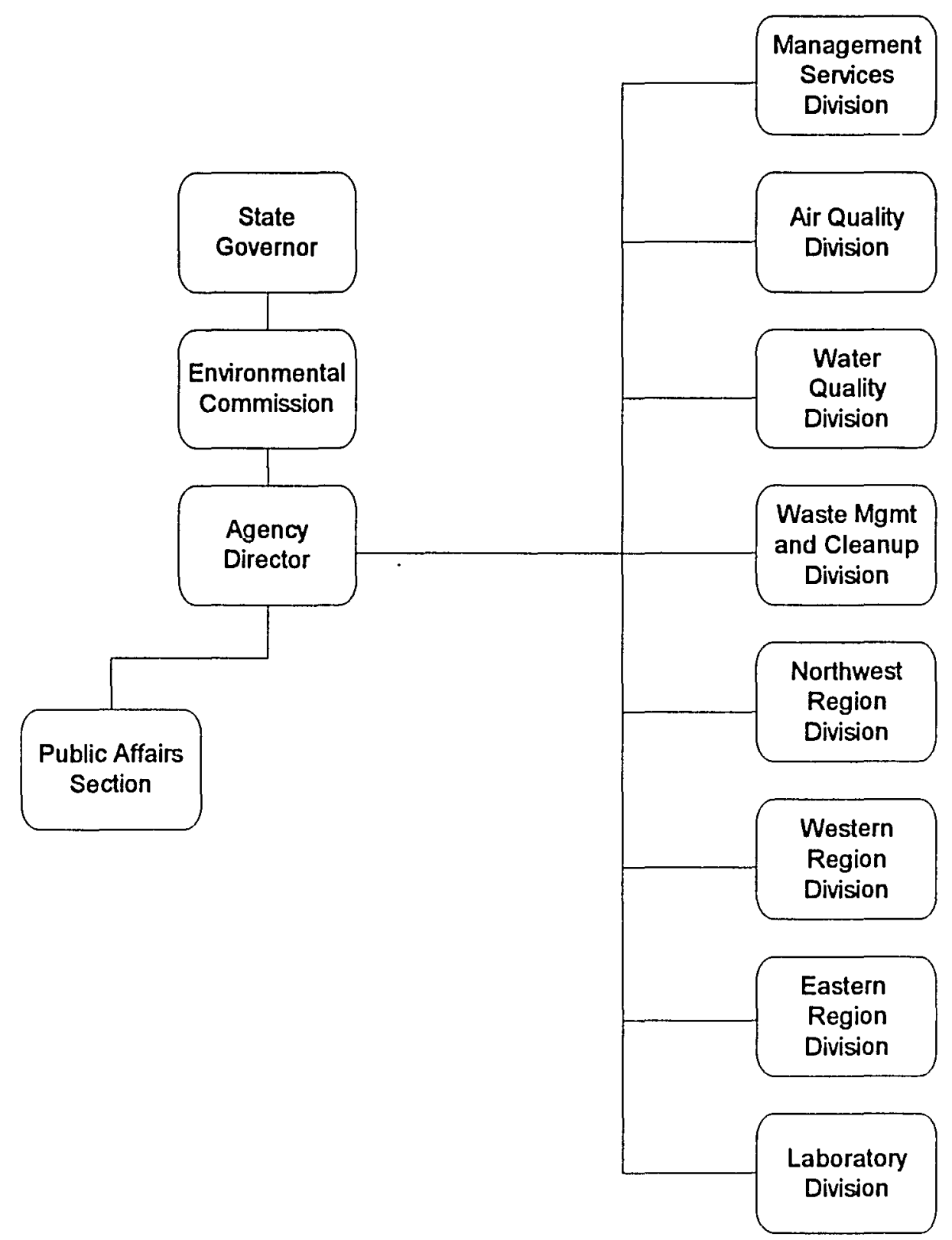


much more to say, and those interviews lasted an average of ninety minutes.

Before each interview all subjects had to complete the $\mathrm{PA}$ perception and OCTAPACE questionnaires. After the interview, each manager was given the questionnaires to pass on to their staff with a letter accompanying each questionnaire (see appendices 1 a to 1 ). Interviews with non-management staff were conducted in a similar fashion following the completion of all management interviews. The results of these interviews were categorized and analyzed for commonalities that would represent the shared beliefs, and contradictions that would represent the existence of subcultures. The details of these findings are discussed in chapters four through seven.

There was an overwhelming amount of archival data at Ecology Agency. The inspection of these documents was the first phase of the study. The information gathered at this phase was used to construct the PA scale, frame interview questions, and guide in the selection of the Pareek's (1994) scale. There were generally three categories of documents: 1. Those documents that were written by outsiders (newspapers, journals, etc..) about the agency. 2. Those documents written by and about the agency for public consumption, and 3 . Those documents written by the agency 
for internal consumption. Most of these documents proved useful in gaining insight about the workings of the organization from different angles. The most important or insightful documents were historical documents and procedure manuals. All these sources were used for the analyses that follow.

Observations were accomplished at each site where the interviews were held. These observations included looking at the physical layout of offices and other working areas. Several staffers agreed to be observed while they conducted inspections and/or enforcing permits. Meetings and public hearings were also observed to study the interaction patterns of organizational members and community groups. General communication patterns among organizational members were also informally observed.

The combination of all these qualitative methodologies were incorporated into the overall discussion of the culture of this organization that comes in later chapters.

\subsection{Pragmatic Issues}

Several problems were encountered during the course of this study. The data collection phase posed the most problems. They include: difficulties in gaining entry into 
organizations, control over individual participation, and the design of questionnaire and its pre-test.

\subsubsection{Gaining Entry into Organizations}

The initial study design sought to study a banking organization. A list of all banks in the region was compiled. No banks would grant the level of access necessary to successfully gather the necessary data. A small bank agreed to be researched, but the CEO later refused to sign the informed consent form and the data collected, although informative, was of limited value because of the size of the bank which had around twenty members.

It was back to square one once more, and this time it was just a matter of looking for a willing organization that was large enough, regardless of industry. A business directory for the area was consulted. Several organizations were contacted. As was the case with banks, large organizations that met the requirements either refused to be studied totally, or allowed very limited access that would not suffice. Finally, the Ecology Agency agreed to be researched. In fact, the $\mathrm{EA}$ was not on the original list of organizations. A conservation with the EA Human Resources manager about a different issue led her to suggest the 
possibility of the EA participating in the study. After consulting with the other management in the organization, access was granted.

Once at the EA, the access was tremendous and cooperation from management and staff was phenomenal. Responsiveness, the cultural credo, was observed from the start. Phone calls were returned promptly the majority of the time, and the vast majority of organizational members kept their appointments, or called in advance to cancel or reschedule.

\subsubsection{Control over Individual Participation}

Managers were interviewed first. None of them refused to participate in the study, but several staff members did. The distribution of questionnaires was done by section managers. The organizational chart indicated how many subordinates each manager had, and from that information, appropriate number of surveys, statements of consent, and introduction letters were compiled, usually the night before.

After the interview the manager would be given the surveys to pass on to their staff. This was necessary to ensure that the origin of each survey (division and section) was known for analysis purposes. The instructions to the 
respondents were clear, and each was ensured confidentiality. The completed surveys, wherever possible, were to be turned to the reception area where large envelops were provided (see appendix 1 b for the introduction letter and instructions). In some cases, however, that was not always possible to ensure a particular way of handling completed surveys because there were several managers who supervised remote staffers. Some surveys, then, had to be mailed in. There is no evidence that such an arrangement might have, in any way, affected the responses.

\subsubsection{Designing and Pre-testing the Survey Instrument}

This part of the study took place after initial entry at EA was granted. The process is described earlier in this chapter and in appendix 1. However, a few points need to be addressed here. First, apart from the general aim of the PA perceptions survey, there was desire to make the instrument's language simpler and the scope short to accommodate all levels in the organization, and to encourage participation. In so doing some important details might have been sacrificed.

Further, the pre-test of the instrument did not contain demographic questions, and the layout of the pre-test instrument was not taken into consideration. In the final 
version of the instrument the 'education' variable was on the right hand side, while all others were on the left, of the survey form. As a result, some respondents missed it. It was determined that those who did not respond to this question didn't do it consciously since they responded to all the other demographic data consistently. This, then, was a design flaw that could have been detected in the pretest phase and addressed.

Second, a theoretical disposition to attribute micro data (individual responses) to a macro phenomenon (culture and PA system) may seem to others as a "big jump". This study was conscious of that and consulted other works where this was done. The most noteworthy of these studies is Cooke and Rousseau's (1983) Organizational Culture Inventory where individual data is aggregated to determine a priori defined cultural style. The present study utilized a similar approach using the OCTAPACE and the PA Scale with the rationale that collective values and beliefs have to be determined at the micro level in order to determine the commonalities or lack thereof.

What would have been more revealing, in retrospect, would have been to construct an instrument based solely on the qualitative findings such as responsiveness, political savvyness, scientific correctness, etc, (see chapter 5) to 
see how widely shared these values were. This approach, obviously, would have taken more time and resources than was possible. The reader might want to consider this as a suggestion for further research. 


\section{Chapter 3}

\section{Organizational Theory and the Emergence of the Organizational Culture Perspective}

\subsection{Introduction}

Turbulent times can inspire creativity. The spirit, and perhaps the instinct, of human survival facilitates this condition. This condition holds true in all faucets of human experience, including the world of ideas. Organization theory, like all fields of study, has evolved through the process of dialectical reasoning. What has been considered the operating paradigm at one time, has been questioned the next when its tenets began to fail to answer questions, or offer solutions to problems. Another way of thinking, or paradigm, has risen from the ashes of an outmoded one. That new paradigm has operated until it too was questioned, and the cycle has began again.

The great depression in the $30 \mathrm{~s}$ and the decline of American industrial competitiveness in the late seventies led organization students to question prevailing organizational theory paradigms and look for alternate explanations for the reason behind those turmoils. The great depression saw the decline of the "rational" or "classical" paradigm, and the emergence of the "human relations" paradigm while the industrial competitiveness 
crisis of the late seventies ushered in the "organizational culture" paradigm at the expense of the "systems" model. Through these change processes, learning has occurred and built up, and sometimes in different directions. In such cases, different paradigms have operated concurrently, and sometimes overlapping. Such overlaps result from the fact that organization theory is a product of several academic disciplines, particularly economics, sociology, social psychology, and lately, anthropology. Business, political science and its derivative public administration, have used the models developed in the former disciplines and have added very little to them. But, because of the divergent nature of the inspiration prevalent in organization theory, perspectives are also divergent. Complex organizations, then, can be likened to elephants, and ourselves, the researchers from different disciplines, who try to describe them are like the six blind men of Hindustan. As with the six blind men, our description and interpretation of an organization is done from our own particular experience of it. For this reason, one can safely argue that there is no universal organization theory. Rather, there are several perspectives, from different eras and disciplines, that attempt to explain and predict how organizations, and the people in them, will 
behave in varying organizational structures, cultures, and circumstances (Ott, 1989). Even within the same perspective there are varying perceptions of what constitutes reality. The reason behind this observation stems from various types of thinking prevalent in the social scientific community about the perception of human beings and their role in the world (Smircich, 1985).

Ott (1989) has chronologically organized the various organizational theory perspectives into "schools"; classical, classical philosophers, neo-classical, human Relations, "modern" structural, systems and contingency, power and politics, and organizational culture lott, 1989; Shafritz and ott, 1987). This is perhaps the most comprehensive and historical look at the field of organization theory to date.

Others have been much simpler, stewart and Garson (1983) divided the field into five approaches; classical, human relations, decision making, neo-human relations, and systems. The Steward and Garson's approach does not claim a historical evolution in the approaches they chose, but they share with Shafritz and ott the basis upon which the classical, human relations, and systems perspectives emerged. Robbins (1990), taking largely from scott and Mitchell (1972), also shares the basis of the emergence of 
those common perspectives although he uses different terminology [a common problem in organization theory literature search. Koontz, (1961, 1980) described management (organization) theory as a "semantic jungle"]. In addition, much like shafritz and Ott, Robbins also sees organization theory as an evolution, divided into four periods, with each period representing an emphasis represented by theorists of the time. His four theory types and their periods are as follows: Type I: Rational model, 1900-1930; Type II: Human relations model, 1930-1960; Type III: Contingency model, 1960-1975; and Type IV: Power and politics, 1975- .

In Robbins, and stewart and Garson, the organizational culture perspective is not considered at all because this paradigm was still in its infancy at the time these works went to press ${ }^{3}$. These works are helpful in that they shed light in the understanding to earlier paradigms, particularly the classical and human relations. This study sought to add to our general understanding of the organizational culture paradigm by exploring the effect the

\footnotetext{
${ }^{3}$ Robbins' first edition was in 1983. This was barely a year after the first four influential works to be discussed later. That same year, December, 1983, Administrative Science Quarterly had a special edition on organizational culture. This edition, some believe, established organization culture as a legitimate area of inquiry.
} 
process of performance appraisal might affect an organization's culture. But, before exploring this relationship it is important to understand what organizational culture is, and the circumstances within which this line of thinking about organizations emerged. This will be a brief historical look at this paradigm that has been with us for less than two decades and yet has had profound impact on how we look at organizations.

\subsection{The Emergence of the Organizational Culture Perspective}

Since the early eighties, the concept of organizational culture has dominated the management literature in a profound way. Four books published within a space of one year 1981/1982 all became best sellers: Ouchi (1981); Pascale \& Athos (1981); Deal \& Kennedy (1982); and Peters \& Waterman (1982). Peters \& Waterman's In Search of Excellence, broke non-fiction sales records. These works popularized the concept of organizational culture in both industry and academia. Waves of other books and articles followed, and they are still being produced.

The impetus of this development was primarily the perceived precarious state of American industry in relation to the foreign competition. Since the end of the Great 
Depression, particularly the end of World War II, American industry faced its greatest expansion. World war II simultaneously destroyed every other industrial power while solidifying the American industry. The U.S. emerged from this war as the greatest industrial power the world had ever seen. Until the mid-sixties, over half the goods produced and consumed world wide were produced and consumed within her boarders. This status, some would argue, made American industry arrogant.

American industry did not feel the need to modernize or look at improving the way it did things. Many felt their country was number one and that was their god given right and would never be challenged again, or so thy thought. Starting in the mid-sixties, Japan and Europe(particularly West Germany), started to make their presence felt in the market place. Their industrial complexes were newer and used the latest technology. The first American industry to feel the competition was the steel industry. By the midseventies, U.S. steel manufacturers were laying off their employees. By the late seventies the auto industry started to feel the competition. This time, everyone in the U.S., including politicians, got worried. The first question raised then was, "what are the Japanese doing that we are not?" 
The auto industry crisis was a product of primarily two sources: The oil shock and the apparent superiority of Japanese auto design. The oil shock of the seventies made petroleum prices skyrocket in the U.S.. Americans who were used to driving large cars that consumed large amount of gasoline felt the pinch. The American auto industry was unprepared to meet the sudden demand for smaller and more fuel efficient cars. The Chrysler corporation, the smallest of the big three (General Motors and Ford were bigger) auto manufacturers felt the market shift the most. Japanese cars were generally smaller and simply better designed. Customers found them extremely reliable and fuel efficient. These cars were, therefore, perfect for the American market of the late seventies. The problem was compounded when American manufacturers started to rush newly designed smaller cars into the market. Design problems, such as the exploding fuel tanks, began to surface. Most American consumers, as a rule, stayed away from American cars, particularly smaller ones.

Besides its own organizational problems, Chrysler became a symbol of American industrial failure. By 1978 , Chrysler was on the verge of bankruptcy. Corporations usually come and go through either outright bankruptcy or takeover, but for this corporation it was a complex problem. 
Corporate leaders attempted to merge with other healthier corporations like Volkswagen of West Germany, but organizational problems at Chrysler frightened would be partners. The next unthinkable step was filing for bankruptcy. Unthinkable because the manufacture and marketing of durable goods like automobiles is much more complex than the manufacture and marketing of items like breakfast cereal. When consumers go out to buy corn flakes they never think of the need for service and spare parts in the future. Hence, they can buy such a product from a company that is not likely to be in business the next day. Buying a car, on the other hand, is tantamount to entering into a long term relationship. Consumers like to know if they will have service and spare parts from the manufacturer in the future. If Chrysler had declared bankruptcy, consumers would not have been willing to purchase its cars. The struggle to save Chrysler culminated in a loan from the federal government. During the Chrysler crisis, the question of what was wrong with American industry and what was right with Japanese industry dominated the debate. To answer that question, researchers from different disciplines, particularly business, descended on Japan to study that country's successful organizations. Pascale and Athos published the first of such research efforts in 1981 
entitled The Art of Japanese Management. Ouchi (1981), who had also assisted Pascale and Athos in their initial field research in Japan, also published his book, Theory $Z$, that same year. These two works, particularly Ouchi's, pointed out the holistic nature or clan mentality of Japanese industry. Ouchi's theory $\mathrm{z}$ described, in fact, American companies that practiced Japanese style management. This work offers the first detailed discussion of organizational clansmanship or culture. That same year, Schein (1981), published a little known article in sloan Management Review entitled "Does Japanese Management Style Have a Message for American Managers?"

A year later, 1982, Deal and Kennedy published Corporate Cultures and Peters and waterman published In Search of Excellence. Both these works looked specifically at the U.S.'s successful corporations. Peters and Waterman stated...

As we worked on research of our excellent companies, we were struck by the dominant use of story, slogan, and legend as people tried to explain the characteristics of their own great institutions... The vast majority of people who tell stories today about T. J. Watson of IBM have never met the man.... (I)n organizational sense, these stories, myths, and legends appear to be very important, because they convey the organization's shared values, or culture $(1982$, p. 75$)$.

Deal and Kennedy also stated... 
The early leaders of American business such as Thomas Watson of IBM, Harley Proctor of Proctor \& Gamble, and General Johnson of Johnson and Johnson believed that strong culture brought success. They believed that the lives and productivity of their employees were shaped by where they worked...The lessons of these early leaders have been passed from generation to generation of managers; the cultures they were so careful to build and nourish have sustained their organization through fat and lean times. Today these corporations still have strong cultures and still are leaders in the marketplace (1982, p. 5).

These arguments on the importance of organizational culture essentially launched the organizational culture paradigm. The rational paradigm and its successor, the systems paradigm [see Thompson, 1967, and Katz and Kahn, 1966, for a discussion on the tenets of the systems paradigm, and Weiner, $(1948,1964)$ for the discussion on the complex relationship that exists between a system and its parts] were discredited as inadequate when it came to explaining the success or failure of organizations. After all, all complex organizations were designed pretty much the same way with their hierarchies, divisions of labor, and the like.

Organizational culture offered a new way of looking at organizations. Barnard (1938) had already identified the elements upon which the organizational culture model is based. Peters and Waterman stated.

The stream that today's researchers are tapping is an old one, started in the late 1930's by Elton Mayo and Chester Barnard... In various ways, both challenged ideas put forward by Max Weber, who defined the 
bureaucratic form of organization, and Frederick Taylor, who implied that management really can be made into an exact science... Chester Barnard, speaking from the chief executive's perspective asserted that a leader's role is to harness the social forces in the organization, to shape and guide values. He described good managers as value shapers concerned with the informal social properties of organization (1982, p. $5-6)$

Since 1982, hundreds more books and articles dealing with organizational culture appeared. Administrative Science Quarterly and Organizational Dynamics anchored the new paradigm by publishing special issues in 1983 and 1984 respectively. Business Week also had a special on organizational culture in 1981.

The following is a brief discussion of major themes which have dominated the organizational or corporate culture literature. Niost organizational culture literature seem to fall in the following four categories of themes: Socialization; Stories as a means of conveying culturally based values; Managing culture and relationship between business strategy and organizational culture and; Epistemology and research methodology (Denison, 1990). Socialization is a theme that most organizational culture writers touch on, particularly Schein (1992), Sathe (1985), Van Maanen (1975, 1976, \& 1983) Van Maanen \& Barkely (1984), Wanous (1980), Weick, (1979), Scott (1990). Of most interest in this literature is the view of culture from a 
symbolic interactionist perspective. This perspective holds that culture is symbolic of the interactions of humans in their environment and symbolism becomes a source of meaning and purpose from which the purpose of organizational existence is drawn (see also Pfeffer, 1981a \& 1981b).

Stories as a means of conveying culture is a theme found in most organizational culture literature as well. Martin \& Powers (1983), Martin \& Siehl(1983, Autumn), Siehl and Martin (1984), Deal \& Kennedy (1982), and Wilkins (1983), Meyer (1984), are good examples. In this theme, the focus is on story-telling as the prime vehicle upon which the acculturation process depends. Managing culture and the relationship between business strategy and culture of the organization is a theme mentioned frequently in the literature, particularly by Ouchi (1981), Schwartz \& Davis (1981), Deal \& Kennedy (1982), Peters \& Waterman (1982), Kotter \& Heskett (1992), Tichy, 1983, Kilman et al. (1985), Raelin, 1986. This theme is based on the assumption that culture has inertia and once values are established they endure until a force from outside is exerted to change them. This implies the necessity of cultural knowledge in attempts at organizational change (Denison, 1990). 
The final major theme found in the organizational culture literature is that of epistemology and research methodology which is basically a critique of survey and/or quantitative based research methodologies in organizational research. Gregory (1983), ott (1989), Schein (1992), Pettigrew (1979), and others all make a strong case for qualitative research methodologies in the studying of organizational cultures. This theme is based on the assumption that culture is a complex concept to be sufficiently uncovered using quantitative methodologies.

These four themes cover what most organizational culture writers have been trying to convey in the last decade and a half. Two points generally emerge from most of the literature, particularly the most popular, and these are: strong cultures are indicative of successful organizations (Ouchi, 1981; Deal \& Kennedy, 1982; Peters and Waterman, 1982; Pascale \& Athos, 1981), and, related to the first point, ideologies, symbols, and shared beliefs have an impact on organizations, quite apart from their objective material, or structural characteristics (Denison, 1990; Pondy, Frost, Morgan, \& Dandridge, (Eds) 1983; Sproull, 1981).

The organizational culture literature has made, essentially, two contributions to the study of 
organizations: It has represented a return to the inductive approach to studying organizational behavioral characteristics away from quantitative approaches popularized by the "Systems" school of organizational theory (Ott, 1989). The organizational culture literature has also drawn attention to the symbolic structure of organizational life and to the importance of meaning systems in organizations and, hence, the importance of leadership (Schein, 1992, 1984, 1983 Summer, 1980; Leavitt, 1986; Louis, 1981; Smircich, 1983, 1985; Smircich \& Calas, 1987). This study sought to extend the understanding of the organizational culture paradigm by exploring the role human resource management function of performance appraisal play in shaping an organization's culture. All the mentioned cultural influences and characteristics notwithstanding the conduct of performance appraisal has the potential to shed light to organizational membership on what is valued by organizational leadership. Managers might not consciously think they are perpetuating the culture by conducting $P A$, but they may, in fact, be doing exactly that. 


\section{Chapter 4}

\section{Understanding the Performance Appraisal Process}

\subsection{Introduction}

All organizations must manage human resources. Organizational goals can only be achieved through the cooperation of organizational members. Typically, Human Resource Management (HRM) functions through systems that address different aspects of organizational membership issues from the time they come in (recruitment and selection) to the time of their exit (layoffs or outright termination). Major HRM functions include designing and implementing employee; performance appraisal, recruitment, selection, compensation, training, and development. All HRM functions to varying degrees have a bearing on how organizational members view their organization.

In this study the focus was on one element: performance appraisal, and specifically, individual perceptions over the performance appraisal process and outcomes. This chapter reviews select PA literature and later discusses the PA process at the Ecology Agency, and how that can be related to its culture. 


\subsection{Performance Appraisal Literature Review}

Few management functions have been a focus of behavioral science literature as much as the PA systems and processes. Much of the research in this field has come from industrial psychologists, who over the past half century, have published thousands of works, mostly in search of the perfect system. One only needs to look briefly at back issues of Journal of Applied Psychology, Applied Psychology: An International Review, Personnel Psychology, and Journal of Organizational Behavior Management, to appreciate the scope of coverage. And this is just the tip of the iceberg. If one looks further at hundreds of management journals in publication today, it becomes obvious that few issues in management science have captured the interest of organizational researchers as much as PA.

The interest in researching this subject matter is fueled by the fact that most organizations, like EA, use some form of PA as standard practice, although an overwhelming number of those users constantly voice their dissatisfaction with either the process or its outcomes. Locher and Teel (1988), in a study of PA trends, found that most organizations have PA programs in place $(94 \%$ of 324 respondents). That number was up by five percentage points from a similar study conducted a decade before. 
There is clearly a trend towards wider formal PA use in organizations. In the same study, $87 \%$ of the organizations were found to use some combination of ratings and narrative appraisals just as the Ecology Agency system. In $92 \%$ of the organizations in that study, just as is the case at Ecology Agency, the appraisals are performed by the employee's immediate supervisor.

Some similarities between $\mathrm{EA}$ and the majority responses in the Locher and Teal study are as follows: In $74 \%$ of the cases, the appraisals are reviewed by the appraiser's superior; In 998 of the organizations, employees are informed of the PA results, and in $77 \%$ of those cases employees are given the opportunity to make written comments on their appraisals; In 698 of the cases, appraisals are given annually and; $82 \%$ of the organizations provide written instructions for appraisers and $60 \%$ provide training. The Locher and Teal study shows that PA is a widely used managerial tool in most organizations, and yet, as mentioned before, most practitioners voice their dissatisfaction with it (see Mohrman, Resnick-West, \& Lawler, 1989; Maroney \& Buckeley, 1992). A brief look at snme of the PA literature below identifies the sources of some of the dissatisfactions with the system, and hence the focus of most previous studies. 
For decades researchers have focused on developing PA systems that were free from systematic errors such as leniency, central tendency, halo, and contrast upon realizing that most $P A$ users experienced difficulties in overcoming these biases. Such attempts have been explored in a number of studies in an effort to find a way to make PA systems more objective, reliable and valid (Landy \& Farr, 1983; Kingston \& Bass, 1981; Pulakos, 1984; Banks \& Murphy, 1985; Landy, 1985; Smith, 1986; Cleveland, Murphy \& Williams, 1989 and others). Despite such concerted efforts most agree that very little progress has been made in this respect, even after decades of work (Landy and Farr, 1983). In attempts to address the noted PA biases, several researchers have focused on the following aspects of $\mathrm{PA}$; structure (Dorfman, Stephan, \& Loveland, 1986; Finn \& Fontaine, 1884; Schneier, Beatty, \& Baird, 1986; Silverman \& Wexley, 1984), feedback potential (Ilgen, Mitchell, \& Frederickson, 1981; Stone \& Stone, 1984), goal setting and objectives (MacGregor, 1960; Dorfman, Stephan \& Loveland, 1986; Rathjen, 1984), rater training (Pulakos, 1984; Smith, 1986; Martin \& Bartol, 1986). These four areas form the basis for most PA studies in the past decades.

What these and other studies show, above all, is that $\mathrm{PA}$ is a human process and it is, therefore, severely limited 
in its objectivity because of the inherent lack of objectivity in humans. What most studies have revealed about the practice of $\mathrm{PA}$ is that perceptions (including attitudes, beliefs, and attributes) of PA participants (both subordinate and supervisor) have a direct link to all aspects of PA (Ford, Kraiger, \& Schechtman, 1986; Cardy \& Dobbins, 1986). In other words, the contents of the PA system or the process of implementing it matters less. What matters, above all, is how it is perceived by the users.

If there is consensus in PA literature, it is in advocating the participation of PA users (supervisors and subordinates alike) in the design of the systems they use. Most of these observation have been noted in studies focusing especially on perceptions over the feedback appraisees receive in the PA process. Negative perceptions of the accuracy of feedback subordinates receive in that process have been related to distrust in the PA process. In most cases, researchers have found that when appraisees participate in the design of the system they are more likely to perceive the system positively (Burnside, 1982; stone, Gueutal \& McIntosh, 1984; Stone \& Stone, 1984, 1984; Greenberg, 1986; Mohrman, Resnick-West, \& Lawler, 1989; Pearce \& Porter, 1986; and others). Also, if supervisors 
are engaged in ongoing constxuctive communication with their subordinates throughout the review period (coaching), then the formal PA review is positively perceived by the subordinate.

Even though dissatisfaction with the PA process exists in most organizations, most don't have the will, and sometimes the know how to take corrective steps prescribed by previous research (see especially Maroney and Buckeley, 1992). In spite of their dissatisfactions with the PA systems, most organizations don't have a ready substitute for it. This is a question of normative justifications of the use of the systems versus the reality at the implementation end. In other words, most organizations feel they have to have a system of evaluating their members because they have to have a way of knowing who their better performers are for a variety of reasons mentioned in chapter one, and yet, on the other hand, the problems associated with the implementation of the systems leads most organizational members, supervisors and subordinates alike to be cynical of the system.

As long as people in organizations receive promotions, layoffs, pay checks, and the like on individual bases, there will always be a need to evaluate organizational members individually. Most organizations, therefore, continue to 
use formal performance appraisals because they don't have a ready substitute for it. This is one reason most of them still utilize the systems they have. Another reason, and perhaps the most noted but also related to the first, has to do with legal considerations organizations have in this era of rising discrimination litigations. Organizations feel they need some way to justify the decisions they might get sued for. Well documented PA is one way they have to do that (Mohrman, Resnick-West, \& Lawler, 1989; Maroney \& Buckely, 1992i).

Whatever the noted shortcomings of the PA process, its implementation, however, has some impact on the way organizational membership feels about its organization, positively or negatively. This study, assuming such impact, sought to uncover if this impact can be extended to explain the nature of an organization's culture in terms of the PA system's impact on an individual's behavior. As the research methodologies chapter pointed out, this study focused on individual perceptions about the system summarized by, the four dimensions of Feedback, Coaching Environment, Fairness, and system Integrity. The results from that analysis will be discussed in chapter six. Two of those four dimensions (Feedback and Coaching Environment) were extracted from the EA management 
Iiterature as the espoused tenets of the system. Fairness and system integrity were added as the desired objectives of the system. As already noted from the preceding discussion, the most important part of the $\mathrm{PA}$ system is the way it is perceived by the users. With that as the background, this study, then, set out to evaluate the perceptions of the users of the PA system at Ecology Agency towards those dimensions. The rationale here was that the elements in the system itself are only important in so far as they are perceived. The PA elements become important only when they are positively perceived. The discussion that follows looks into the characteristics of the Ecology Agency's performance appraisal system.

\subsection{Performance Appraisal at Ecology Agency}

The EA has two PA systems, one for management staff and the other for non-management staff. Both systems are based on the state PA system that comes from the Personnel and Labor Relations Division of the Executive Department, and is spelled out in the performance Management System Reference Manual. The system for managers is the most comprehensive of the two. This discussion will focus on that one because the system for represented employees only has select areas from the management one, with no unique features. 
The Performance Management System has three parts:

Individual Employee Development Plan; The Interim Progress Report; and Performance Categories. The individual employee development plan part provides an opportunity for the evaluator and evaluatee to discuss development goals for the evaluatee for the coming review period. This section then is supposed to be completed at the beginning of the review period and has to be monitored throughout the review period. The Interim Progress Report part requires that the evaluator and evaluatee meet at least once during the review period, preferably midpoint, to discuss and note progress towards meeting performance expectations and development goals. This is the time when course corrections should be undertaken and any necessary adjustments made to the work Output (to be discussed later) measure definitions and/or the development plan.

These two parts are essentially MacGregor's (1960) management by objectives as he elaborated Drucker's (1954) ideas into the context of performance appraisal. This approach to $\mathrm{PA}$ is designed to facilitate greater communication between supervisor and subordinate. A greater part of the EA's PA, however, are the performance categories. There are eight performance categories, each of which has several elements that define it. These categories 
are: Individual characteristics; Managerial; Interactive skills; Leadership; Administration; Work output; People Management; and Job knowledge. The descriptions for each of these are in appendix 2. From these, there are elements that are also found in the EA culture discussion in the next chapter. These appear in the interactive skills section and they are: Political Awareness, Process literacy, Responsiveness, Professionalism, Technical Competence, and Teamwork. These aspects will be dealt with in totality with other elements in the culture of this agency the next three chapters that follow. The Results from Quantitative inquiry chapter will focus on the teamwork value as operationalized through Pareek's (1994) ethos.

The Work Output Category is the only category that is unique for each individual as it is defined by the appraiser, based on the position description, for the incumbent/position being evaluated. The appraiser is required to describe the requirements of the position and the standards upon which these requirements will be evaluated at the beginning of the evaluation period. This information or requirements form the basis for each individual's work plan for the appraisal period. Articulating the work output or work plan constitutes perhaps the single most challenging task for all managers at 
the EA. The level of skills required to successfully accomplish this is mixed within the management ranks. Most managers have openly admitted that they didn't know how to do this well. This is further complicated by the fact that most positions, particularly in the program areas and the laboratory, are constantly changing due to changing situations and needs, and updating the work plans becomes an ongoing task that most managers would rather not do-and in most cases they don't.

Section managers at the EA, particularly in program areas and the laboratory, are often the experts in the tasks of their respective sections, and the majority of them are working managers. These working managers are supposed to be team leaders who spend most of their time working on their own projects and less on management tasks as the performance management system requires them to. Several managers admitted to spending less than ten percent of their time in management tasks.

In the grand scheme of things then, PA is a very low priority. The "too much on the plate" analogy to illustrate exploding workloads is repeated throughout the agency. Managers feel overworked and pressured to meet numerous deadlines that they don't take the time to devote to the PA process or other management tasks. They lead their teams 
well and most spend time coaching their subordinates as the organization requires, but most fall short of completing the formal PA reviews for their subordinates.

In interviews, however, most managers were not philosophically opposed to the concept PA. They realize its important place in management. However, the EA leadership, particularly division administrators, has played lip service to the importance of it by not bringing sanctions to bear on those that did not perform timely PAs. Even employees realize how unimportant to the EA PA is, and yet, most are also not philosophically opposed to it.

The most noted reason why most EA members don't take PA seriously is that the results thereof are not tied to anything significant. As one manager noted...

.. (W) hen I was in the service (military) PA was taken very seriously. The results from each appraisal follow you as long as you are in the service. But here (at the EA), nobody seems to care. For that reason they are not a really priority for me...

And one employee added...

Personally, I feel performance appraisals are very useful. In this agency, pay raises are automatic and have little to do with performance. Therefore, the top performers don't get compensated and the poor performers don't get reprimanded...

Another employee commented bluntly...

... I was told everyone gets the same review, if you can fog a mirror- your work is acceptable, if you walk on water- you may get a good review... 
The performance management system for managers is supposed to later be tied to pay increases. However, until then, it is difficult to determine if that is going to make a difference in the EA member perceptions.

Normatively, performance appraisal is supposed to be a tool to facilitate management. Whenever management views the system as a burden, then the system has either broken down or is well on its way to that. Some of the PA literature reviewed earlier suggested that user involvement in the design of the system is one of the most effective determinants of system success. At the EA, the system was not conceived in-house, nor did the users offer input. The agency simply adopted a mandated system and gave it predetermined weights to performance categories to ensure agency wide consistency. There is, therefore, no sense of ownership to towards the system-and hence to desire to make it work.

There is one additional constraint to the ultimate objectives of the PA process- Labor Union representation. The non-management permanent staff are represented by a union and their contract specifies that pay increases are to extended to those members that meet satisfactory performance. This leads some managers to not doing PA to poor performers so they won't have to deal with the 
confrontational situations where union representatives would be involved. The end result is that such managers simply don't do PAs for all their staff. After all, how would they explain selective appraisals? The other alternative, then, is to do PAs in such a way that everyone gets the same score, always satisfactory. Because of this reality, most question the integrity of the PA process. As one employee remarked. . .

.. As for the performance appraisal system, it is a necessary evil. It can be a tool if used correctly. However, by union agreement, the performance appraisal has limited official meaning...

As with most organizations, despite the noted constraints and problems, the EA management conducts periodic PA reviews. 74 of the respondents, 270 of the 364 , had been appraised within the last four years. $58 \%$ had been appraised within two years, and $40 \%$ within the previous year. The managers who do PAs recognize the value of doing them and are committed to this managerial task. The quantitative data in chapter six will show that PA perceptions of those who had been recently appraised were, on average, higher than those for not recently appraised or had never been appraised.

The EA PA system and process, and individual perceptions thereof, is quite mixed. A minority of managers 
adhere to the rules of the Performance Management system from which the PA component is drawn. Those that do, though, create a climate conducive to the culture of the organization. That culture is the subject of the next chapter. 


\section{Chapter 5}

\section{Ecology Agency Culture}

\subsection{Introduction}

This chapter analyses the culture of the Ecology agency from information derived qualitatively. Interviews, observations, and archival data were the main sources of the information presented here. The initial part of the study comprised of searching from archival sources that included agency bulletins (internal newspapers) going back to the beginning of the agency, and other historical documents written either by or for the agency. Most of this information was obtained from the agency library, the human resources (HR) department, and the public affairs department. During that search, preliminary interviews with the HR manager, the librarian, and a few other officials took place, primarily to clarify unclear points or procedures.

During this phase of the study, that lasted about a month, notes were kept on what was observed, read, or said that seemed relevant to understanding the culture of the agency. Questions for later interviews with management and select non-management personnel were drafted and revised several times until the collection of questions in appendix 1d were finally adopted. These questions were followed 
methodologically during the first ten interviews after which the order was adjusted to fit the situation the interviewee appeared to be comfortable with. What follows here, then, is what was said, written, and observed about the EA.

Every Ecology Agency(EA) facility's reception area has the mission statement placard displayed conspicuously. It reads :

To protect, maintain, and enhance the environment of the state.

This agency has strived to achieve:its mission statement for over half a century, first as a department within the Boarci of Health, and later as a separate agency.

Since the early eighties, as most governmental agencies suffered from radical budget reductions that limited their growth and scope of responsibilities, the EA doubled in size to become one of the largest and most respected agencies in the state. This chapter discusses the basic assumptions, values, and behaviors the EA members adhere to in their role as protectors of the state's environment, and the reasons behind that agency's phenomenal growth in the last decade. Figure 5.1 on the next page illustrates the culture triangle through which this chapter seeks to shade light to the workings or internal dynamics at the EA. As the figure illustrates, in most groups, there are assumptions which are 
THE CULTURE TRIANGLE

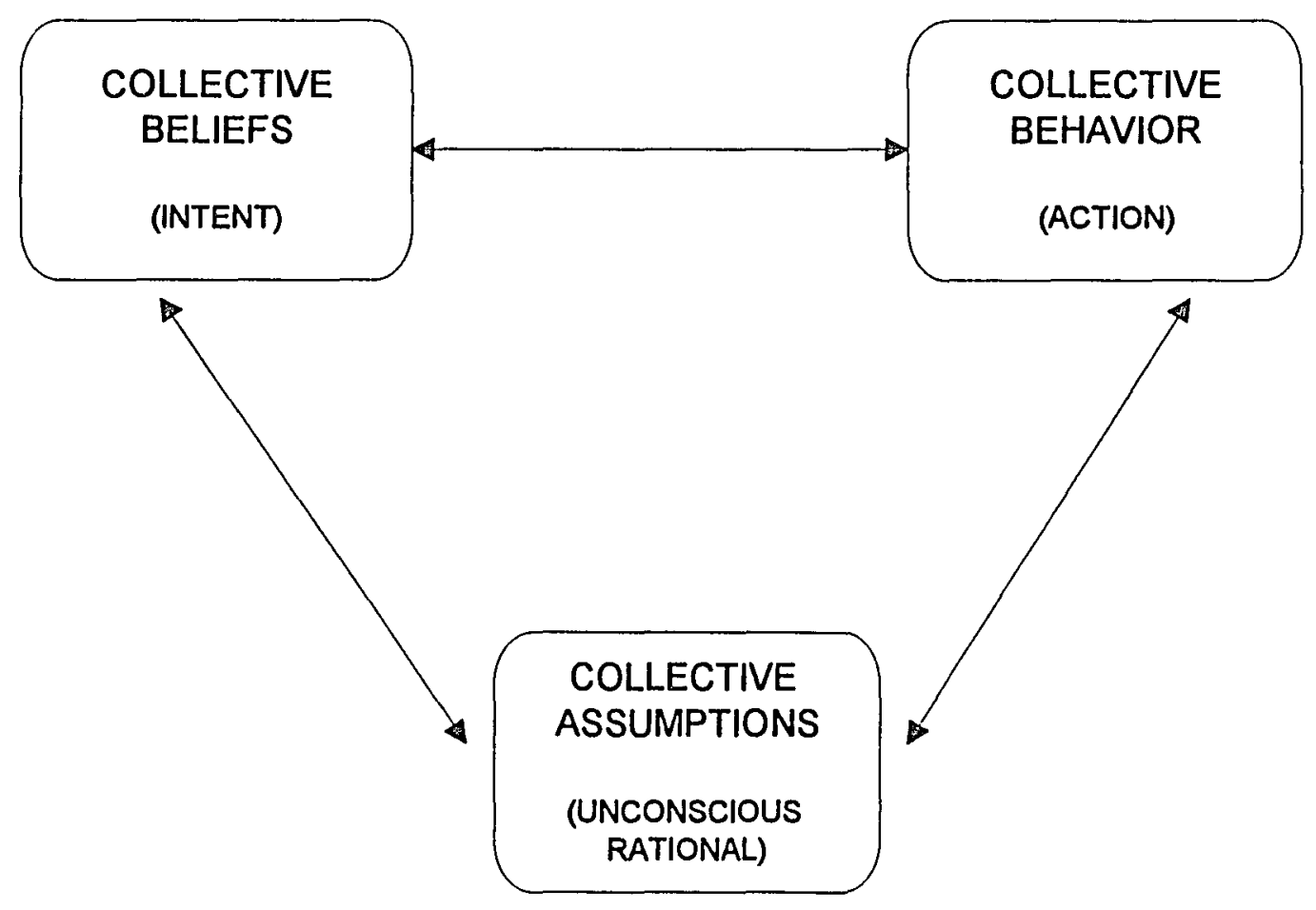

Beliefs: $\quad$ A conscious set of integrated values, concepts, theories, and expectations which shape what people hold to be true or false, relevant or irrelevant, good or bad, etc. about their environment. Belief statements (oral or written) generally are messages about what people intend to do or think they should do.

Behavior: Observable, overt actions- how people operate on a day- today basis.

Assumptions: The unconsious rationale for continuing to apply certain beliefs or specific behaviors. When people develop successful belief /behavior patterns that deal with defined problems/ opportunities or help to menage undefined anxieties, they tend to rely on these patterns whenever similar circumstances arise. If many of these situations occur over time, the use of such patterns becomes less and less consciously acknowledged and people begin to apply the patterns unknowingly. When this occurs, such patterns are termed unconscious 'assumptions'.

Source: Adapted from Conner (1985), pp. 16 
unconsciously embedded in the collective psyche of individual membership. Such assumptions lead to collective beliefs over key issues related to what is considered appropriate, or normative. Collective beliefs lead to collective behavior. While collective beliefs represent collective intent, collective behavior represents collective action.

Collective action reinforces both the collective assumptions and the collective beliefs. This cycle, thus, feeds on itself continuously as long as nothing dramatic happens to shake its foundation. Something dramatic would be something that leads organizational membership to question practices that have long been held as legitimate. For example, when an organization faces bankruptcy, in the case of the private sector, or severe budget reduction or outright program elimination, in the case of the public sector, organizational members, including the leadership, engage in practices that are tantamount to finger pointing and the leadership has to make some drastic changes that would have been considered unthinkable during normal or good times. Such actions lead to changes in, first, the collective behaviors, then in the collective beliefs and later in collective assumptions. Over time, these new characteristics form the foundation of a new culture until another crisis emerges. This process can take a few years 
(for relatively newer organization), to decades for older organizations.

This organizational culture dynamic is consistent with Schein's (1992) three level model upon which this study is based. In that model, collective behaviors and other observable phenomenon represent the first level of organizational culture. Collective beliefs represent the second level, and collective assumptions make up the third level.

In this study, the goal was to discover the EA culture at those three levels. The sections that follow summarize those cultural elements and the forces that shape them. To fully understand and appreciate the EA culture, however, it is necessary to understand the history of the agency and the dominant elements of technology, politics, and law that define it. Later, this chapter summarizes the functions of each of the EA's divisions and, finally, the three main cultural influences. But first, a discussion of the main elements of the EA culture.

\subsection{The Anatomy of a Techno-Pollegal Culture}

The Ecology Agency culture can be characterized as Techno-Pollegal. Key elements in this characterization are technology(techno) and politics/law (pollegal). Much of 
what the EA does is touched in some significant way by each of those elements, and hence, most members are sensitive about them.: This section operationalizes these two elements.

Technology in this chapter refers to the scientific approaches to problem solving. The problems are environmental pollutants. The EA, like most environmental protection agencies, has a long tradition of striving to find scientific ways of dealing with these problems. The rationale has always been that superior scientific work is that which can stand up to outside scrutiny, either by industrialists or environmentalists.

Throughout the decades, the EA has enjoyed superior reputation. The attitudes and values that go into producing high caliber scientific work have endured and flourished here. These attitudes and values include working long hours, repeating procedures more times than expected "just to be sure", putting quality above quantity, being true to the science and, sometimes, not necessarily to the organization, and so on.

The importance of technology, once again, can be understood in terms of the fact that the EA is an organization that was founded, and exists, for the sole purpose of cleaning-up, maintaining, and enhancing the State's environment. The tools and processes of 
accomplishing this goal are, and have always been, scientifically based. Engineers, biologists, and chemists, who will be collectively referred to in this chapter as technologists, have always been the core workforce at the EA. They run the three program areas of Air Quality, water Quality, and Waste Management and Cleanup. All other functions within Management Services and Laboratory Divisions at the EA serve those three program areas. The main concern for technologists, as already mentioned, has consistently been in the "scientific correctness" of what they do. This concern for scientific correctness is what characterizes the techno end of the techno-pollegal culture. As a state agency, the EA has had to be sensitive to the wishes and concerns of the State Legislators, the public, environmental and industry interest groups. Generally, the EA is caught up in the middle of an on-going struggle between environmentalists who want absolutely no pollution of any kind on one hand, and industrialists who view any attempts (directed at their businesses) at pollution control as merely attempts to cut into their profit margins, on the other. The EA's role is to find the middle and workable ground where the environment can be reasonably protected and industry can still be productive and competitive. Such middle ground is not readily achievable. Technologists can, and in most cases do, 
determine the scientific feasibility of alternate courses of action for individual cases. Convincing environmentalist and industrialists of these practical optimal solutions, on the other hand, is a task most technologists are not professionally prepared for. In addition to the technologists, therefore, the EA has had to attract and retain individuals with political and legal skills to help the agency cope with that politically charged environment. This group, referred to as pollegals in this chapter, is what characterizes the pollegal end of the Techno-Pollegal culture.

These two sets of concerns, represented by these two sets of individuals, can be viewed as spheres of influence that have impacted the EA's culture profoundly, by determining how that organization does its work. The basic assumptions, values, and behaviors of individuals at the EA can then be traced to these two concerns. In fact, the history of this organization can be understood in terms of the shifting of these two spheres of influence over time, starting off as almost distinct spheres (see figure 5.2 on the next page) in the early years, to near consolidation today (see figure 5.3 on the next page). This shift will be understood through the discussion that follows in later sections. 
Figure 5.2 Structure of the Techno-Pollegal Culture in the Early Years

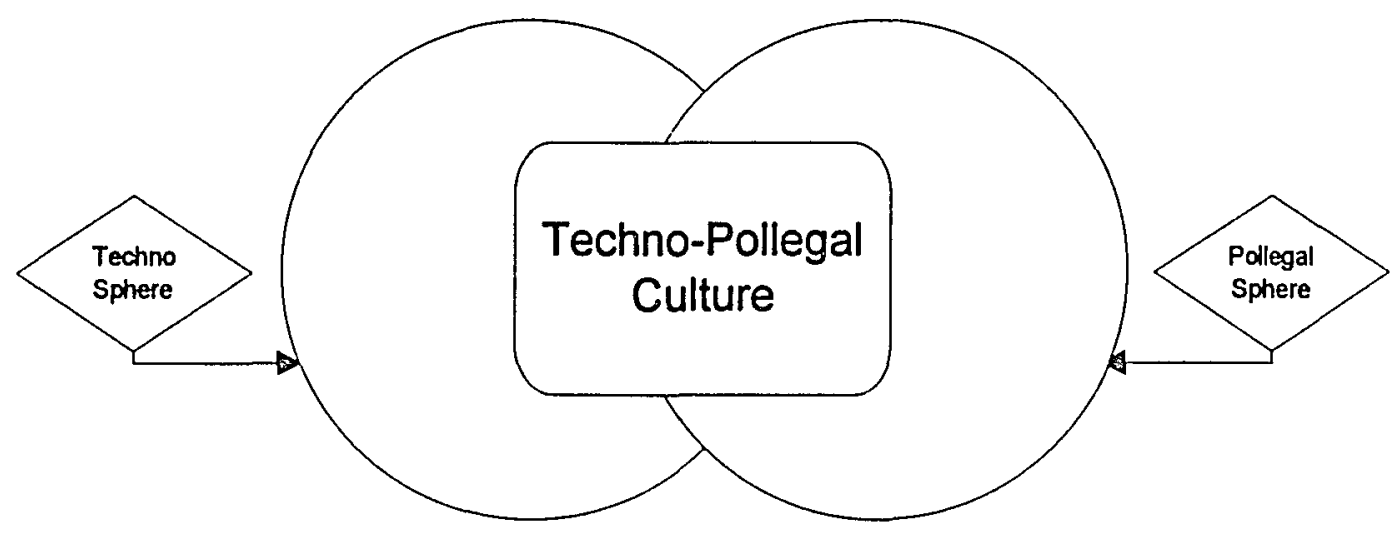

Figure 5.3 Structure of the Techno-Pollegal Culture Today

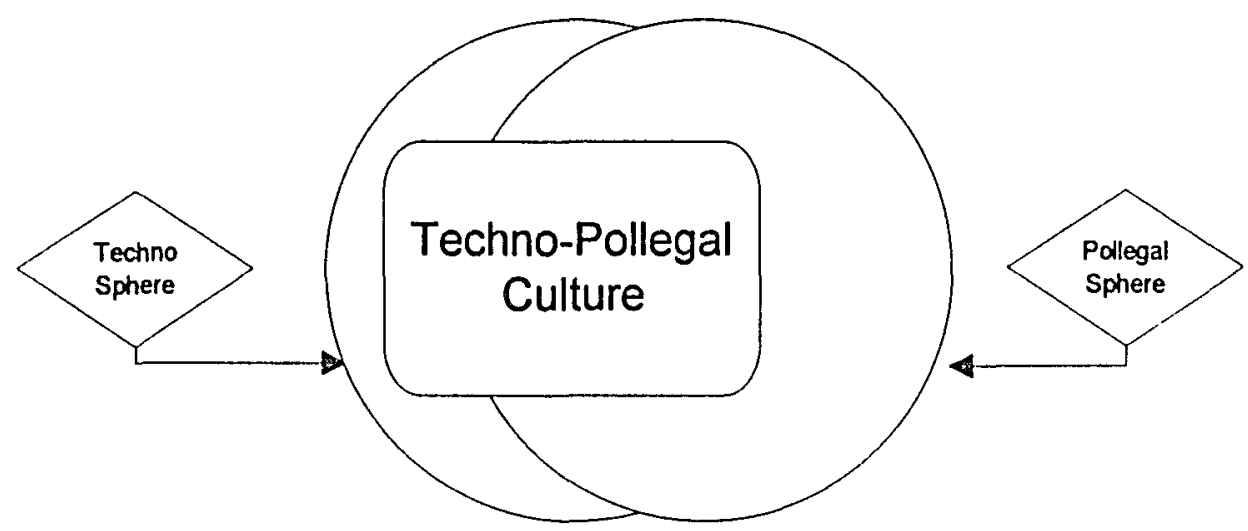




\subsection{History of Ecology Agency}

To understand the current culture of the EA, it is necessary to understand the socio-political environment and history from which this organization emerged because the State, which the EA represents, prides itself as the state that has historically stood in the forefront of issues, policies, and laws designed to promote sound environmental quality.

The pollution of one of the largest rivers in the state was the driving force behind most environmental concerns of the time. This river, which flows through the heart of the state's largest city was an eyesore, even to those that did not consider themselves environmentally conscious. The environmental activists seized on this opportunity, and sensing the governor's unpopularity, and decided to go directly to the voters in form of a referendum (ballot measure). This ballot measure was became an anti-Martin referendum.

In 1938 the voters approved a measure enacting a comprehensive water pollution control law. This approval led to the creation of the state Sanitary Authority (SSA), a department within the Board of Health, to implement the new law. The primary focus of this new department was to clean 
up the visibly polluted river. This was the precursor to the EA.

Technologists ran the SSA programs. All managers were technologist, mostly engineers from a local state University. Incidentally, that university was one of only about six universities nation-wide that prepared students for environmental work. This was a close knit group (good old boys) that took pride in the scientific work they did. Fer people questioned their technological prowess.

Some argue, however, that during this period, enforcement of environmental laws was much weaker. In other words, industry did not often do what it was told. Although the laws were on the books, the SSA did not often have enough personnel or adequate powers to do the necessary enforcement. In addition, the technologists chose to spend most of their time dealing with the technological aspects of the problems at headquarters, and less time interacting with the regulated community.

In 1969, mainly due to complaints of non-enforcement, a commission was set-up, the Environmental Quality Commission, to act as the watch-dog of a structurally adjusted SSA. The name was changed to the EA. At that same time, the EA was set up as a new agency separate from the Board of Health. The Environmental Quality Commission would also act as the EA's policy making body. From that time the head of the EA 
(Director) would be a political appointee, appointed by the Commission. Previously, the head of the SSA had to have had sixteen years of technical environmental experience. The director of EA did not have to have a similar background. Only administrative and political connections were necessary. Also, governors would recommend for appointment those individuals they felt would best reflect their own political agenda with relation to environmental issues, either soft or hard. This change shifted the pollegal and techno spheres closer together. No longer was this organization only concerned primarily with scientific issues, now it had to also concern itself with political and legal staff. Engineers were now essentially bureaucrats. At the time of restructuring, additional responsibilities were added to the EA. These additions continued throughout the seventies, thereby broadening the scope of the EA activities. Solid waste responsibilities, hazardous waste, and noise reduction are examples. The Civil Penalty authority was also granted to the EA. This was more significant because for the first time the EA had tacit authority to penalize and collect fines from violators virtually in-house.

In the 1980s, several laws and regulations were passed by both the state and the federal government that for the first time made households accountable for pollutants they 
created. For example, woodstove emission program was enacted in 1983 along with the opportunity to Recycle law. Several other laws and programs have been enacted since 1985. These additions to the EA responsibility also added additional personnel to the agency by over $1400 \%$. In 1970 the EA had only about fifty members. Now it has over seven hundred. From 1984 to present the employee membership jumped by over 100\%, from around 350 to over 700 . Administratively, the first years of the new the EA (1970 to 1975 ) were turbulent. There were five directors within a six year period. Part of the reason for that turbulence was that the proper role of the EA was not properly defined. Each succeeding director took it upon himself to define that role. Veterans from the old SSA were not easily persuaded to change their ways. After those first six years, one director served for eight years, followed by the last director who served for ten years. About a week into this study, this latter director resigned to join the US Environmental Protection Agency. These last two directors learned to balance the need for stability, which veteran staff valued, and need for progressive change, which the new laws and regulations mandated. Currently, an acting director presides while a search is underway for a permanent one. What the $\mathrm{EA}$ is today is mostly attributable 
to the tenure of the last director who served from 1984 to 1994 .

\subsection{Current Ecology Agency Organizational Structure}

Figure 2.1 on page 26 shows the current organizational structure of the EA. The following is a summary of the functions of each division. More details are provided for the program area divisions. This is intended to facilitate a deeper understanding of the scope of these divisions and their sections.

\subsubsection{Air Quality}

The air quality division oversees all the programs designed to preserve, protect, and enhance the state's air quality. Figure 5.4 on the next page illustrates the breakdown of that division's responsibilities.

The Planning and Development Section attains and maintains air quality standards statewide and works to prevent significant deterioration of air quality in what are considered "clean air areas". This section also maintains data bases statewide and controls "point source" emissions.

\footnotetext{
"In pollution language, "point source" refers to identifiable source of pollution. The opposite of that is what is referred to as "non-point source". Point sources can be cars or industrial plants that emit carbon monoxide and hydro-carbons and other pollutants into the atmosphere. Non-point sources are more common in water pollution. These can be from
} 
Figure 5.4 Air Quality Division Organizational Chart

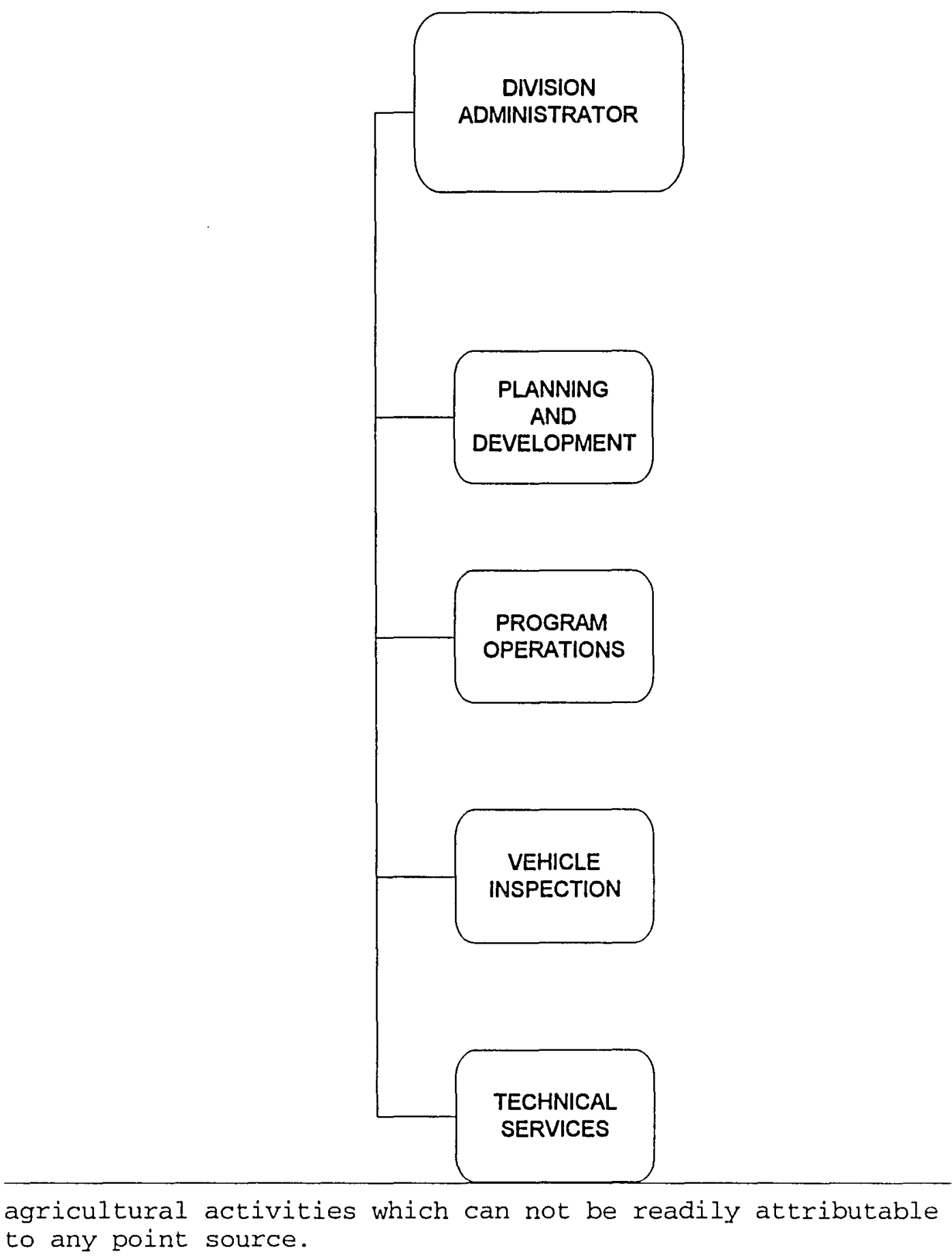


Further, this section develops, implements, and promotes control strategies for significant non-point emissions.

The Program Operations section issues and maintains Federal Operating Permits consistent with attainment and maintenance strategies and regulations. They also track compliance of sources of pollution. From time to time they also develop revisions to the federally mandated permit and toxic air pollutant control programs, and coordinates the development of industrial permit revisions of the state's version of the Federal Operating Permit Program. Small Business Assistance Program, Asbestos Training Certification, Air Pollution Tax Credits are all functions of this section.

The Vehicle Inspection section is perhaps the most known EA program, particularly in large metro areas. All motor vehicles registered in two of the state's largest metropolitan areas have to be tested for emissions and noise every two years. This section maintains the seven testing sites in the state. With one section manager, five lower managers, and a staff of about sixty, this section is the largest in the agency. Besides the vehicle testing duties, the section is responsible for educating the public on the severity of automobile emissions in the region. 
Technical Services section provides technical services to programs in the division. It coordinates with the Laboratory Division to provide air quality monitoring data by designing and implementing statewide air monitoring network which enables the agency to report the air pollution index daily.

\subsubsection{Water Quality Division}

The Water Quality Division strives to protect the recognized beneficial uses of state's water resources by maintaining and enhancing the quality of its surface and ground waters. Figure 5.5 on the next page illustrates the structure of this division.

The Groundwater section assesses quality and trends in quality of groundwater by working to prevent and correct related pollution problems. They develop control strategies to deal with pollution problems from farming, sewage disposal, and industrial waste. Further, they develop control strategies to enhance protection around public water supply wells.

The Surface Water section assesses quality and trends in quality of surface water by primarily coordinating water quality studies on lakes, rivers, and near coastal waters. This section is also involved in identifying nonpoint source 
Figure 5.5 Water Quality Division Organizational Chart

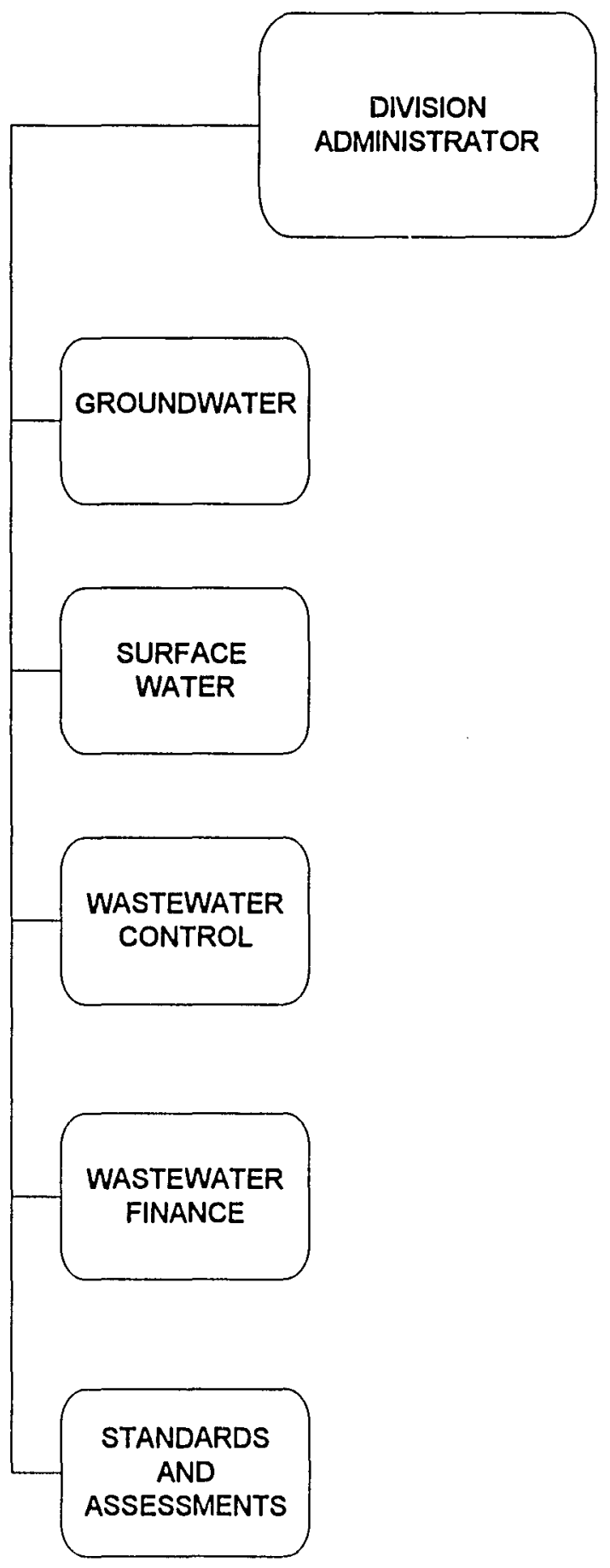


water pollution problems and coordinates efforts to solve them.

The Wastewater Control section manages sewage wastes generated by municipal sewage treatment plants by certifying sewage treatment plant operators and approving sludge management system plans. Additional responsibilities for this section include: The management of the discharge and disposal of wastewater from industrial, commercial, and agricultural sources; Review of applications for tax credits, and the regulation of the underground injection of pollutants.

The Wastewater Finance section manages the financing programs to help municipal permitees solve water quality problems that require financing of new wastewater collection, transport, treatment or disposal systems. The Standards and Assessment section manages the overall water quality program plan by establishing the maximum daily loads and waste load allocations to be achieved for those streams and water bodies that do not currently meet water quality standards. Further, this section develops control strategies to deal with pollutants affecting oceans, lakes, estuaries, and streams. 


\subsubsection{Waste Management and Cleanup Division}

The Waste Management and Cleanup Division is the newest of three program areas. Its program goals are to reduce waste, assure that waste generated is properly managed, reduce and prevent pollution, respond to emergency spills, and clean up sites contaminated with hazardous substances. Program responsibilities include oversight of the reduction, generation, and disposal of hazardous and solid waste; reduction of toxics use; underground storage tank management and compliance; the discovery, investigation, and cleanup of hazardous substance sites which threaten public health and the environment. Another significant part of this program is the pollution prevention area where the focus is on avoiding the generation of waste by identifying alternatives to the use of toxic substances. The WMC division is structured as shown on the figure 5.6 on the next page. A brief discussion of each of the sections follow.

The Cleanup Policy and Program development section develops rules and policies, and coordinates the development of environmental cleanup programs. They also handle legislation, budgeting, and strategic planning for the entire division, as well as administer contracts with private cleanup contractors and cooperative agreements with 
Figure 5.6 Waste Management and Cleanup Division Organizational Chart

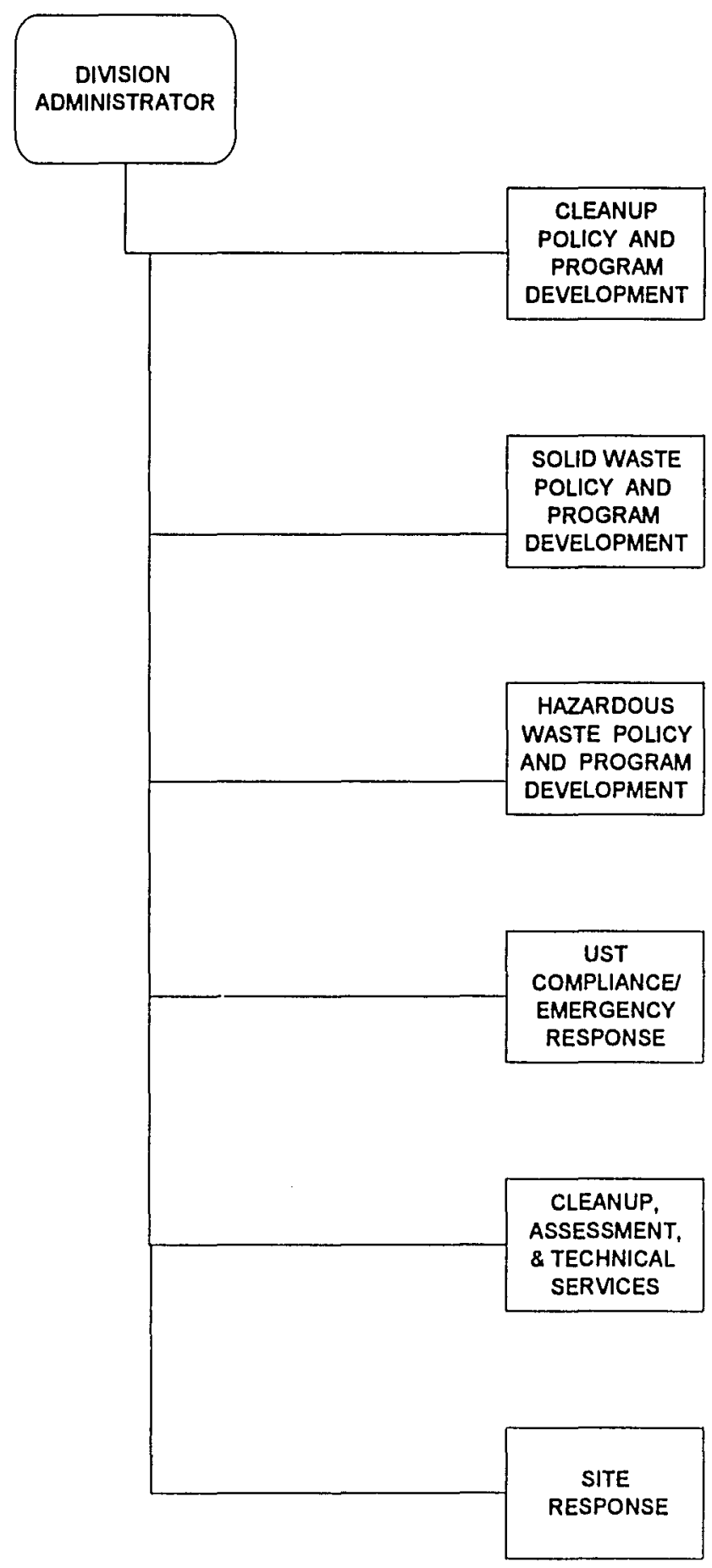


the U.S. Environmental protection Agency (EPA).

The Solid Waste Policy and Programs section plans and implements policy and programs to ensure that solid waste is reduced and properly managed. This section also coordinates household hazardous waste collection events and implements the state's Recycling Act and its comprehensive plan for waste reduction. They also have the responsibility to ensure that municipal and solid waste is properly disposed statewide.

The Hazardous Waste Policy and Program Development section develops program, policies, and rules for the agency, and coordinates federal program requirements with the EPA. This section also manages the hazardous waste information system, facilitates the planning of program activities, and implements the EPA hazardous waste permitting program and corrective action cleanup.

The Underground Storage Tank Compliance and Spill Response section ensures that the underground storage of oil and hazardous materials is accomplished in a manner that prevents contamination of groundwater and leaks of materials into the environment. This section is responsible for coordinating the agency's response to spills of hazardous substances.

The Cleanup Assessment and Technical Services section manages the centralized functions relating to the 
investigation and cleanup of leaking underground tanks containing petroleum. They provide site assessment and keep a ranked inventory of contaminated sites. They also provide oversight for voluntary cleanup that is paid for by the responsible party.

The Site Response section provides oversight for the cleanup of the state's worst toxic waste sites. These sites are often referred to as "orphan sites" because the party responsible for creating the waste is either unknown or unwilling or unable to pay for the cleanup. Most of what the Site Response does is in collaboration with the US EPA.

\subsubsection{Regional Divisions}

The three program divisions discussed above are the core of the EA's operations and are based at the agency's headquarters. The functions of these divisions, as already discussed, are to interpret the environmental laws and set up criterion through which these laws are implemented. Few sections within the program divisions actually deal directly with the regulated communities. There are few exceptions: Sections within WMC, Site Response and UST Compliance and Spill Response actually visit sites and oversee actual cleanup work; The Vehicle Inspection section within Air 
Quality is another section that deals directly with the public. The majority of EA work, is carried out by people located in the regional divisions. Each of the three regions has sections that implement each of the program areas as shown on figures $5.7,5.8$, and 5.9 of the divisional organizational charts on the next three pages.

\subsubsection{Management Services Division}

The Management Services Division forms the center of administrative work in the agency. It provides central management services for the agency in accounting, budgeting, information systems, financing, mailroom, purchasing, property control, intergovernmental coordination, pollution bond fund, tax credit program assistance, library services, safety and healthy services, and human resources services. The breakdown of the areas of responsibilities is outlined in the divisional organizational chart, figure 5.10, on page 90.

\subsubsection{Laboratory Division}

The Laboratory Division provides sampling, monitoring, and analytical support services to all the program areas. The data resulting from these efforts is utilized by the program areas to determine attainment or nonattainment 
Figure 5.7 Eastern Region Division Organizational Chart

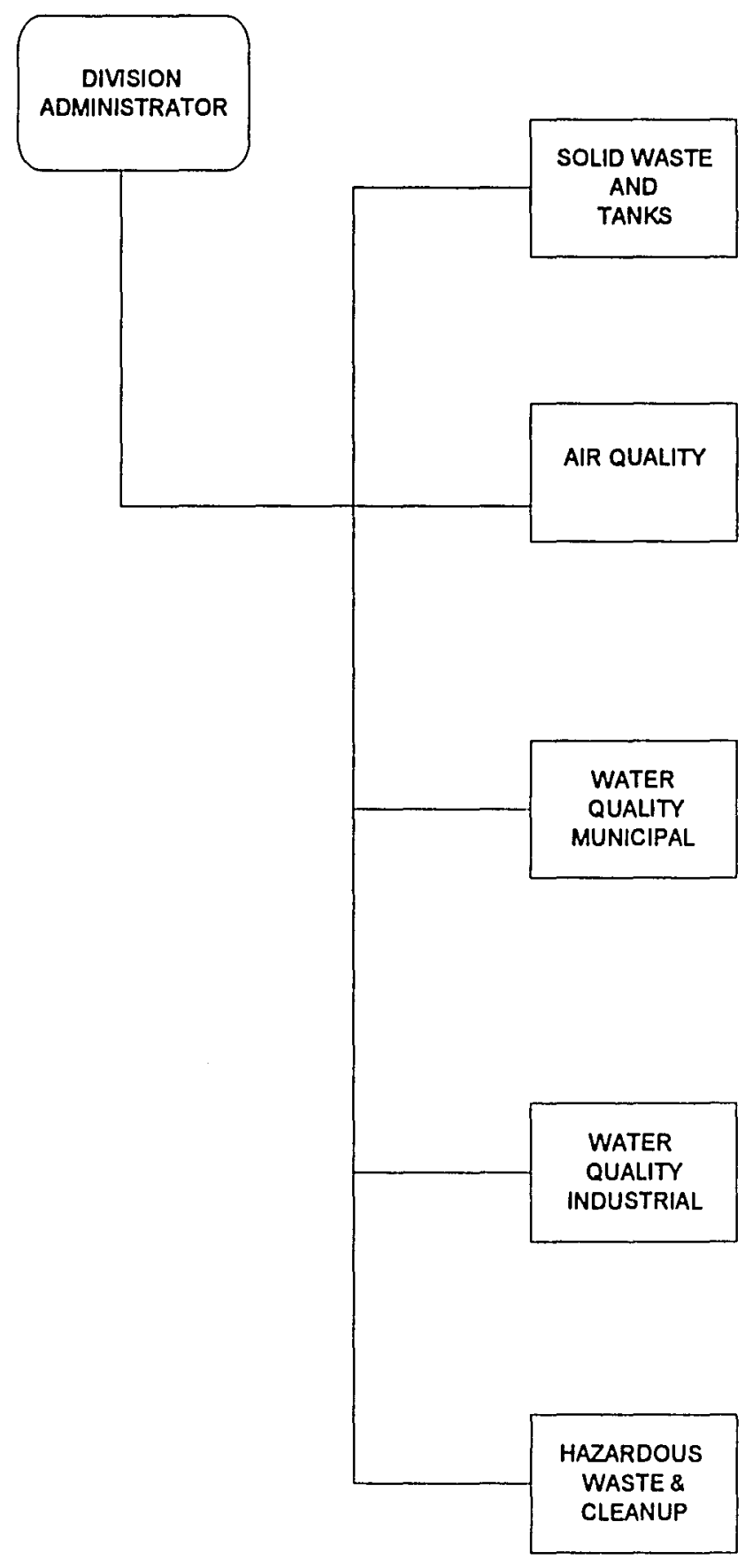


Figure 5.8 Northwest Region Division

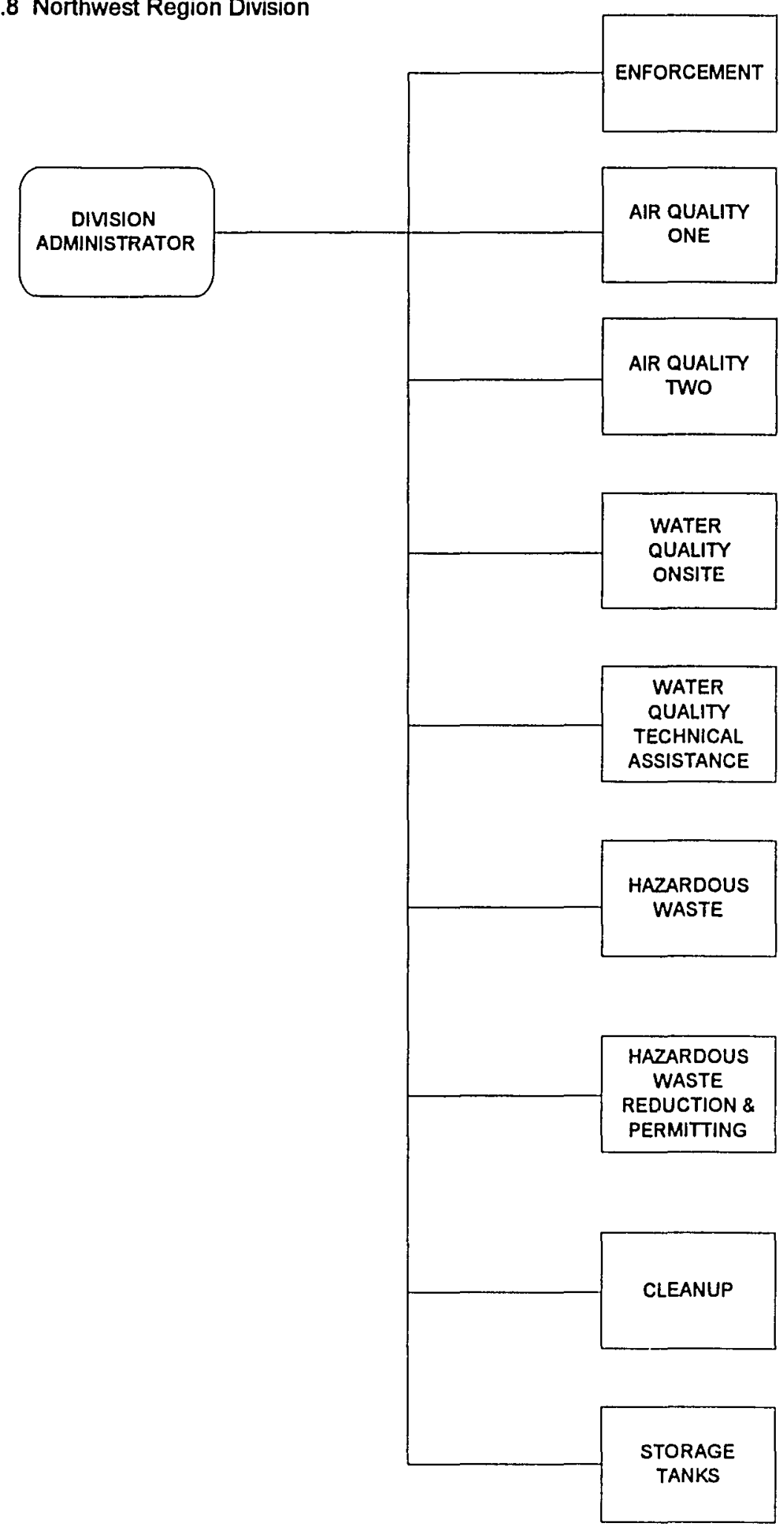


Figure 5.9 Western Region Division Organizational Chart

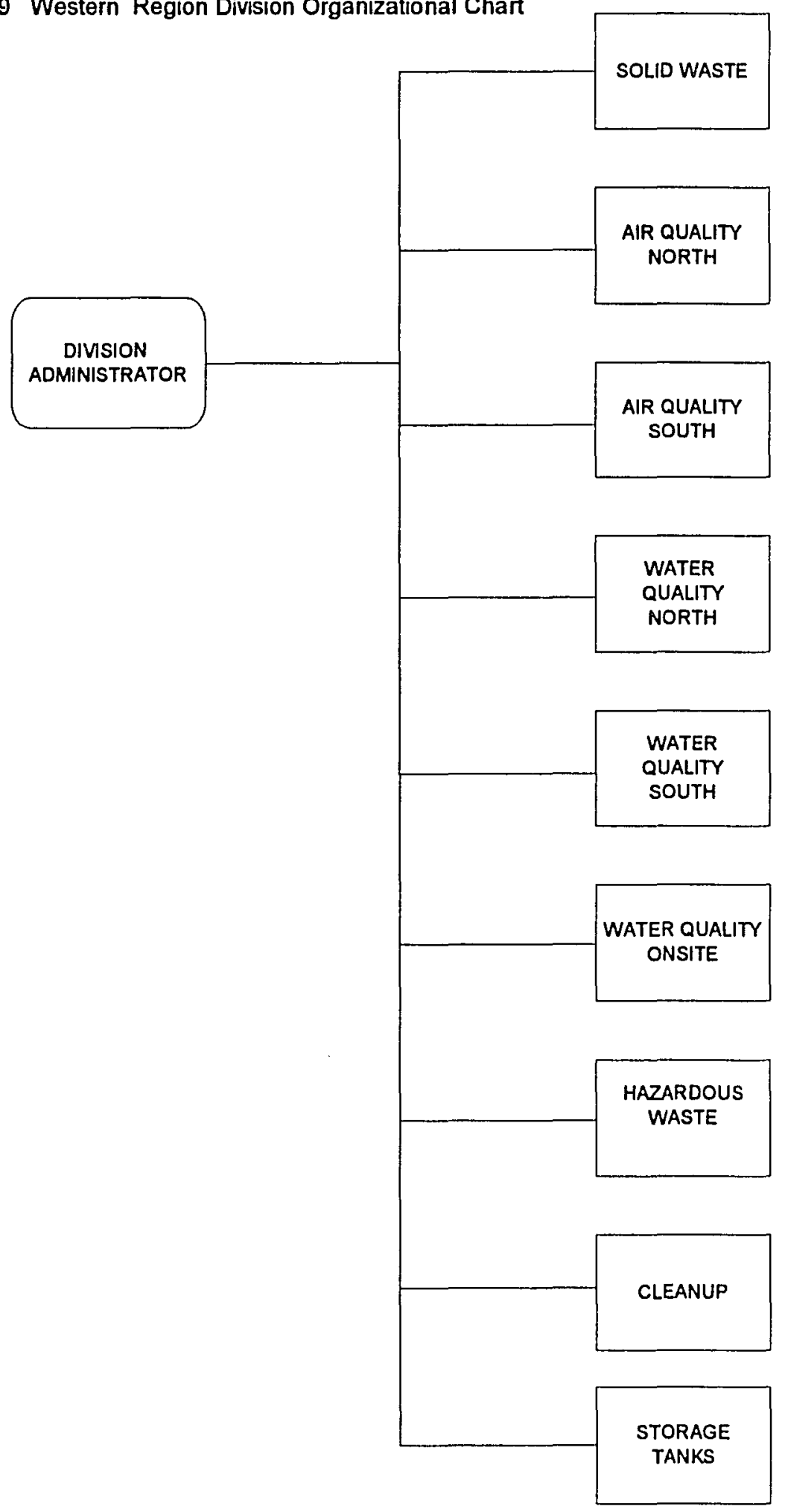


Figure 5.10 Management Services Division Organizational Chart

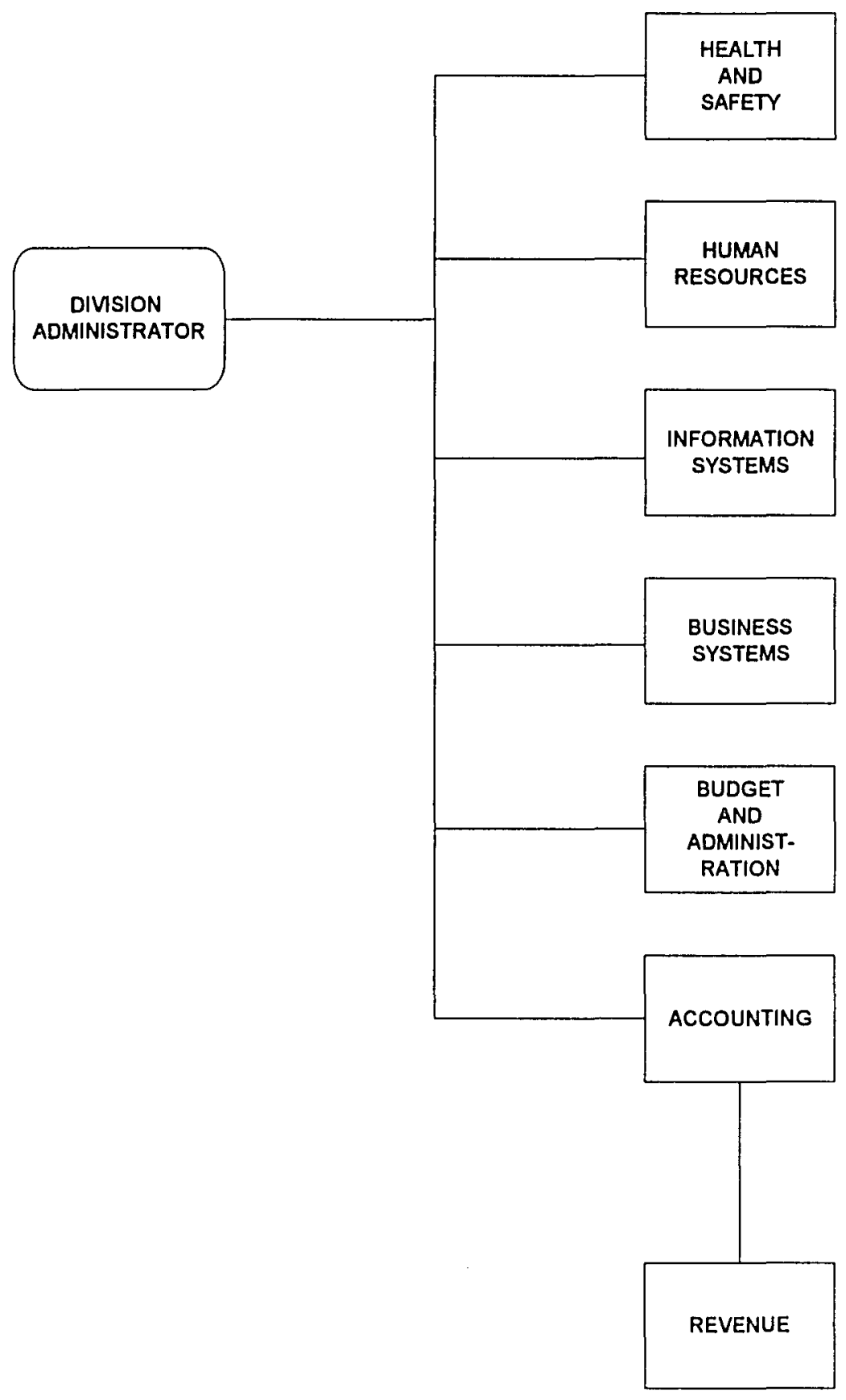


status with ambient environmental standards, to provide compliance information for the agency's inspections, to give insight into unknown pollution events, and to provide legally defensible data for the agency's civil and criminal litigations. This division also provide scientific and technical assistance in the areas of environmental chemistry, biological assessments, air and water metrology, analytical methods and quality assurance.

The breakdown of the laboratory division is illustrated in figure 5.11 on the next page.

\subsubsection{Summary}

The core of the EA work resides in the three program areas of Air Quality, Water Quality, waste Management and Clean Up. The standards for implementing these programs are established at the agency's headquarters in the respective divisions. The bulk of the actual implementation is carried out by the three regional divisions. The Management Services and laboratory divisions exist to support those six divisions.

The culture of the EA, which has been characterized as a techno-pollegal, can be broken down in terms of its divisions. Figure 5.12 on page 93 illustrates that alignment. The Management Services Division is entirely in 
Figure 5.11 Laboratory Division Organizational Chart

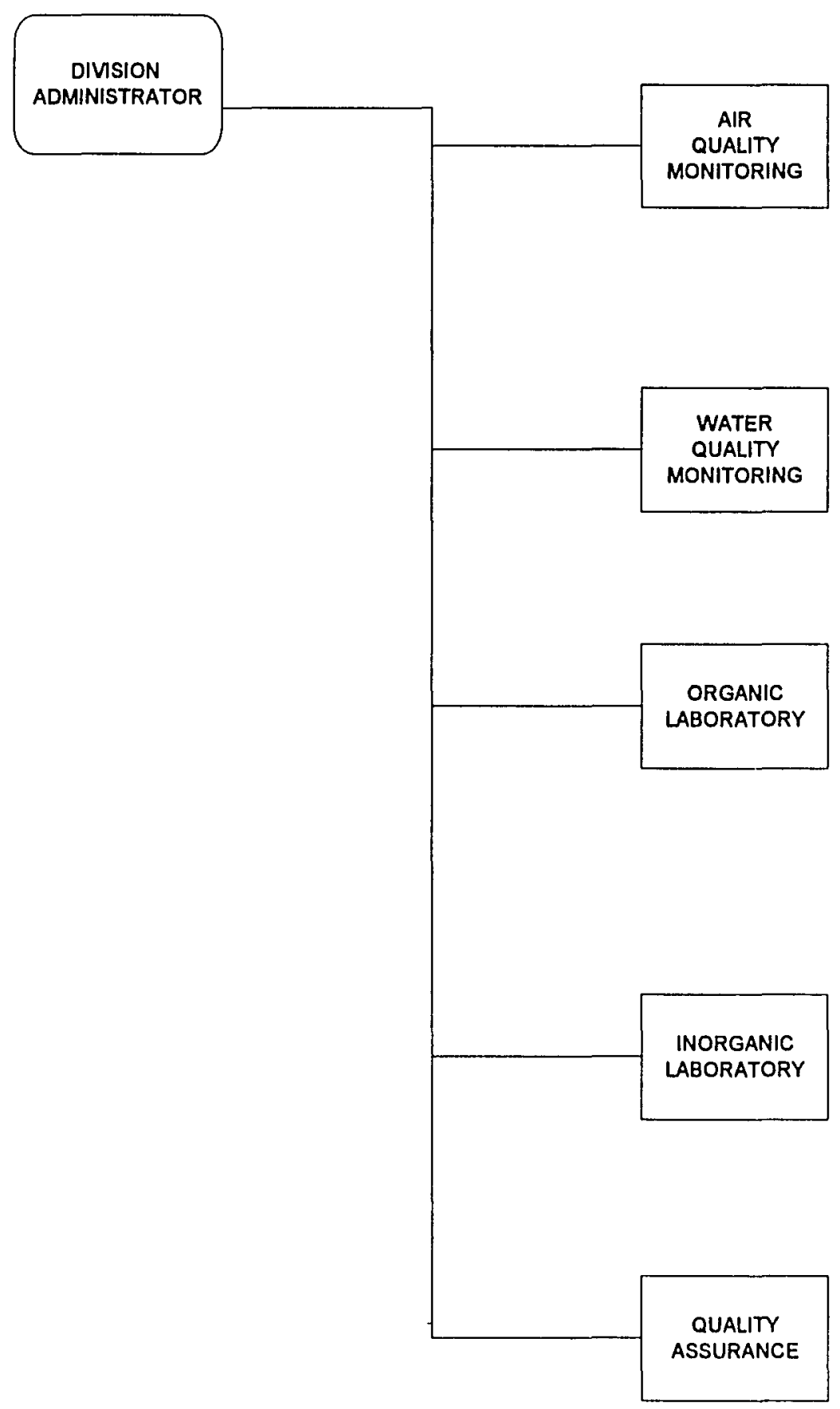




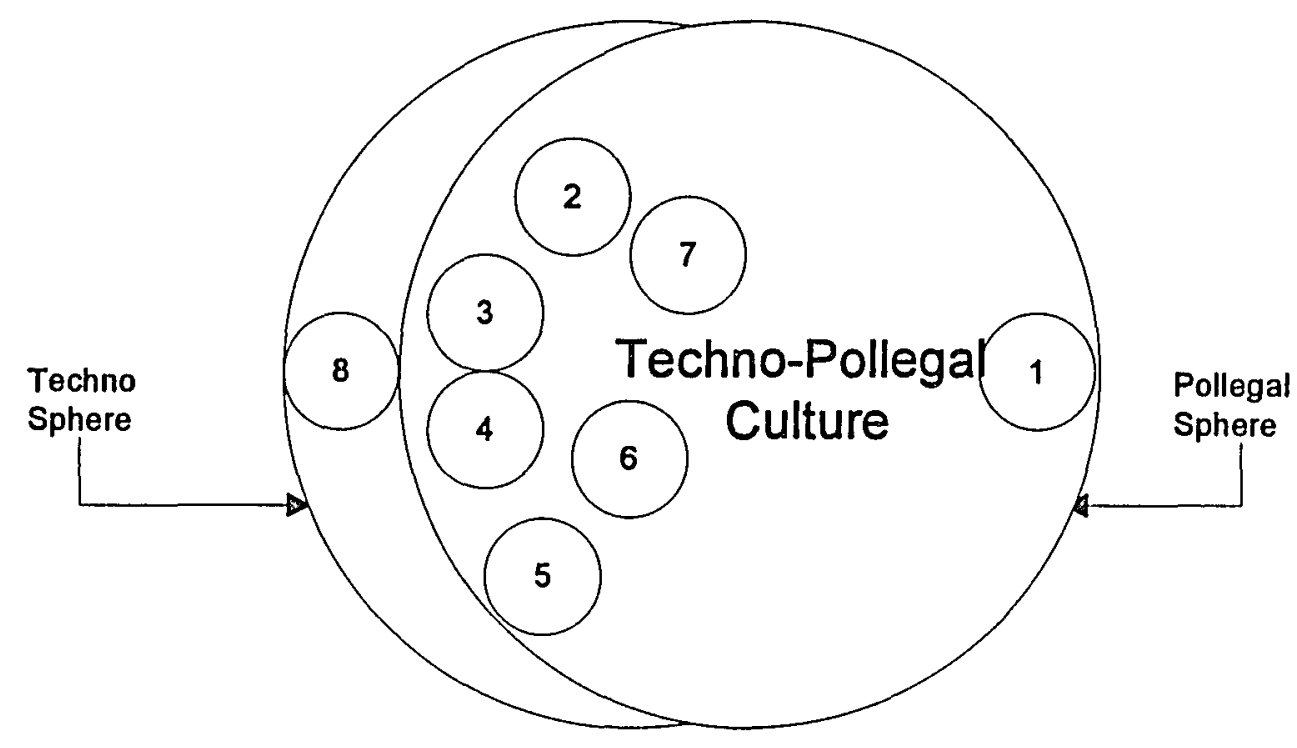

Key:

$1=$ Management Services Division

2 = Air Quality Division

$3=$ Water Quality Division

$4=$ Waste Management and Cleanup Division

$5=$ Northwest Region Division

$6=$ Western Region Division

$7=$ Eastern Region Division

$8=$ Laboratory Division 
the pollegal sphere while the Laboratory Division is entirely in the techno sphere. All the other divisions, the core of EA, are in both spheres. "When the legislature is in session", one manager in one of these divisions pointed out, "we lean more on the political side, and all other times we are more on the techno side". Such an alignment is a direct result of the history of the agency, nature of the work they do, and the following commonly noted cultural influences: Societal Culture, Nature of the work or business, and the Views of the leader. ${ }^{2}$

The following sections discuss these cultural influences and how they manifest themselves.

\subsection{Societal Cultural Influence}

Northwest natives take pride in the nature and sanctity of their environment. In fact, most of the people who live in the northwest moved there from other parts of the country for the love this state's natural landscape. This love for

\footnotetext{
${ }^{2}$ The leader in this regard is the previous director who resigned to take a position with the U.S. Environmental Protection Agency at the beginning of this study. It is widely believed that Fred, who was the longest serving director in agency history, built this agency to what it is today. His views, therefore, are what has shaped those of the organizational members, over half of which had never known EA without him.
} 
the environment has affected the culture of the EA from the outset. This societal involvement can be understood in terms of the proliferation of environmental groups in the state and in the region, and the societal base from which these groups emerge.

The Environmental Federation of the State, a private organization, lists twenty-four groups whose primary purpose is to be a voice for some aspect of environmental concern such as Friends of Opal Creek, River Network, and etc. These groups challenge the EA both positively and negatively. Positively because they often are the biggest advocates of the EA programs. Not only do they support the EA in its disputes with polluters, but they also voluntarily assume a share of the environmental public education load.

The negative aspects have to do with these groups' frequent failure to see the big-picture. Meaning, the vast majority of these groups are only concerned with their narrow goals and have no patience for looking at the other issues the EA has to be equally concerned about. For example, "Friends of Long River" may feel that the EA is not doing enough to clean up Long River. The reasons behind the EA's actions may be budgetary, or there may be other rivers which are in worse shape than Long River and, therefore, higher on the EA's priority list. Friends of Long River may then sue the EA for failure to do its job. The EA is then 
dragged into court, devoting even more of the scarce resources, to defend itself against "Friends of Long River" allegations.

The involvement of environmental groups in the state's environmental activities has a long history. Part of that was discussed in the EA history summary at the beginning of this chapter. Remember, it was environmental groups that spearheaded the creation of SSA which led to the EA. These groups have continued to grow in strength and sophistication. In the early years, few of these groups had lawyers and engineers on their payrolls to scientifically and legally challenge the work the SSA, and eventually the EA, did. Now they do. In fact, some of these groups actually have on their payrolls former the EA staff who are well versed in the workings of the EA's programs.

The big battles over environmental issues have traditionally been waged in the western states. The most remembered have been battles over the spotted owl and fish habitat. Most environmental groups emerged from such battles. An organization like the EA cannot escape such influence, as one EA official commented...

... (T) he people around here love their outdoors. They love to fish, hunt, camp, hike, and ski. There are people who have moved out here from the big cities of the East so they can get to do those things. They look at our job (water quality) as being very important. The bottom line, I believe very strongly, is that EA would not be the same organization elsewhere. The public involvement here affects what 
we do.... (W) hen I have attended meetings in other states where I get to meet my counterparts from other states I am amazed at how far ahead of everybody we are. I think this has to do with the level of public involvement in the work we do...

That societal involvement in environmental issues translates into higher levels of commitment on the part of people who run EA. Committed, determined, knowledgeable, are words one hears consistently when EA members discuss their attitudes towards work. This attitude, apart from being influenced by the northwest societal culture, is also a product of the nature of the business of protecting the environment.

\subsection{Nature of the Business Cultural Influence}

Environmental protection, like all functions conducted by a governmental body, is subject to public debate. The central feature of this debate is the concept of what constitutes public good. In other words, at what point is protecting the environment more important than jobs or other modes of comfort? The work the EA does is, in essence, a battle of balancing these two competing interests. The weapons of fighting this battle are politics, law, and technology. The discussion below will summarize the nature and influence of those weapons.

Politics, one definition states, is a process of deciding who gets what, when, and how. As simple as this 
definition may be it, nevertheless, summarizes the public policy making process. A simple diagram, figure 5.13, on the next page illustrates that dynamic process in terms of a simple input-output model. At the input end are interested parties who make demands on their elected officials to either pass or not pass laws or regulations that will affect them. In environmental politics, the two groups that often push for opposite demands are environmental groups and industrial groups. Environmental groups demand tougher measures to curtail pollution sources. Industrial groups, on the other hand, fight for leniency noting the adverse effects stringent regulations can have on their bottom line. Other groups, even private concerned citizens, can play a role from time to time on issues they believe might affect them. The EA members also push for issues that have a potential to change the way they do their work. For example, they might push for more enforcement powers or more resources to expand their operations.

Politicians pay attention to the inputs to varying degrees based on their political judgements of how the decisions they make might be interpreted by their constituencies at election time. In this state, the biggest proponents of tough environmental legislation are elected officials from urban centers whose constituencies are the 
Figure 5.13 The Environmental Policy Making Process

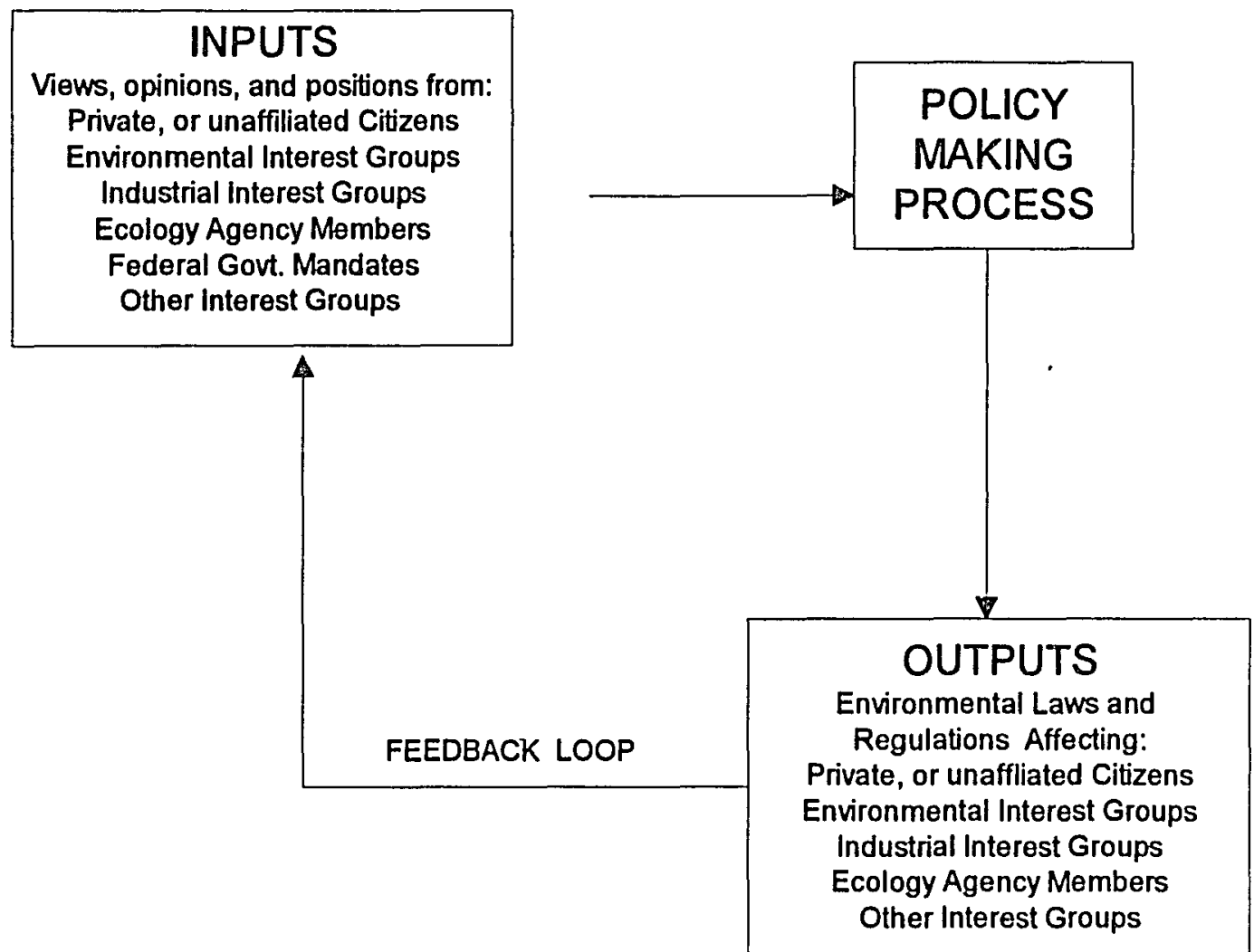


urban professionals who enjoy the recreational aspects environmental protection efforts.

In rural and semirural areas, the main constituencies are farmers and those involved in the timber industry. For these individuals, and the politicians who represent them, environmental laws, particularly those pertaining to water quality and solid waste disposal, are unnecessary at best and criminal at worst. Politicians are elected in these latter districts with pledges, as one the EA official commented, "to stop this nonsense". In this state, most of the elected officials come from higher population densities and, therefore, most environmental protection initiatives prevail with minor compromises. Federal government mandates constitute another input constituency. The major debate nowadays in the nation's 104 th congress surround this issue. There are strong initiatives to put an end to such mandates, especially those that go unfunded.

In the policymaking process, or the black box as some refer to it, all interested groups participate to some degree through their elected officials in raising their opinions, but it is through compromise that the laws and regulations (outputs) are enacted. The EA officials have the job of operationalizing those laws and regulations in order to be able to implement them. Much of this work, as already noted, is done by the three program area staff at 
the EA headquarters. The regional staff later implements these laws and regulations.

Even before actual implementation takes place, feedback starts flowing back to elected officials over some aspect of the law or regulation objectionable to some interested party. These objections continue throughout the implementation phase. Such objections fall into basically two categories: 1 . Those who believe the laws or regulations are bad or too tough on business and individuals (industrial groups); 2 . Those who subscribe to the notion that the same laws or regulations are too lenient and that either more or better laws and regulations are needed to effectively protect the interests of the public (environmental groups). Consequently, objections to policy outputs may either involve reducing the amount of environmental laws and regulations, strengthening them, or simply improving regulatory procedures to increase administrative efficiency, a concern to mostly the EA officials themselves.

Despite public pressure, elected officials from rural areas often change their stance on environmental issues once they are in the state capital. The data provided by the EA on the reasons for environmental efforts can be very convincing. Convinced or not convinced, however, rural and semi-rural politicians are often outnumbered by their colleagues from metropolitan areas. The environmental laws 
and regulations are often passed over their objections. The task for the $E A$ has been to find ways to convince these officials' constituencies, especially the regulated parties themselves, that doing business does not necessarily mean polluting. This effort has made the EA appear to be playing different roles at different times: Law Enforcer;

Facilitator; and Educator. This effort has been, to varying degrees, a concern to all the EA directors over the years, but it was most successfully led by the longest serving director of the EA, to whom this discussion now turns.

\subsection{Views of the Leader Cultural Influence}

It is practically impossible to talk to anyone at the EA about the EA without the name of the longest serving director surfacing. This man had a comprehensive vision for what he wanted the EA to be. He, more than anybody else, was responsible for recognizing and then moving the techno and pollegal spheres of the techno-pollegal culture closer together.

On January 11, 1984, the Environmental Commission named Fred to be the director of the EA effective February 1, of that year. A graduate of a local state university where he majored in Mathematics and History, Fred came to the EA from a rich political and analytic background. He served as an 
Executive Assistant to a US Congressman before taking a top position with the Peace corps. At his appointment to head the EA, he was a Deputy state Treasurer.

Such a mix of experience made Fred an effective director for the time. Unlike most of his predecessors, he understood the political process and how to best thrive in its environment. His biggest concern then was to avoid, at all cost, negative political "bombshells". As a result, he worked harder and longer hours than anybody to make sure no mistakes would be made that could hurt the agency's reputation. There was a time when Fred signed every permit that the EA issued. He spent the first few years developing his strategy. He visited/with organizational members in the field and tried to remember all their names. When time came to move ahead with his plans, he proceeded. His biggest move was to move the agency from a purely technical organization to one that reflected the political and legal nature of what it did. That meant hiring managers who were politically savvy and had, a sense of the big picture of what the EA did.

His next move was to accelerate the process of bringing the public, particularly industry and environmental interests, into the program enacting process by expanding hearings on most issues that affected them. His reasoning was that it was better to bring these often warring parties 
into the process in order to avoid dealing with them in

court later. This was a classic case of "cooptation", a

lesson learned by the Tennessee Valley Authority as

described by Selznick (1949).

"Responsiveness" became one of his watchwords. This was

his way of letting the EA members know that the public, when properly treated, such as the courtesy to have their phone call returned promptly, are likely to be allies in the fight to protect the environment, regardless of their feelings towards government. Remember, the eighties were the Reagan years. This was the era of government bashing. Fred understood the necessity of having an agency that was well respected at a time when the public was generally hostile towards government. In 1994 he circulated a memo to remind his troops, once again, on the necessity of responsiveness. He wrote. .

Responsiveness has been a theme in the Agency for several years now. Much emphasis has been placed on responsiveness, particularly as it relates to returning telephone calls within 24 hours, taking timely enforcement actions and reducing permit backlogs. EA staff have worked hard on improving responsiveness. This has done much to maintain and enhance our credibility. At this point, though as I have said to many of you directly through divisional meetings, we need to evaluate our progress and intensify our efforts regarding responsiveness. Responsiveness results in people valuing and believing what we say and being willing to help us get the job done. It helps with the likelihood of people accepting the need to do things, such as not burning their woodstoves at certain times or having their car's emission systems inspected, that they would rather not do. Being responsive says to people 
that we listen and we care. On the other hand, not being responsive undermines our credibility, puts us on the defensive, and makes it more difficult to get the environmental results we want....

Within that "responsiveness" memo, and in conversation with the EA staff, there were philosophical values regarding the conduct of work and the relationship the EA members had to have with the public that he imparted to his subordinates. He commented...

Our efforts (as EA members), to be effective, must recognize that people want to comply with the law and protect the environment. The vast majority of our goals for environmental protection depend upon individuals and businesses complying with our laws and requirements when we are not present. They are better able to do this when they understand and accept our rules and regulations.

To further carry out the dual need for responsiveness and political "bombshell avoidance", Fred moved to reorganize EA structurally. The already discussed the current EA organizational structure is a result of the reorganization that took place in the final months of his tenure. The structure that was in place when he took over is illustrated in figure 5.14 on the next page.

As the chart shows, the bulk of the EA staff was located at the headquarters. One manager likened this arrangement to "too many chiefs and very few Indians". There was only one administrator for all the regional operations. He was supported by five managers and a staff of approximately fifty. They did, with few exceptions, the 
Figure 5.14 Ecology Agency Organizational Chart Before Reorganization

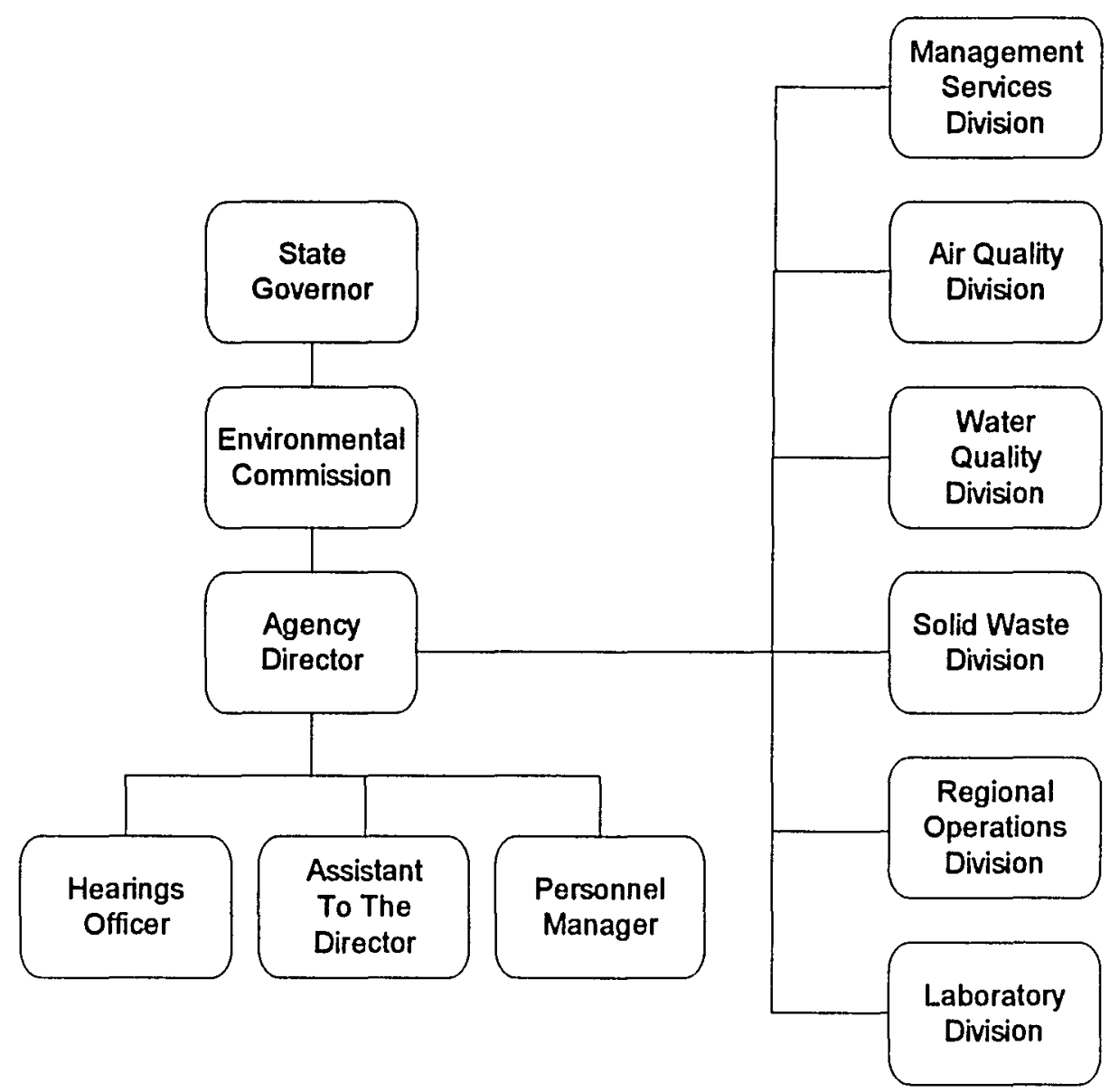


work that is now done by three administrators, twentyfour managers of the same classification as the previous five, and a staff of approximately three hundred. The work was overwhelming for regional staff, as one regional veteran commented, "frustrating". Much of what they did, particularly in the case of issuing discharge permits, had to be cleared through headquarters. That led to what appeared to be unnecessary delays and double work. One former regional manager commented... ... (0) ur job was to draft permits and then send them to headquarters for finalization. Often, the headquarters people totally changed everything we had done in such a way that some of us even wondered why we had to spend so much time doing what would always be drastically changed...

The rationale for centralizing most operations was to ensure consistency. But by striving for consistency, । particularly in issuing discharge permits, responsiveness was sacrificed. Since regional people did not have the final say on particulars of each permit, they were less able to answer pertinent questions the regulated community asked. They had to refer them to headquarters. This process had the makings of the all too familiar "bureaucratic red tape" or "bureaucratic run around" in the eyes of the EA clients. These perceptions were also clear to Fred, and he considered reorganization as the most likely solution. Staffers in the regions also understood the importance and 
rationale behind reorganization, and the vast majority of them backed Fred.

Reorganization was accomplished by moving a great number of positions and their functions from the headquarters to regional operations. Director Diarmuid O'Scannlain, had regionalized most operations in the early seventies in a manner that alienated him from the EA staff. The Oregon Times wrote in $1974 \ldots$ ... (T) he reorganization he (O'Scannlain)
instituted, decentralizing the department and
creating five regional district offices, uprooted
personnel-sometimes abruptly-and did not enhance
his popularity.. The similarity between the circumstances that greeted both Fred and O'Scannlain is striking. Both succeeded popular directors, Young and Day respectively, whose styles were also similar. Like Day, Young did not like "rocking the boat". They were both maintainers of the status quo, comfortable with staying in the background and not drawing attention to themselves, and prudent about not ruffling too many feathers. These traits made the two directors popular with the veteran staff that was not eager to change. When Fred and O'Scannlain came on the scene, several laws and regulations were just coming on line. This meant more new staff and reevaluation of the old ways of doing business. 
Furthermore, both Fred and O'Scannlain saw themselves as change agents and did not shy away from drawing attention to themselves. Some EA staffers who remember O'Scannlain thought that he wanted to draw attention to himself for political reasons. They thought he simply wanted to use the EA as a spring board to future political office by tackling highly controversial issues that would make the EA, and subsequently him, a household name. L.B. Day, O'Scannlain's predecessor, accused him of spending too much time on the road (away from the office), making speeches and isolating himself from his staff. O'Scannlain defended his actions by noting that his directorship differed from that of Day because he saw his responsibility as not merely one of making tough decisions, but of going to the people to encourage public support for often unpopular policies.

As his rift with the EA staff increased O'Scannlain attacked them for their conservatism. He stated...

...(D) epartment engineers are reluctant to impose tough standards on industry. The problem with longtime staff...is that they hate environmentalists...

Another factor affecting both O'Scannlain and Fred was that both came on board at a time when government, as already mentioned, was philosophically under attack from conservatives. This attack was spearheaded from the Nixon and Reagan White Houses. 
It appears, then, that O'Scannlain and Fred wanted the same thing. The only difference was in implementation and style. As already mentioned, Fred was politically wise and understood how to politically outmaneuver his opponents. His biggest challenge was reorganization. Having pushed the idea of responsiveness for years, reorganization was then pushed as the next logical step in the quest to accomplish that goal.

While similar objections to reorganization were raised at this time, as were raised during O'Scannlain's tenure, such objections were muffled by the approach to reorganization Fred took, that had visible traces of what many considered a dose of humanitarianism. As positions were reassigned to the regional divisions that were created, there was an element of volunteerism that accompanied it. Staffers with similar qualifications were allowed to trade positions to suit themselves. This softened the reorganization blow somewhat and toned down the criticisms. This was Fred's last accomplishment before he left for the US EPA. The legacy he left at the EA will undoubtedly remain for sometime to come. The ultimate effects of reorganization, however, are still to be seen. The summary of the cultural influences will sum up his and others' contributions. 


\subsection{Summary of the Cultural influences}

Societal culture, the nature of the business, and the views of the leader have all contributed to the technopollegal culture of EA. These three sources of organizational culture are not independent of each other: the leader's basic assumptions are influenced by the broader culture (Fred was a Northwest native), the organization's line of business is affected by the leader's assumptions (EA's responsiveness, need for political savvyness, etc.), and the nature of the business (the dynamic nature of the policy making process, the general pollegal environment, and the scientific nature of the work) both affects and is affected by the societal culture.

The EA culture can then be summarized at all three levels of basic assumptions, values, and artifacts and creations (or behaviors) in terms of the modified schein (1992) figure 5.15 on the next page. As the figure shows, importance of the environment, pollegal aspects, scientific prowess, and work process are the basic assumptions upon which the values of this techno-pollegal culture are based. These values are scientific correctness, responsiveness, teamwork (most work involve project teams), collaboration, project and task orientation, and the sanctity of environmental protection. These values translate behaviors 
Figure 5.15 Ecology Agency Culture in Terms of Schein's

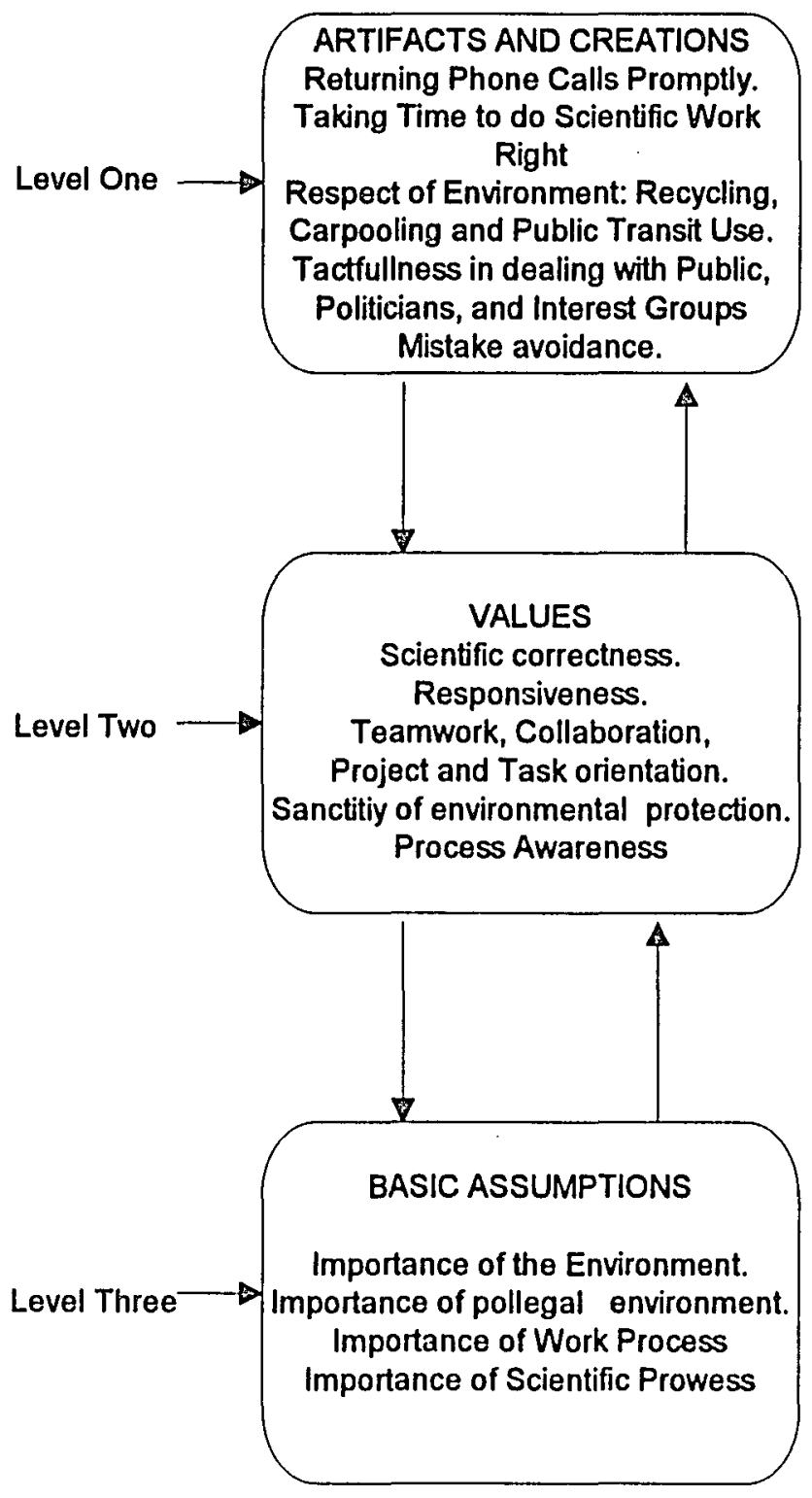

Visible, but often not decipherable
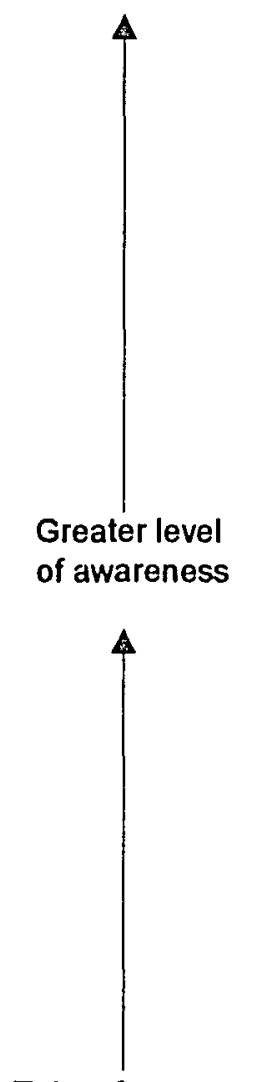

Taken for granted.

Invisible. Preconscious

Source: Adapted From Schein (1992), pp. 14 
such as returning phone calls relatively promptly; taking time to do scientific work right the first time; respect of environment, evidenced by greater organizational member participation in carpooling, use of public transport, and recycling; tactfulness in dealing with members of the public, politicians, and interest groups; and general mistake avoidance.

These aspects of the EA culture are what seem to be predominant. The adherence to each one of these elements depend on an individual's division, section, and level in the organization. Program Divisions at headquarters and Regional Divisions tend to be more techno-pollegally balanced. They form the core of the culture, and their staffs constitute over $80 \%$ of the EA workforce. The Laboratory division adheres mostly to the techno aspects as the Management Services Division gravitates to the pollegal aspects of that culture.

The next chapter takes a look at the adherence to the teamwork value quantitatively, and how that interacts with the performance appraisal perspectives outlined in chapters two and four. 


\section{Chaptex 6}

\section{Results from Quantitative Inquiry}

\subsection{Introduction}

Overall, the EA culture characterization presented in chapter five captures its essence. This chapter looks quantitatively at certain cultural elements and how those interact with individual members' perception of the performance appraisal process. Openness, Collaboration, Confrontation, and Trust are the selected ethos in this regard. The overall hypothesis in this study is that the performance appraisal process, operationalised in terms of individual organizational member perceptions thereof, has a positive effect on an organizations culture. In this case, the hypothesis is that individual member PA perceptions over the Coaching Environment, Feedback, Fairness, and System integrity will have a significant positive effect on the four ethos from the OCTAPACE scale.

The first four hypotheses tested the effect of all the PA perception dimensions on each of the four ethos. In each case, the data showed that the PA perceptions, especially Coaching and Feedback, had a significant effect on each of the ethos. The fifth and sixth hypothesis tested the impact of the conduct of PA as a function of its frequency and an individual's length of service. The results from these operations showed that individuals recently appraised had, 
on average, higher mean scores on the PA perception scale than those who had been appraised longer. Also, newer organizational members had higher PA perception scores than longer serving members. These results show that the conduct of PA can have a positive effect on the culture of an organization since PA perceptions had a significant positive effect on the organizational ethos.

These four ethos can be understood in terms of the teamwork value mentioned in the last chapter. In other words, it is difficult to envision effective teamwork without considering those four ethos. Apart from the logical inference just extended, effective teamwork as a value system and as an organizational behavior element has been a subject of great academic inquiry starting as early as the Hawthorne studies in the late twenties. McGregor (1960) and Likert (1961) each added to our general understandings of effective teamwork. Current understanding of the concept is exemplified by the works of Larson \& LaFasto (1989); Kinlaw (1991); Dyer (1987); and Varney (1989). In these works and others, Trust, Collaboration, and Communication are noted, among other elements like commitment, loyalty, etc., as important attributes of all effective teams. These elements are highly related, but each has unique features that function to reinforce each other. 
Larson and LaFasto, in their "Collaborative Climate" chapter state that...

"Working well together" is a fundamental ingredient in team success... It was usually a climate that fostered collaboration ${ }^{1}$, and interviewees, when pushed, almost always explained this climate by referring, in one way or another, to "trust". Trust is one of those mainstay virtues in the commerce of mankind. It is the bond that allows any kind of significant relationship to exist between people... Our content analysis of the data indicate that trust is produced in a climate that include four elements: 1 . honestyintegrity, no lies, no exaggerations; 2 . openness- a willingness to share, and a receptivity to information, perceptions, and ideas; 3 . consistencypredictable behavior and responses; and 4. respecttreating people with dignity and fairness... (p. 85).

In most effective teams, members feel free to openly communicate their feelings to other team members. Conflicts, in these types of teams, are openly confronted without expecting defensiveness. This process reinforces both trust and collaboration. To evaluate the teamwork value, then, it is important to look at those ethos that appear to sustain the concept.

The EA, as already discussed, is organized into eight divisions that are further organized into smaller sections of an average of ten members. These sections are intended to function as teams. In qualitative inquiry, the team

\footnotetext{
${ }^{1}$ Emphasis mine throughout this passage.
} 
value was mentioned constantly, particularly by managers. Most mentioned that the organization as a whole does not adhere to teamwork, but sections do. This is understandable because different divisions deal with different problems and, hence, there is little understanding of what goes on in areas outside one's own. Division administrators emphasize the team value for the whole organization because they have "the big picture" and understand the intricate relationship of all the programs. For example, one administrator mentioned. .

.. (A) Il program areas are related, and we have to make everyone understand that... We have to function as a team in this organization... If the Air quality people go and inspect a client and find them in compliance with Air Quality regulations, but see potential water Quality problems, then, they have to contact the water Quality people before they tell that client that he is in compliance. To the client, EA is EA. They don't necessarily know that there are different programs run buy different people. So, if the Air Quality people tell the client he in compliance, the client will think he is okay with EA. When the water Quality come in later and tell him he is not, he is going to think he is getting mixed messages from EA... We have to avoid that. That is why we have to function as a team to deal with all pollution violations at once, otherwise we are not going to do our job properly...

In this chapter, this cultural dimension of teamwork represent a slice, albeit small, of the overall culture of the EA explored in the last chapter. Here that slice is isolated and is tested through the extended hypotheses that individual member perceptions of the PA process affect it. 
This espoused value is also a central feature in the PA process's category of "interactive skills". These skills, include: 1. Team building. 2. Consensus building. 3 . Communication. 4. Networking. 5. Liaison role. 6 . Cooperation. 7. Persuasion/Negotiation. 8. Listening Ability. and 9. Customer service. These features are defined in appendix 2 .

The first part of this chapter will provide a quick summary of the findings by division, level in the organization, and select demographic features on both the PA perception scale and the four dimensions on the OCTAPACE scale. This summary will present the means and standard deviations for each dimension by grouping. Following that discussion will be the "linkage" discussion and analysis. The focus of that section will be to determine if PA Perceptions have a positive statistical significance effect on the selected cultural ethos. That discussion will represent the actual test of the first four hypothesis extended in chapter two. The test of the final two hypotheses will be discussed in the final part of the chapter.

Throughout this chapter, the sample size ( $N$ values) will change periodically due to missing data. Also, although surveys were sent or handed to all organizational members, some chose not to participate in the study. The 
final count of all who participated in the survey was 413, out of approximately 700 members. Forty-nine of the received surveys were unusable due to missing data. The total number used, therefore, was 364 .

This number is representative of the EA staff because the surveys were received from all divisions and levels in the organization. Some EA members felt they could not participate in the study because they had not been with the organization long enough to have an opinion about the issues the surveys raised. The majority of the discarded surveys came from newer members that chose to participate but could not respond to a majority of survey items.

If the initial decision would have been to sample the organizational population, there is no evidence that the response rate would have been any different. There would have been, certainly, much fewer cases to work with. In retrospect, therefore, the proper decision was made at the outset. Throughout the discussion that follows, then, the final count of returned surveys will be considered a representative sample. Figure 6.1 on the next page presents a summary of the respondents' particulars. 
Table 6.1 DEMOGRAPHIC PROFILE OF ECOLOGY AGENCY RESPONDENTS

$\mathrm{N}=364$

Gender

Male $61 \%$

Female $38 \%$

Ethnicity

White (Non-hispanic) $91 \%$

Black (Non-hispanic) $01 \%$

Hispanic $03 \%$

Asian $02 \%$

Native American $.8 \%$

other 048

Education

Some High School $0 \%$

High School Graduate $03 \%$

Some College 13\%

College Graduate 25\%

Some Graduate Studies $20 \%$

Graduate Degree 27\%

Level in Organization

Division Administrators 028

Section Managers $17 \%$

Non-managers $81 \%$

Tenure in organization
Less than a year

More than a year, but less than two $08 \%$

More than two years but less than four 228

More than four years $55 \%$

Date of Last Performance Appraisal

Less than a year ago $39 \%$

More than a year ago, but less than two $18 \%$

More than two years ago, but less than four $16 \%$

More than four years ago $08 \%$

Never been appraised $18 \%$

Note: Percentages may not equal $100 \%$ due to rounding and/or missing data. 


\subsection{Sumary of Findings}

Table 6.2 summarizes the general results from both surveys. The scores for each dimension ranged from 5 to 20. Organizational wide means from those scores represent the organizational standard, and all the other scores by divisions or demographics represent agreement or deviations, either more or less inclination towards the ethos or the PA perception dimensions. Mean scores on the PA Perception Scale dimensions of 10 and below represent disagreement with that dimension, mean scores between 10 and 14 represent moderate agreement with that PA perception, and mean scores of 15 and above represent strong agreement or strong positive perception over the dimension. As the tables on the next few pages will show, there is a definite pattern of moderate agreement with all the PA Perception dimensions except system Integrity which is constantly low. As one goes from the top of the organization, Division Administrators, to the bottom- staff, perceptions get weaker, but stay moderate. perceptions get weaker, but stay moderate. In other words, the higher the level in the organization, the higher the mean scores.

The OCTAPACE Scale has norms, as shown on table 2.1 in chapter 2. The EA scores on that scale were consistently between the highs and lows. This means that the organizational ethos measured here are moderately 
adhered to at the EA. However, as with the PA Scale dimensions, the scores vary less as one moves from one part of the organization to another, and more as one moves up and down the hierarchy. These differences, as the tables that follow show, are not strikingly great due to the moderate inclination to the ethos throughout the organization. The major difference on both scales is between Division Administrators and non-management staff. This demonstrates the "big picture, small picture" differences, particularly on issues of teamwork as was noted earlier. Division Administrators, who represent the organizational leadership espouse the teamwork concept because they see that as one way for EA to do its work.

\section{TABLE 6.2 Mean Organizational Scores on PA and OCTAPACE Scales}

$\begin{array}{llll} & \text { N } & \text { MEAN } & \text { S.D. } \\ \text { COACHING ENVIRONMENT } & 351 & 14 & 3.6 \\ \text { FAIRNESS } & 343 & 14 & 2.9 \\ \text { FEEDBACK } & 338 & 12 & 3.7 \\ \text { SYSTEM INTEGRITY } & 348 & 10 & 2.9 \\ \text { OPENNESS } & 359 & 14 & 2.9 \\ \text { CONFRONTATION } & 359 & 14 & 2.7 \\ \text { TRUST } & 359 & 14 & 2.8 \\ \text { COLLABORATION } & 358 & 14 & 2.4\end{array}$




\begin{tabular}{|c|c|c|c|}
\hline \multirow[t]{2}{*}{ TABLE 6.3} & \multicolumn{3}{|c|}{$\begin{array}{l}\text { Mean Management Scores on } \mathrm{BA} \text { and the } \\
\text { OCTAPACE Scales }\end{array}$} \\
\hline & $\mathrm{N}$ & MEAN & S.D. \\
\hline $\begin{array}{l}\text { COACHING ENVIRONMENT } \\
\text { FAIRNESS }\end{array}$ & $\begin{array}{l}62 \\
59\end{array}$ & $\begin{array}{l}14 \\
14\end{array}$ & $\begin{array}{l}3.5 \\
3.0\end{array}$ \\
\hline $\begin{array}{l}\text { FEEDBACK } \\
\text { SYSTEM INTEGRITY }\end{array}$ & $\begin{array}{l}59 \\
61\end{array}$ & $\begin{array}{l}12 \\
10\end{array}$ & $\begin{array}{l}3.6 \\
2.9\end{array}$ \\
\hline $\begin{array}{l}\text { OPENNESS } \\
\text { CONFRONTATION }\end{array}$ & $\begin{array}{l}62 \\
62\end{array}$ & $\begin{array}{l}15 \\
14\end{array}$ & $\begin{array}{l}3.0 \\
2.6\end{array}$ \\
\hline $\begin{array}{l}\text { TRUST } \\
\text { COLLABORATION }\end{array}$ & $\begin{array}{l}62 \\
62\end{array}$ & $\begin{array}{l}14 \\
14\end{array}$ & $\begin{array}{l}2.6 \\
2.3\end{array}$ \\
\hline \multirow[t]{2}{*}{ TABLE 6.4} & $\begin{array}{l}\text { ement } \\
s\end{array}$ & 8 on 1 & the \\
\hline & $\mathrm{N}$ & MEAN & S.D. \\
\hline $\begin{array}{l}\text { COACHING ENVIRONMENT } \\
\text { FAIRNESS }\end{array}$ & $\begin{array}{l}275 \\
270\end{array}$ & $\begin{array}{l}14 \\
14\end{array}$ & $\begin{array}{l}3.5 \\
2.9\end{array}$ \\
\hline $\begin{array}{l}\text { FEEDBACK } \\
\text { SYSTEM INTEGRITY }\end{array}$ & $\begin{array}{l}265 \\
273\end{array}$ & $\begin{array}{l}12 \\
10\end{array}$ & $\begin{array}{l}3.7 \\
2.9\end{array}$ \\
\hline $\begin{array}{l}\text { OPENNESS } \\
\text { CONERONTATION }\end{array}$ & $\begin{array}{l}283 \\
283\end{array}$ & $\begin{array}{l}14 \\
14\end{array}$ & $\begin{array}{l}2.9 \\
2.7\end{array}$ \\
\hline $\begin{array}{l}\text { TRUST } \\
\text { COLLABORATION }\end{array}$ & $\begin{array}{l}283 \\
283\end{array}$ & $\begin{array}{l}14 \\
14\end{array}$ & $\begin{array}{l}2.9 \\
2.4\end{array}$ \\
\hline
\end{tabular}




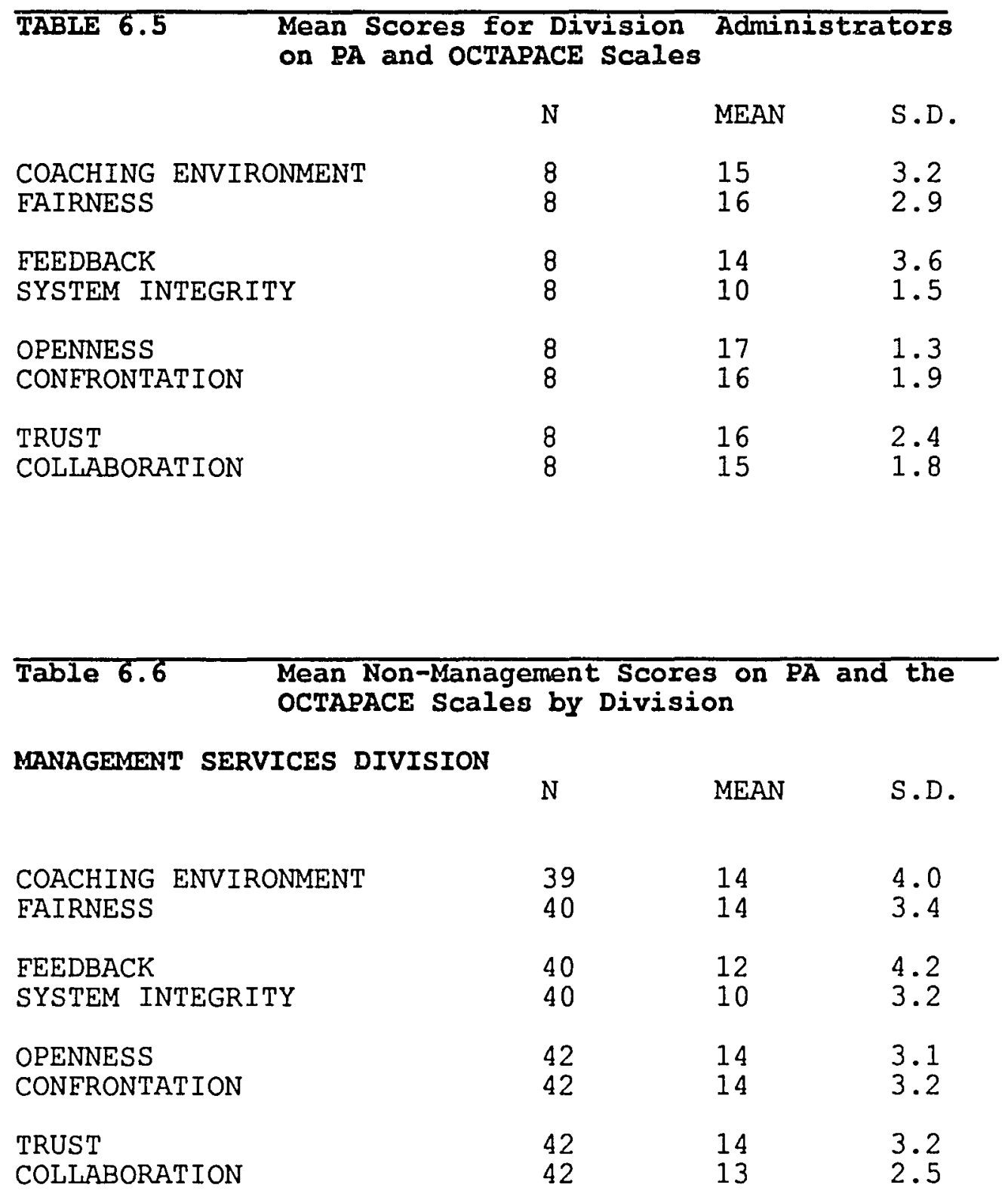


Table 6.6 Continues...

AIR QUALITY DIVISION

$\begin{array}{lccc} & \text { N } & \text { MEAN } & \text { S.D. } \\ \text { COACHING ENVIRONMENT } & 36 & 12 & 3.5 \\ \text { FAIRNESS } & 33 & 14 & 2.7 \\ \text { FEEDBACK } & 32 & 11 & 3.7 \\ \text { SYSTEM INTEGRITY } & 36 & 9 & 3.0 \\ \text { OPENNESS } & 37 & 14 & 3.3 \\ \text { CONFRONTATION } & 37 & 13 & 2.9 \\ \text { TRUST } & 37 & 13 & 3.0 \\ \text { COLLABORATION } & 37 & 13 & 2.7\end{array}$

WATER QUALITY DIVISION

$\begin{array}{llll} & \text { N } & \text { MEAN } & \text { S.D. } \\ \text { COACHING ENVIRONMENT } & 25 & 13 & 3.0 \\ \text { FAIRNESS } & 23 & 13 & 2.7 \\ \text { FEEDBACK } & 23 & 11 & 2.8 \\ \text { SYSTEM INTEGRITY } & 25 & 10 & 2.5 \\ \text { OPENNESS } & 25 & 15 & 2.1 \\ \text { CONFRONTATION } & 25 & 13 & 2.3 \\ \text { TRUST } & 25 & 14 & 1.9 \\ \text { COLIABORATION } & 25 & 13 & 1.8\end{array}$


Table 6.6 Continues...

WASTE MANAGEMENT AND CLEANUP DIVISION

COACHING ENVIRONMENT

$\mathrm{N}$

MEAN

S.D.

49

14

3.6

FAIRNESS

48

15

2.3

FEEDBACK

SYSTEM INTEGRITY

48

48

11

3.2

OPENNESS

50

CONFRONTATION

50

14

TRUST

50

14

2.8

COLLABORATION

50

14

2.5

NORTHWESTERN REGION

DIVISION

N

MEAN

S.D.

COACHING ENVIRONMENT

70

13

3.6

68

13

3.3

FEEDBACK

SYSTEM INTEGRITY

65

69

11

4.0

OPENNESS

73

10

3.0

CONFRONTATION

16

2.8

73

14

2.6

TRUST

73

15

3. 0

COLLABORATION

73

15

2.3 
Table 6.6 Continues...

WESTERN REGION DIVISION

$\begin{array}{llll} & \text { N } & \text { MEAN } & \text { S.D. } \\ \text { COACHING ENVIRONMENT } & 50 & 15 & 3.5 \\ \text { FAIRNESS } & 49 & 15 & 2.7 \\ \text { FEEDBACK } & 49 & 12 & 3.6 \\ \text { SYSTEM INTEGRITY } & 48 & 11 & 3.2 \\ \text { OPENNESS } & 50 & 15 & 2.5 \\ \text { CONFRONTATION } & 50 & 14 & 2.6 \\ \text { TRUST } & 50 & 15 & 2.6 \\ \text { COLLABORATION } & 49 & 14 & 2.0 \\ \text { EASTERN REGION DIVISION } & & & \\ & \mathrm{N} & \mathrm{MEAN} & \mathrm{S} . \mathrm{D} \\ \text { COACHING ENVIRONMENT } & 36 & 14 & 3.2 \\ \text { FAIRNESS } & 36 & 15 & 2.6 \\ \text { FEEDBACK } & 36 & 13 & 3.3 \\ \text { SYSTEM INTEGRITY } & 36 & 11 & 2.9 \\ \text { OPENNESS } & 36 & 14 & 3.2 \\ \text { CONFRONTATION } & 36 & 14 & 2.9 \\ \text { TRUST } & 36 & 13 & 3.3 \\ \text { COLLABORATION } & 36 & 14 & 2.4 \\ & & & \\ & & & \\ & 36 & & \end{array}$

IABORATORY DIVISION

COACHING ENVIRONMENT

N

MEAN

S.D.

FAIRNESS

3.0

FEEDBACK

37

12

3.8

SYSTEM INTEGRITY

2.8

OPENNESS

39

CONFRONTATION

39

14

2.4

14

2.0

TRUST

39

14

39

13

2.2

2.1 


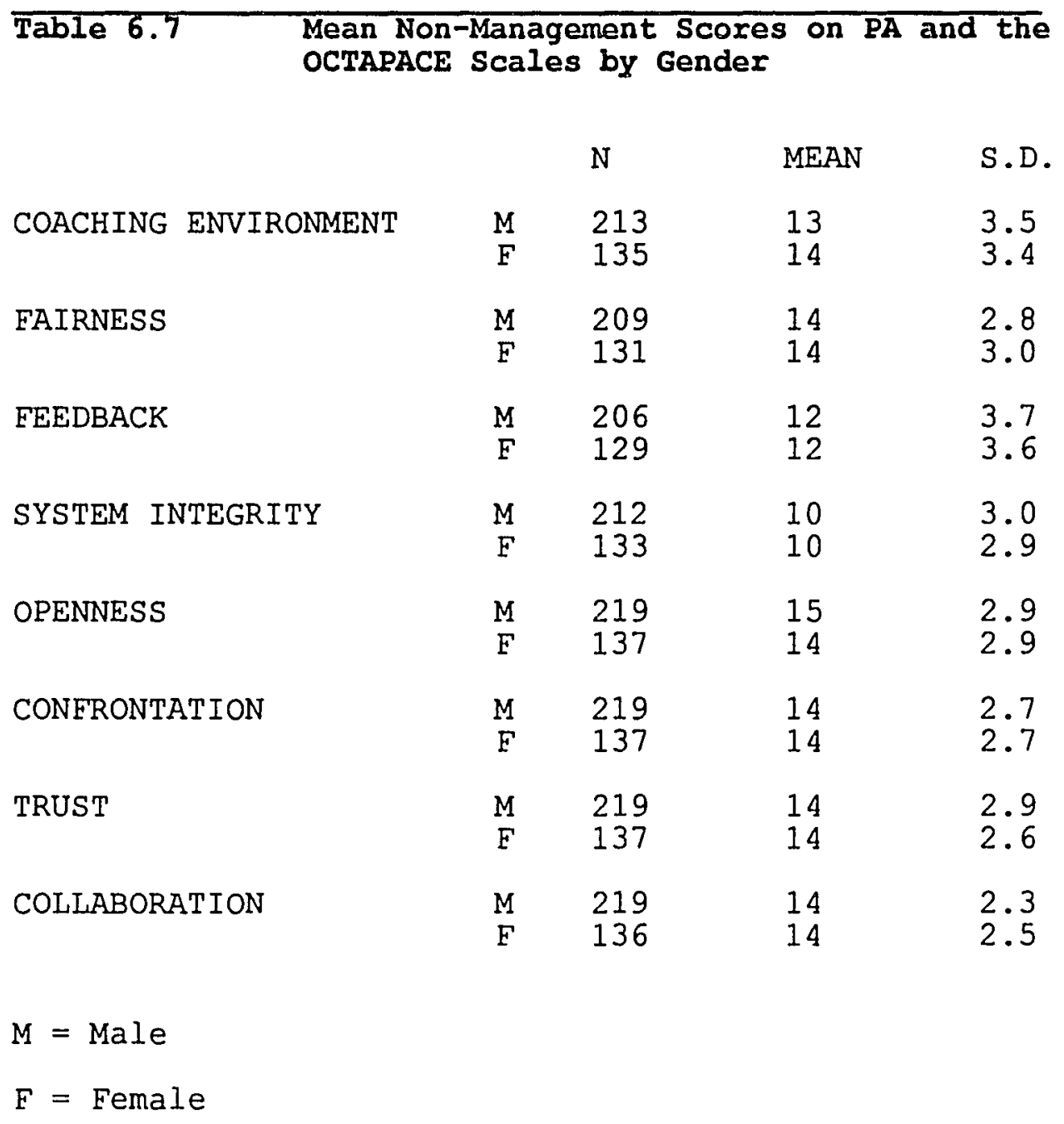



$\begin{array}{ll}\text { Table } 6.8 & \text { Mean Non-Management Scores on PA and the } \\ \text { OCTAPACE Scales by Education }\end{array}$

\begin{tabular}{|c|c|c|c|c|}
\hline & & $\mathrm{N}$ & MEAN & S.D. \\
\hline COACHING ENVIRONMENT & $\begin{array}{l}\mathrm{G}^{\star} \\
\mathrm{NG}\end{array}$ & $\begin{array}{r}256 \\
54\end{array}$ & $\begin{array}{l}14 \\
14\end{array}$ & $\begin{array}{l}3.5 \\
3.9\end{array}$ \\
\hline FAIRNESS & $\begin{array}{l}\text { G } \\
\text { NG }\end{array}$ & $\begin{array}{r}248 \\
53\end{array}$ & $\begin{array}{l}14 \\
14\end{array}$ & $\begin{array}{l}2.8 \\
3.4\end{array}$ \\
\hline FEEDBACK & $\begin{array}{l}\text { G } \\
\text { NG }\end{array}$ & $\begin{array}{r}245 \\
53\end{array}$ & $\begin{array}{l}11 \\
12\end{array}$ & $\begin{array}{l}3.5 \\
4.1\end{array}$ \\
\hline SYSTEM INTEGRITY & $\begin{array}{l}\text { G } \\
\text { NG }\end{array}$ & $\begin{array}{r}253 \\
53\end{array}$ & $\begin{array}{l}10 \\
11\end{array}$ & $\begin{array}{l}2.8 \\
3.4\end{array}$ \\
\hline OPENNESS & $\begin{array}{l}\text { G } \\
\text { NG }\end{array}$ & $\begin{array}{r}259 \\
56\end{array}$ & $\begin{array}{l}15 \\
13\end{array}$ & $\begin{array}{l}2.8 \\
2.9\end{array}$ \\
\hline CONERONTATION & $\begin{array}{l}\text { G } \\
\text { NG }\end{array}$ & $\begin{array}{r}259 \\
56\end{array}$ & $\begin{array}{l}14 \\
13\end{array}$ & $\begin{array}{l}2.6 \\
3.3\end{array}$ \\
\hline TRUST & $\begin{array}{l}\text { G } \\
\text { NG }\end{array}$ & $\begin{array}{r}259 \\
56\end{array}$ & $\begin{array}{l}14 \\
13\end{array}$ & $\begin{array}{l}2.8 \\
3.1\end{array}$ \\
\hline COLILABORATION & $\begin{array}{l}\text { G } \\
\text { NG }\end{array}$ & $\begin{array}{r}259 \\
56\end{array}$ & $\begin{array}{l}14 \\
14\end{array}$ & $\begin{array}{l}2.2 \\
2.9\end{array}$ \\
\hline $\begin{array}{l}\text { * College Graduates } \\
\text { * Non-College Graduates }\end{array}$ & & & & \\
\hline
\end{tabular}




\section{Table 6.9 Mean Non-Management Scores on PA and the OCTAPACE Scales by Region}

\begin{tabular}{lllll} 
& & $\mathrm{N}$ & MEAN & $\mathrm{S} . \mathrm{D}$ \\
COACHING ENVIRONMENT & $\mathrm{H}^{\star}$ & 110 & 13 & 3.4 \\
& $\mathrm{R}^{\star \star}$ & 156 & 14 & 3.6 \\
FAIRNESS & $\mathrm{H}$ & 104 & 14 & 2.6 \\
& $\mathrm{R}$ & 153 & 14 & 3.0 \\
FEEDBACK & $\mathrm{H}$ & 103 & 11 & 3.2 \\
\multirow{2}{*}{ SYSTEM INTEGRITY } & $\mathrm{R}$ & 150 & 12 & 3.7 \\
OPENNESS & $\mathrm{H}$ & 109 & 9 & 2.6 \\
& $\mathrm{R}$ & 153 & 11 & 3.1 \\
CONFRONTATION & $\mathrm{H}$ & 112 & 14 & 2.9 \\
& $\mathrm{R}$ & 159 & 15 & 2.9 \\
TRUST & $\mathrm{H}$ & 112 & 13 & 2.7 \\
& $\mathrm{R}$ & 159 & 14 & 2.7 \\
COLLABORATION & $\mathrm{H}$ & 112 & 14 & 2.6 \\
& $\mathrm{R}$ & 159 & 14 & 3.0 \\
& $\mathrm{H}$ & 112 & 13 & 2.4 \\
& $\mathrm{R}$ & 158 & 14 & 2.3
\end{tabular}

* Headquarters: refers to program divisions only, excluding Management services division.

* Regional Divisions

\subsection{Hypothesis Testing}

The central part of this study was to investigate j.f a relationship existed between an organization's performance appraisal process and its culture. To accomplish this end, the performance appraisal process was operationalized in terms of organizational member 
perceptions with regard to dimensions of Feedback, Coaching Environment, System Integrity, and System Fairness.

These four dimensions, as already discussed in chapter two, constitute the leadership espoused values upon which the PA process itself is based. The organizational ethos of Openness, Confrontation, Trust, and Collaboration represent the cultural dimension of teamwork that is also espoused by the agency. PA Perceptions, therefore, as the first four extended hypotheses stated, have to have a significant positive effect on the ethos. In these first four hypothesis, regression is used to test if a relationship exist between the PA Perceptions and the four mentioned organizational ethos.

In all operations the PA perceptions are independent variables and the OCTAPACE dimensions are the dependent variables. Tables 6.10 to 6.13 on the next two pages show the outputs from the these operations. As the tables show, all the PA Perception dimensions individually and collectively have a highly statistically significant $(\mathrm{p}<$ .001) positive effect on all the ethos. They collectively account for $19.28,31.68,21.48$, and $29.6 \%$ of the variance in Openness, Trust, Collaboration, and Confrontation respectively. The major finding in this regard is the impact perceptions of a Coaching Environment and Feedback 


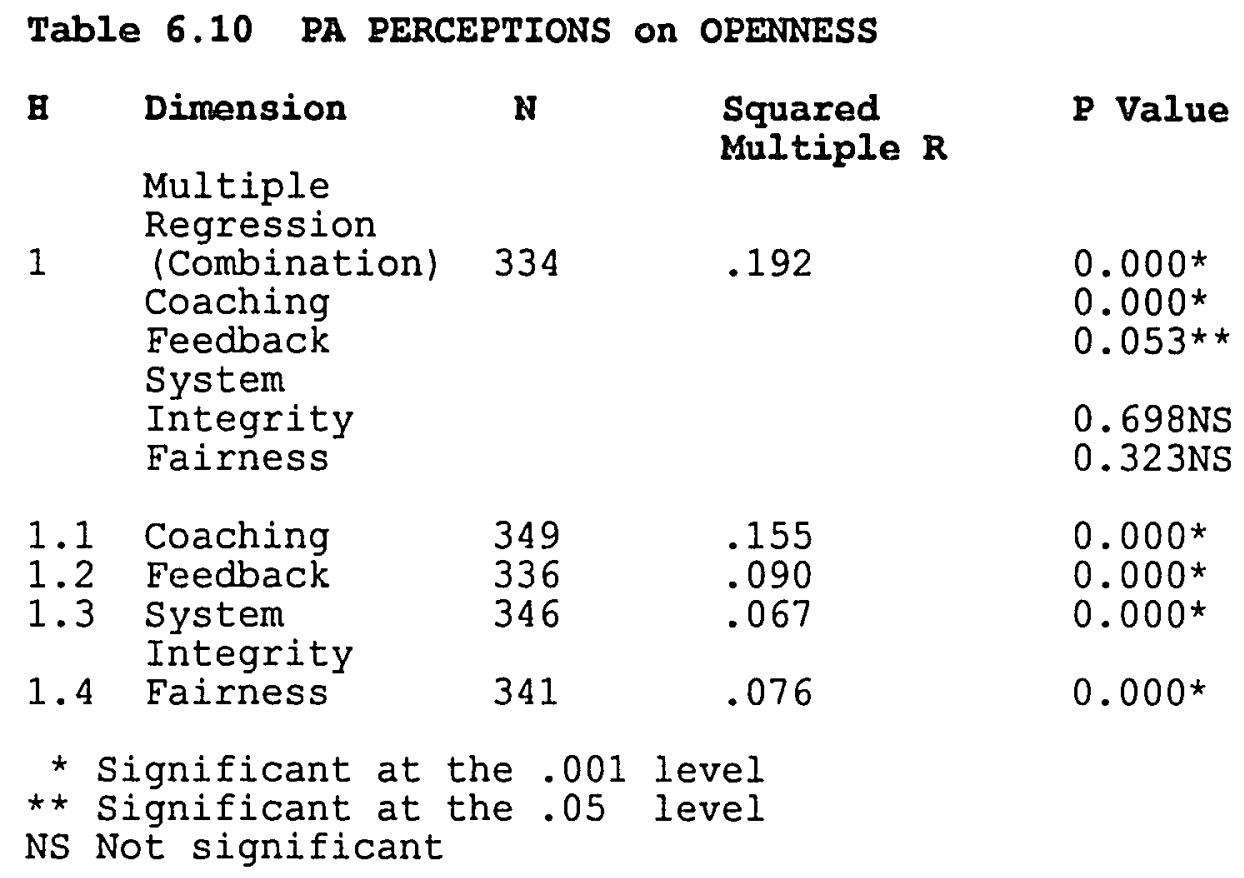

Table 6.11 PA PERCEPTIONS on TRUST

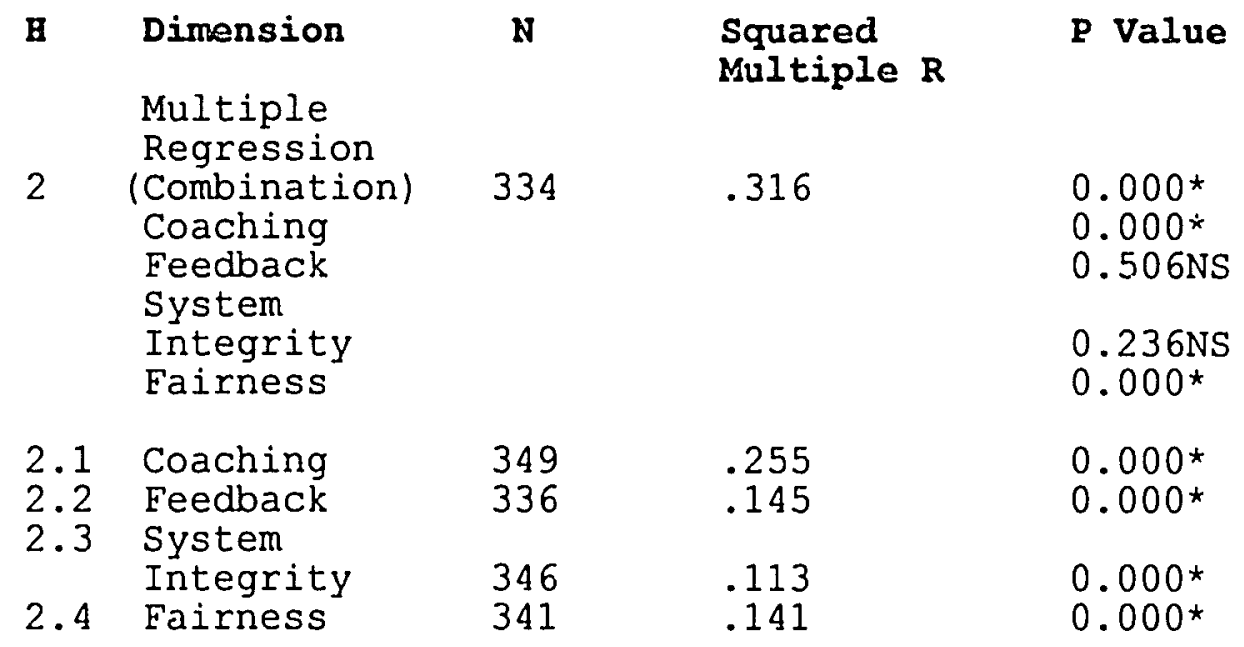

* Significant at the .001 level

NS Not Significant 


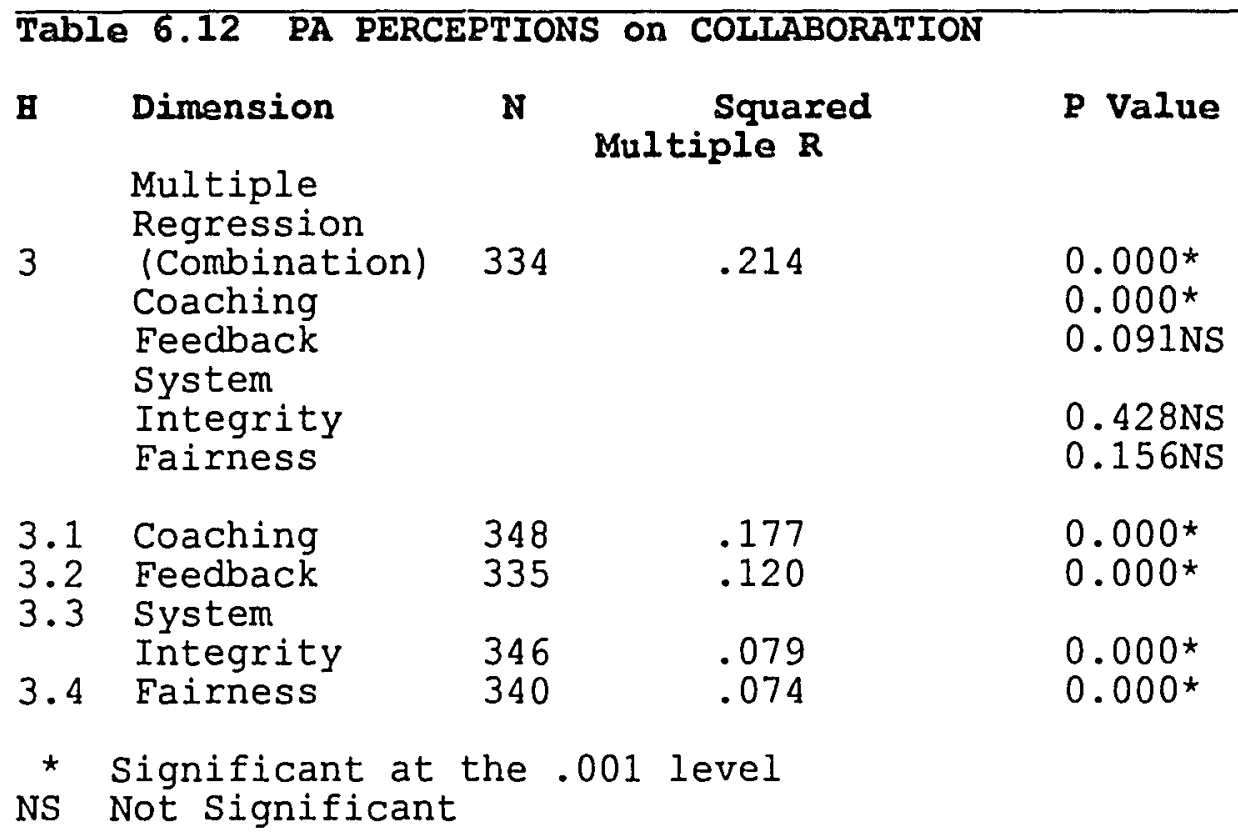

\section{Table 6.13 PA PERCEPTIONS On CONERONTATION}

B Dimension

Multiple

Regression

4 (Combination)

Coaching

Feedback

System

Integrity

Fairness

4.1 Coaching $\quad 349$

4.2 Feedback

4.3 System

Integrity

4.4 Fairness
N

334
336

346

341
Squared Multiple $R$

P Value

.296

$0.000^{*}$

$0.000 *$

$0.809 \mathrm{NS}$

$0.001 *$

0.000 *

$0.000^{*}$

$0.000 *$

.147

.159

0.000 *

.136

0.000 *

* Significant at the .001 level

NS Not Significant 
have on teamwork ethos.

Managers at the EA who engage in coaching their subordinates cultivate a sense of Openness, Collaboration, Trust, and Confrontation that facilitate effective teamwork concept. This further enhances the quality and the perceptions of feedback subordinates get during the formal performance appraisal process. This suggests that the EA enhances its teamwork value by emphasizing coaching as part of the PA process. In this regard, then, the PA process at the EA affects the culture.

In regional divisions based in smaller towns, the EA: members expressed a stronger sense of teamwork, and the managers there were more likely than their headquarters counterparts to express their adherence to the coaching principle. Further analysis of variance on these data reveal statistical difference in means of $p<.05$ on the Coaching dimension between these groups. Significant differences also exist also on Openness $\mathrm{p}<.05$, Confrontation $\mathrm{p}<.05$, and Collaboration $\mathrm{p}<.001$.

The physical setting of regional offices facilitate the teamwork culture too. They are usually small structures (maximum two stories). Members of different program and sectional units share the same work space. There is more communication across programs, unlike at the headquarters where different program areas are separated by floors in an eleven floor structure. The "regions" 
members also tend to be less formal than their headquarters counterparts. Adding the coaching feature to that environment ushers in a truly team culture as the data shows.

Hypotheses five sought to further evaluate the effect the PA process has over the team culture by evaluating if there was a statistically significant difference in means on the PA scale as a function of recency of last appraisal. In other words, this hypothesis stated that the members who were recently appraised would have higher means on the PA scale. There were five different groups in this regard (see table 6.1). To test this hypothesis these five groups were collapsed into two groups: 1. Those who were appraised less than a year ago. and 2. "Those who were appraised over a year before or were never appraised. The results are on table 6.14 on the next page.

Fairness, System Integrity, and Feedback were highly significant at $p<.01$. Mean scores on Feedback, system Integrity, and Fairness for recent apprajsees were, respectively: $1.9,1.7$, and .24 above those of not-sorecent appraisees. These data suggest, above all, that frequency in performance appraisals result in favorable perceptions of the process by organizational members. And as shown in the first four hypotheses, these perceptions affect the team culture. This is true across the agency, and is a function of management choice. In other words, 
those managers who engage in frequent performance

Table 6.14

ANOVA BY DATE OF IAST PERFORMANCE APPRAISAL

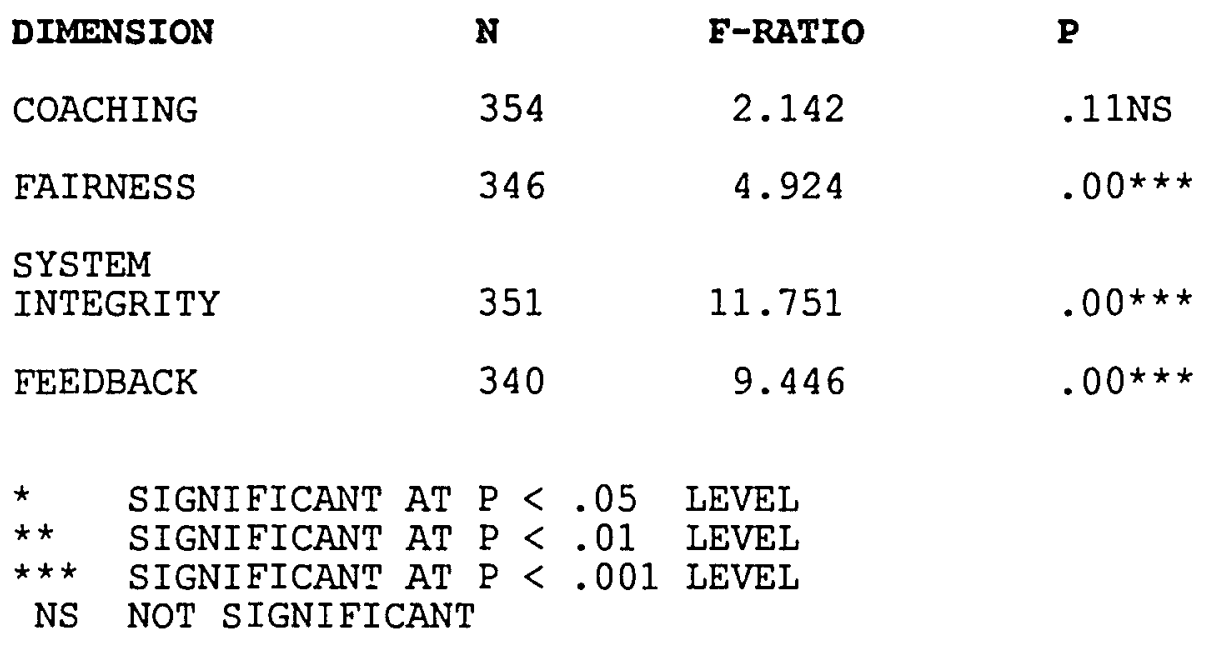

evaluations strengthern their teamwork ethos. This also implies that they perform performance appraisals in conjunction with ongoing coaching because if the coaching environment is equal (the coaching dimension was statistically insignificant between the two groups), then those that do PA frequently develop a stronger sense of teamwork in their work units.

But, to what extent is this relationship between recency of last appraisal and perceptions over the dimensions of both scales a function of time spent in the organization? This was the inquiry suggested in hypothesis six. Hypothesis six stated that those who have 
been with the organization longer than four years would have lower PA perception scores than those that are newer in the organization. This is essentially the difference between learning for the first time and reinforcement. The results of that analysis of variance are on table 6.15 below.

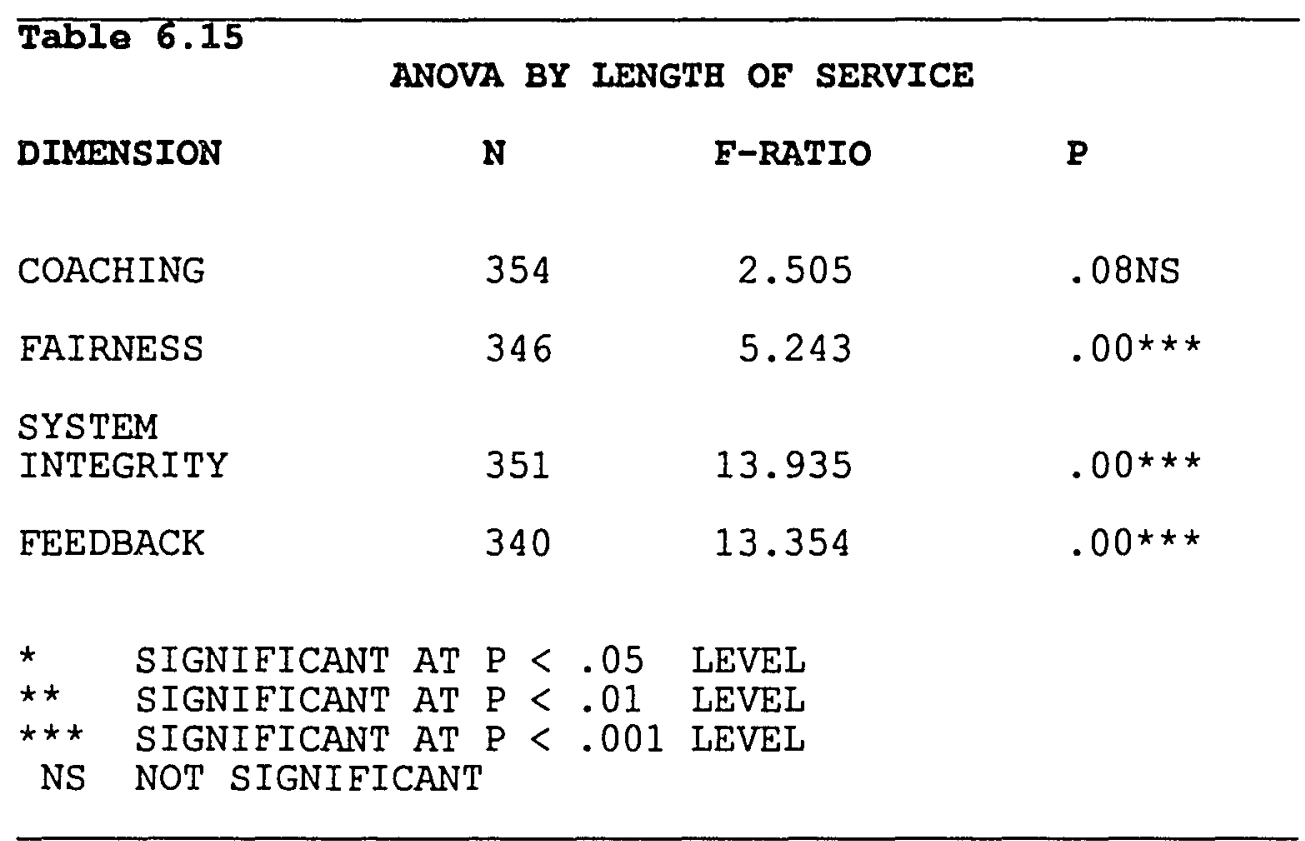

As the table shows, Fairness, system Integrity, Feedback, are highly significant at $\mathrm{p}<.05$ and higher. On Feedback and System Integrity, newer staff means were 2.2 and 1.9, respectively, higher than those of older staff.

It appears from these data that newer staffers benefit from the PA process because they are still learning the culture. The difference in scores then 
between newer and older staff is the difference between those learning for the first time or first few times and those who are being reinforced after a long time in the organization. The PA process, then, serves to both educate the newer staff and reinforce the older staffers. In a cross-tabulation between length of service and recency of last appraisal, it becomes clear that both group's perceptions are helped by frequency of appraisals (see table 6.16 on the next page). $39.8 \%(N=145)$ were appraised in the last year. Of those, only 9.68 ( $N=16)$ had been with the organization for less than a year, compared to $53.7 \%(\mathrm{~N}=78)$ of older employees. The effect of recency of PA to PA perceptions is not a function of length of service, rather it is a function of managerial prioritization. In other words, those managers that do PA frequently do it to all their subordinates irrespective of length of service.

Consider the newest employees for example ( $N=54)$, or $14.8 \%$ of all respondents, 62.98 had not yet been appraised, even though organizational policies require PA for all newer employees before they can get off probationary status. This suggests that, even where PA is required for those reasons, many managers that don't do PA still don't do it. 


\section{Table 6.16}

Frequency Table of Length of Service (ROWS) by Date of Last Appraisal (ColUMNS)

\begin{tabular}{|c|c|c|c|c|c|c|c|}
\hline & 1 & 2 & 3 & 4 & 5 & $\mathrm{~N}$ & 8 \\
\hline 1 & 16 & $2^{\star}$ & $2 *$ & 0 & 34 & 54 & 14.9 \\
\hline 2 & 14 & 3 & $1 \star$ & 0 & 10 & 28 & 7.7 \\
\hline 3 & 37 & 21 & 10 & 0 & 13 & 8 & 22.2 \\
\hline 4 & 78 & 39 & 47 & 29 & 8 & 201 & 55.2 \\
\hline $\mathbf{N}$ & 145 & 65 & 60 & 29 & 65 & 364 & 100. \\
\hline 8 & 39.8 & 17.9 & 16.5 & 8.0 & 17.9 & & 100 \\
\hline
\end{tabular}

REY :

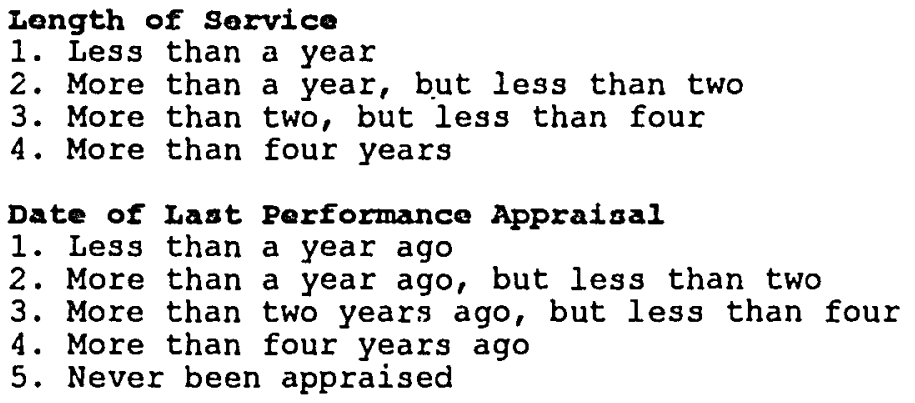

* Possible coding error

\subsection{Summary}

The overall results from all hypotheses tested strongly support the overall hypothesis that the PA process has an effect on an organization's culture in terms of the operationalized measures of PA scale and OCTAPACE ethos. This suggests that the EA culture can be shaped through the 
PA process. In other words, where the concept of teamwork is weak organizational leadership might want to look at the frequency of $\mathrm{PA}$ and the prevalence of a coaching environment. The data shows, very strongly, that individual PA perceptions affect the way they feel about the teamwork ethos. The next chapter discusses these findings and the contributions of this study. 


\section{Chapter 7}

\section{Discussion and Conclusion}

\subsection{Introduction}

The general purpose of this study was to examine the relationship between ar organization's culture and its performance appraisal process. One complex organization was studied utilizing both qualitative and quantitative methodologies. Select dimensions in Pareek's (1994) OCTAPACE scale, a quantitative measure, represented the organization's cultural value of teamwork, and a quantitative instrument, Performance Appraisal Perception Scale, was developed to measure attitudes towards the PA system that were later linked to the OCTAPACE's four dimensions of Openness, Trust, Confrontation, and Collaboration.

These two instruments represented the quantitative measures in the study. Interviews, observations, and archival data represented the qualitative segment of the study. Both these methodologies were used in order to gain a deeper understanding of the culture, each supplementing its weaknesses with the strengths of the other. What was discovered here was a rich culture that is influenced, to a significant degree, by the performance appraisal process. In this chapter, the discussion turns to a summary of the major findings in the study and its limitations. 


\subsection{Major Findings of the study}

The practice of PA can be seen as nurturing the culture by socializing individuals to be constantly aware of the importance of organizational values and behaviors reflected through that process and through the actual instrument. This was the main discovery. The underlining finding is this study, then, is that perceptions people have over the PA process are influenced by the way they perceive their supervisor (coaching environment). If a supervisor is engaged in coaching, his/her subordinates are likely to be receptive to the feedback they receive during the formal performance appraisal review. Being receptive to the feedback leads the appraisee to conclude that the PA system, and the appraisal process itself, is fair. A fairness perception then leads one to believe in the integrity of the system and its contents. If the PA instrument contents reflect the cultural values of the organization, then the exercise of fxequent appraisals teaches new members and reinforces in older members the values of the organization. In this respect, this study has shown, organizational leadership can help to create, maintain, and effectively perpetuate their cultures using the performance appraisal system as a tool.

Qualitative methodologies were utilized to investigate the EA culture at all three levels of Schein's (1992) 
definition and to investigate the nature and scope of the performance appraisal process. Towards the end of the study several EA members were shown the Techno-Pollegal model presented in chapter five and concurred that it captured the essence of their culture. This model establishes that political/legal and scientific concerns, skills, and outlooks define and drive the character of this organization. The performance appraisal process, it was determined, facilitates that culture. Several values and behaviors that make up this culture are included in the EA's performance appraisal instrument. For example, teamwork, political awareness, collaboration, and responsiveness were all dimensions in the performance appraisal instrument (see appendix 2: Interactive Skills, Individual Characteristics, and Job knowledge Characteristics) that were apparent in the observed culture and individuals were appraised on how well they adhered to them.

The secondary discovery was through testing quantitatively the extent to which this first discovery was true. Six specific hypothesis were extended and tested. The first four hypotheses tested if the performance appraisal perceptions had an effect on four measures of Openness, Trust, Collaboration, and Confrontation. These four measures represented the value of teamwork which was one of the values discovered qualitatively. With no 
exception, all the PA perceptions had an effect on all the teamwork dimensions. These were highly significant at $p$ $<.001$. This means that the content of performance appraisal (feedback), the way appraisees perceive the process (system integrity \& fairness), and the way appraisees perceive their supervisor (coaching environment) all have an impact on the cultural value of teamwork at the EA.

Further analysis of the data, hypotheses five and six, revealed that the effect of $\mathrm{PA}$ on culture was a function of managerial choice. In other words, those managers that performed PA regularly developed a stronger teamwork concept in their individual groups. Hypothesis five stated that there would be a significant difference in mean PA perception scores between those that had been appraised in the last year and those that had been appraised over a year before or had never been appraised. The results showed great statistical significance $(p<.05)$ on Fairness, system Integrity, and Feedback. Those that had been recently appraised scored higher than those that had not had a recent appraisal or were never appraised. This result confirmed the fifth hypothesis, indicating that those managers that conduct frequent appraisals invigorate the team value in the people they manage. 
Hypothesis six stated that there would be differences in PA perceptions between those that had been with the organization for less than four years and those that had been with the organization for over four years. This operation was intended to test the significance of PA perceptions as a function of time one has spent in the organization. The results from this test revealed that newer members had higher PA perception scores than older members. This generally means that newer members generally perceive the PA as educational to them about organizational procedures and are more likely to appreciate the feedback they get in the process.

In cross-tabulation between length of service and date of last appraisal the data showed that the conduct of performance appraisal at the EA was a function of individual manager initiative and not a function of how long an individual has been in the organization. In other words, managers that do performance appraisals do so irrespective of their subordinates' length of service, and the same applies to the managers that don't do performance appraisals. These latter managers don't do performance appraisals for all their staff, new and old, and they have generally, according to the data, less teamwork value in their sections. 
This study has shown, then, that the performance appraisal process, especially if undertaken at least annually, affects the culture of the EA organization. Individual PA perceptions, in that context, and as the Iiterature supports, have a strong influence on how individuals perceive their role in the organization (see especially Burnside, 1982; Stone, Gueutal \& McIntosh, 1984; Stone \& Stone, 1984, 1984; Greenberg, 1986; Mohrman, Resnick-West, \& Lawler, 1989; Pearce \& Porter, 1986; and others) discussed in chapter 4.

The principal finding is this study, once again, is that perceptions people have over the PA system are influenced by the way they perceive their supervisor (Coaching Environment). Supervisors that engage in coaching their subordinates are likely develop receptiveness in the latter to the feedback given during the formal performance appraisal review. Being receptive to the feedback leads subordinates endorse PA system, and the PA process itself, as fair. Fairness perceptions leads these subordinates to believe in the integrity of the system and its contents. If the PA instrument contents reflect the cultural values of the organization, as is the case at the EA, then the exercise of frequent appraisals teaches new members and reinforces in older members the values of the organization. In this respect, this study has shown, organizational 
leadership can help create, maintain, and effectively perpetuate their cultures using the performance appraisal system as a tool.

\subsection{Contributions of the study}

This study sought to determine if the performance appraisal process affected an organization's culture. To a significant effect, this study showed that to be the case, at least in the organization studied. This adds yet another dimension to be considered in evaluating the culture of an organization. Story telling, socialization, etc, are all elements that have to be considered, and have been widely accepted as necessary, in organizational cultural studies. However, few studies have empirically tested these.

Performance appraisal, which itself is often considered a structural element designed for organizational control, has the potential to have as much impact as any other mode of communication. In that regard, this study takes a step towards looking at PA as one more criteria to be examined during cultural studies and organizational intervention.

Perceptions over the performance appraisal process have been recognized as the single most crucial element in performance feedback studies (See chapter 4). This study takes yet another step in the direction of making perception evaluation an integral part of PA studies. Based on what is 
known now about PA, even after decades of study, managing PA perceptions remain elusive. Part of the reason for that condition is that methods of diagnosing perceptions are not well developed. This study forms the basis for developing that area of inquiry. Once again, it is important to remember that individual perceptions over the PA process may be more important than the actual content of the appraisal instrument.

\subsection{Study Limitations and Suggestions for Future Research}

The limitation of this study is also its strength. This is a study based on one organization, albeit large, but the results from such an endeavor may not be easily generalized to other organizations in the state system or in other industries. The richness of the findings, however, compensate for the noted limitation.

Another shortcoming of this study has to do with the type of the organization studied. As a state agency, this organization does not have the latitude to design its own PA system. Instead, it has to adapt to the system imposed by the state. Results may have been different, and perhaps more telling, if the data had been gathered at an autonomous organization. This suggests another area of inquiry with respect to the level of autonomy that society, in the form of its elected officials, of course, is willing to afford 
j.ts governmental agencies in the design and implementation of management systems. There is talk about "reinventing government", but that talk does not confront basic management issues private industry takes for granted. Another constraint this study was the restructuring of the organization that took place just before the study began. This might have contributed to the lack of statistical differences between regional and headquarters divisions. Also, a number of managers had never appraised their current staff. This might have affected some of the responses dealing with manager supervisor relationships.

A few days into the study the director resigned. This, again, contributed to organizational instability that may well have affected the results. Again, during the course of the study, state voters approved a ballot measure that required state employees to contribute towards their pension plans (previous to this ballot measure, the state picked up that cost as part of the overall compensation package). This lowered morale of all state employees. Once again, it is difficult to know if the EA members' views about their organization were affected by this development since there were other employees who were already frustrated over the reorganization situation. A similar study a year before or a year from this date might (have) yield(ed) different results. 
Finally, and perhaps most important, the performance appraisal situation at EA was a topic of controversy at the start of the study. October 1st (the study started on September 8) was the day all managers were supposed to turn in their PA reviews to the HR department. Many did not meet the deadline. As early as August the HR manager sent the following memo to all management via Electronic Mail... ... Two matters re performance appraisals: 1) Performance Mgmt system (PMS) for mgmt and exec service employees due to HR October 1 ; and 2) performance appraisals for represented staff.

1. PMS, Although there will be no $\$ \$$ tied to the "pay for performance" system in the foreseeable future, DAs is still expecting to get our management performance appraisal results sometime in November......

2. Per. Appraisals for represented staff. Since all of us have regular, ongoing, insightful communication with staff regarding their performance throughout the appraisal period, I know completing the formal appraisal form is not among our highest priorities. At the same time, however, some disturbing numbers have been brought to my attention. Of 414 performance appraisals due since January 194, a total of only 66 have been completed and turned in.

Many of you know that I'm not particularly interested in riding your case on this subject (and include myself as an offender); but these numbers are distressing. Your Divisions' HR contact will be asking for your input on what we can do to facilitate more timely performance appraisals---whether it's sending you a reminder 2 weeks rather than 6 weeks ahead of due date--whatever thoughts you have that would make this responsibility less onerous(short of not doing it at all!) we want to hear it. Thanks.

This apologetic memo described the nature of PA at the EA. One manager's response was typical of most responses. It 
captured the thinking of most managers with regard to the subject matter...

Regarding PA for represented staff- my explanation is principally workload. When I have to make a choice between UST (underground storage tanks) and Spill Work versus PA, I make it in favor of UST and spill work. That choice is fostered due to the fact that historically there has been no penalty to me as a manager or the employee if the PA is not done. I also like to believe I talk with my staff frequently enough to know how things are going with their work, and the PA doesn't particularly change that relationship. Lastly, with good employees after a year or two it seems repetitious.

Short of constant nagging by someone, I don't think the suggestions you offered will change the percentage much. I don't think most managers believe it's a priority compared to real work. Also, employees don't make it a priority either. I have yet to have an employee come forward and specifically ask me to complete their PA. I know I have never asked my supervisor over the years to complete a $P A$ when it was late.

Other responses from other managers were not that civil. It was within that context that this study proceeded. Such an atmosphere was not conducive to measuring $\mathrm{PA}$ 's impact on culture.

All in all, the results of this study appeared credible, but they have to be viewed in the context presented in this section.

The suggestions for future research speak largely to the noted major findings and limitations of the study. These fall into two general categories of scope and focus. 
The scope of this study could be extended to include several or all state agencies that utilize the same performance appraisal. system. This can provide a strong platform for cross-organizational comparisons of the impact of the PA process on organizational culture. Such an effort can also be extended towards the study of other organizations in other industries to see if the conduct of PA would have the same implications as discovered in this present study. Furthermore, a similar study in stable organizations (those that are not going through a change of leadership or restructuring) that use PA more extensively than the EA may strengthen or sharpen the findings presented in this study. This is assuming that the contents of these organizations' PA systems reflect their cultural values. Future studies can also focus on the content of the organizational culture survey. With time and more resources, it might be possible to design a customized instrument that would capture all the major organizational culture dimensions for a particular organization. The present study utilized an instrument that was limited to just one major dimension of the overall culture of the organization studied. An instrument with all the dimensions mentioned in chapter five would have been more effective in mapping up that relationship between organizational culture and PA. 
These future research suggestions can further inform us the extent to which the performance appraisal process plays in the overall context of an organization's culture. The present study has shown that organizational use of performance appraisal, even in a limited fashion, can have significant impact on an organization's culture. This can only mean that when an organization devotes resources and significant effort towards its performance appraisal process, the end result can be a significantly strong and appropriate culture for that organization, which then leads to the realization of organizational goals. 


\section{REEERENCES}

Akin, G., \& Hopelain, D. (1986). Finding the culture of productivity. Organizational Dynamics, 14(3), 19-32.

Banks, C. G. \& Murphy, K. R. (1985). Toward narrowing the research-practice gap in performance appraisal. Personnel Psychology, 38, 335-345.

Barley, S. R. (1983). Semiotics and the study of occupational and organizational cultures.

Administrative Science Quarterly, 28, 393-413.

Barnard, C. I. (1938, 1968). T'he functions of the executive. Cambridge, MA: Harvard University Press.

Barney, J. B. (1986) Organizational Culture: Can it be a source of sustained competitive advantage? Academy of Management Review, 11, 656-665.

Bates, R. J. (1984). Toward a critical practice of educational administration. In T'. J. Sergiovanni \& J. E. Corbally (Eds.), Leadership and organizational culture. Urbana, IL: University of Iljinois Press.

Becker, H.S., Geer, B., Hughes, E. C., \& Strauss, A. L. (1961). Boys in white: Student culture in medical school. Chicago: University of Chicago Press.

Bennis, w. G. (1984). Transformative power and leadership. In T. J. Sergiovanni \& J. E. Corbally (Eds.), Leadership and organizational culture. Urbana, IL: University of Illinois Press.

Bennis, W. G., \& Nanus, B. (1985). Leaders: The strategies for taking charge. New York: Harper and Row, Publishers.

Bernardin, H.J., \& Buckley, M. R. (1981). Strategies in rater training. Academy of Management Review, 6, 205-22.1.

Bolman, L. G., \& Deal, T. E. (1984). Modern approaches to understanding and managing organizations. San Francisco: Jossey-Bass. 
Burnside, B. J. (1982). Subjective appraisal as a feedback tool. U.S. Army Research Institute for the Behavioral \& Social Sciences Report, Technical Report, 604

Carlzon, J. (1987). Moments of truth. Cambridge, Mass: Ballinger Publishing Co.

Cardy, R. L., \& Dobbins, G. H. (1986). Affect and appraisal accuracy: Liking as an integral dimension in evaluating performance. Journal of Applied Psychology, 71(4), 672-678.

Cleveland, J. N., Murphy, K. R., \& Williams, R. E. (1989). Multiple uses of performance appraisal: Prevalence and correlates. Journal of Applied Psychology, 74(1), 130-135.

Conner, D. R. (1985). The cultural audit workbook: Corporate culture and its impact on organizational success. Atlanta, GA: O.D. Resources, Inc.

Cook, T. D., \& Campbell, D. T., (1979). Quasiexperimentation: Design and analysis issues for field settings. Boston: Houghton Mifflin.

Davis, S. M. (1984) Managing corporate culture. Cambridge, MA: Ballinger.

Deal, T. E., \& Kennedy, A. A. (1982). Corporate cultures: The rites and rituals of corporate life. Reading, MA: Addison-Wesley.

DeNisi, A. S., Cafferty, T. P., \& Meglino, B. M. (1984) A cognitive view of the performance appraisal process. Organizational Behavior and Human Performance, 33, 360-396.

Denison, D. R., (1990). Corporate culture and organizational effectiveness. New York: John Wiley \& Sons.

Dorfman, P. W., Stephan, W. G., \& Loveland, J. (1986) . Performance appraisal behaviors: Supervisor perceptions and subordinate reactions. Personnel Psychology, 66(2), 248-251. 
Drucker, P. F. (1954). The practice of management. New York: Harper and Brothers Publishers.

Dyer, W. G. (1986). Cultural change in family firms. San Francisco: Jossey-Bass.

Dyer, W. G. (1987). Team building: Issues and alternatives. Second Edition. Reading, Mass: Addison Wesley.

Finn, R. H., \& Fontaine, P. A. (1984). Performance Appraisal: Some dynamics and dilemmas. Public Personnel Management Journal, 13(3), 335-343.

Ford, J. K., Kraiger, K., \& Schechtman, S. L. (1986). Study of race effects in objective indices and subjective evaluations of performance: $A$ meta-analysis of performance criteria. Psychological Bulletin. 99(3), 330-337.

Gregory, K. L. (1983). Native-view paradigms and multiple cultures and culture conflicts in organizations. Administrative Science Quarterly, 28, 359-376.

Hofstede, G. (1984). Culture's consequences: International differences in work-related values (vol. 5) (abr. ed.). Beverly Hills, CA: Sage Publications.

Hofstede, G. (1980). Culture's consequences: International differences in work-related values. Beverly Hills, CA: Sage Publications.

Hofstede, G. (1980, Summer). Motivation, leadership and organization: Do American theories apply abroad? Organizational Dynamics, 42-63.

Hofstede, G. (1981). Culture and organizations. International Studies of Management \& organizations, 10(4), 15-41.

Iacocca, L. (1984). Iacocca: An autobiography. Toronto: Bantam Books. 
Ilgen, D. R., Fisher, C. D., \& Taylor, M. S. (1979). Consequences of individual feedback on behavior in organizations. Journal of Applied Psychology, 64(4), 349-371.

I.lgen, D. R., Mitchell, T'. R., \& Eredrickson, J. W. (1981). Poor performaers: Supervisors' and Subordinates' responses. Organizational Behavior and Human Performance, 27, 386-410.

Katz, D., Kahn, R. L. (1966). The social psychology of organizations. New York: John Wiley \& Sons.

Kets de Vries, M. F. R., \& Miller, D. (1986). Personality, culture, and organization. Academy of Management Review, 11, 266-279.

Kilmann, R. H., Saxton, M. J., Serpa, R., \& Associates (Eds.). (1985). Gaining control of the corporate culture. San Francisco: Jossey-Bass.

Kinlaw, D. C. (1991). Developing superior work teams: Building quality and the competitive edge. Lexington, Ky: Lexington Books.

Koontz, H. (1961). The management theory jungle. Academy of Management Journal, 4, 174-188.

Koontz, H. (1980). The management theory jungle revisted. Academy of Management Review, 5.

Kotter, J. P. \& Heskett, J. I. (1992) . Corporate culture and performance. New York: The Free Press.

Landy, F. G. (1985). Psychology of work behavior. Belmont, CA: Brooks/Cole Publishing Company.

Landy, F. J. \& Farr, J. (1983). The measurement of work performance. New York: Academic Press.

Larson, C.E. \& LaFasto, F. M. J. (1989). Teamwork: What must go right/What can go wrong. Newbury Park, CA: Sage Publications.

Laurent, A. (1983). The cultural diversity of Western conceptions of management. International studies of Management and Organization, 13, 18-25. 
Lawrence, P. R., \& Lorsch, J. W. (1967). Organization and environment. Cambridge, MA: Harvard University Press.

Leavjtt, H. J. (1986). Corporate pathfinders: Building vision and values into organizations. Homewood, IL: Dow Jones-Irwin.

Likert, R. (1961). New Patterns of Management. New York: McGraw-Hill Book Company.

Locher, A. H., \& Teel, K. S. (1988). Appraisal irends. Personnel Journal, 67(9), 139-145.

Louis, M. R. (1981). Culture in organizations: The need for and consequences of viewing organizations as culture-bearing milieux. Human systems Management, 2, 246-258.

Maroney, B. P., \& Buckely, M. R. (1992, Summer). Does research in performance appraisal influence the practice of performance appraisal? Regretfully not! Public Personnel Management, $21(2), 185-196$.

Martin, D. C., \& Bartol, K. (1986). Training the raters: A key to effective performance appraisal. Public Personnel Management, 15(2), 101-109.

Martin, J., \& Powers, M. E. (1983). Truth or corporate propaganda: The value of a good war story. In L. R. Pondy, P. J. Frost, G. Morgan, \& T. C. Dandridge (Eds.), Organizational symbolism. Greenwich, CT: JAI Press.

Martin, J., Siehl, C. (1983, Autumn). Organizational culture and counterculture: An uneasy symbiosis. Organizational dynamics, 52-64.

MCGregor, D. (1960). The human side of interprise. New York: McGraw-Hill.

Meyer, J. W. (1984). Organizations as ideological systems. In T. J. Sergiovanni \& J. E. Corbally (Eds.), Leadership and organizational culture: New perspectives on administrative theory and practice Urbana, IL: University of Illinois Press. 
Milgram, S. (1974). Obedience to authority: An experimental view. New York: Harper and Row.

Mohrman, A. M., Resnick-West, S. M., \& Lawler, E. E., III. (1989). Designing performance appraisal systems: Aligning appraisals and organizational realities. San Francisco, CA: Jossey-Bass Publishers.

O'Reilly, C. (1991). Corporations, control, and commitment. In Steers R. and Porter, $L$. (eds.). Motivation and work behaviour. New York: McGraw-hill Publishers.

ott, J. S. (1989). The organizational culture perspective. Pacific Grove, CA: Brooks/Cole Publishing Co.

Ouchi, W. G. (1981). Theory Z: How American business can meet the Japanese challenge. Reading, WA: Addison-Wesley.

Pareek, U. (1994). Studying organizational ethos: The OCTAPACE Profile. In Pfeiffer, J. W.,ed. The 1994 Annual: Developing Human Resources. San Diego, CA: The Pfeiffer Company. 23: 153-165.

Pascale, R. T., \& Athos, A. G. (1981). The art of Japanese management: Applications for American executives. New York: Simon and Schuster.

Pearce, J. L., \& Porter, L. W. (1986). Employee responses to formal performance appraisal feedback. Journal of applied Psychology, 71(2), 211-218.

Peters, T. J., \& Waterman, R. H., Jr. (1982). In search of excellence. New York: Harper \& Row.

Pettigrew, A. M. (1979). On studying organizational cultures. Administrative Science Quarterly, 24, 579-581.

Pfeffer, J. (1981a). Power in organizations. Boston: Pitman Publishing Co. 
Pfeffer, J. (1981b). Management as symbolic action: The creation and maintenance of organizational paradigms. In L.L. Cummings \& B. M. Staw (Eds.), Research in organizational behavior (vol. 3). Greenwich, CT: JAI Press.

Pfeffer, J., \& Salancik, G. R. (1978). The external control of organizations: A resource dependence perspective. New York: Harper \& Row.

Pondy, L. R., Frost, P. J., Morgan, G., \& Dandridge, T. C. (Eds.). (1983). Organizational symbolism. Greenwich, CT: JAI Press.

Pulakos, E. D. (1984). A comparison of rater training programs: Error training and accuracy training. Journal of Applied Psychology, 69(4), 581-588.

Quinn-Mills, P. and Balbaky, S. (1985). Planning for morale and culture. In Walton and Lawrence (eds) HRM trends and challenges. Cambridge, Mass: Harvard Business School Press.

Raelin, J. A. (1986). The clash of cultures: Managers and professionals. Boston: Harvard Business School Press.

Rathjen, D. (1984). Performance appraisal in a government: From attitudes to behaviors : Case study 2. Journal of Organizational Behavior Management, $6(2), 22-35$.

Robbins, S. P. (1990). Organization theory: Structure, design, and applications. (3rd edit.). Englehood Cliffs, N.J.: Prentice-Hall.

Sathe, V. (1985). Culture and related corporate realities: Text, cases, and readings on organizational entry, establishment, and change. Homewood, Ill: Irwin.

Schein, E. H. (1980). Organizational psychology (3rd edit.). Englewood Cliffs, NJ: Prentice-Hall.

Schein, E. H. (1981). Does Japanese management style have a message for American managers? Sloan Management Review, 23, 55-68. 
Schein, E. H. (1983, Summer). The role of the founder in creating an organizational culture. Organizational Dynamics, 13-28.

Schein, E. H. (1984). Coming to a new awareness of organizational culture. Sloan Management Review, 25, 3-16.

Schein, E. H. (1992). Organizational culture and leadership. 2nd Edition. San Francisco: Jossey-Bass.

Schneier, C. E., Beatty, R. W., \& Baird, L. S. (1986). How to construct a successful performance appraisal system, Training and Development Journal, 40(4), 3842 .

Schwartz, H., \& Davis, S. M. (1981). Matching corporate culture and business strategy. Organizational Dynamics, $10,30-48$.

Scott, W. G., \& Mitchell, T. R. (1972). Organization theory (rev. ed.). Homewood, IL: Richard D. Irwin and The Dorsey Press.

Scott, W. R. (1990). Symbols and organizations: From Barnard to the institutionalists. In O. E. Williamson (Ed.), Organization theory: From Chester Barnard to the present and beyond. New York: Oxford University Press.

Selznick, P. (1949). TVA and the grass roots. Beckeley, CA: University of California Press.

Sergiovanni, T. J. (1984). Cultural and competing perspectives in administrative theory and practice. In T. J. Sergiovanni \& J. E. Corbally (Eds.), Leadership and organizational culture: New perspectives on administrative theory and practice (pp. 1-11). Urbana, IL: University of Illinois Press.

Shafritz, J. M., \& Ott, J. S. (1987). Classics of organization theory. Chicago: The Dorsey Press. 
Siehl, C., \& Martin, J. (1984). The role of symbolic management: How can managers effectively transmit organizational culture? In J. G. Hunt, D. M. Hosking, C.A. Schriesheim \& R. Stewart (Eds.), Leaders and managers: International perspectives on managerial behavior and leadership. New York: Pergamon Press.

Silverman, S. B., \& Wexley, K. N. (1984). Reaction of employees to performance appraisal interviews as a function of their participation in rating scale development. Personnel Psychology, 37, 703-710

Smircich, L. (1983). Organizations as shares meanings. In L. R. Pondy, P.J. Frost, G. Morgan, \& T. C. Dandridge (Eds.) Organizational symbolism . Greenwich, CT: JAI Press.

Smircich, I. (1985). Is the concept of culture a paradigm for understanding organizations and ourselves? In P. J. Frost, I. F. Moore, M. R. Louis, C. C. Lundberg, \& J. Martin (Eds.), Organizational culture. Beverly Hills, CA: Sage Publications.

Smircich, L., \& Calas, M. B. (1987). Organizational culture: A critical assessment. In F. M. Jablin, I. L. Putram, K. H. Roberts, à L. W. Porter (Eds.), Handbook of organizational communication. Beverly Hills, CA: Sage Publications.

Smith, D. (1986). Training programs for performance appraisal: A review. Academy of Management Review, $11(1), 22-40$.

Smith, P. B. \& Peterson, M. F. (1988). Leadership, organizations and culture: An event management model. Beverly Hills, CA: Sage Publications.

Sproull, L. S. (1981). Beliefs in organizations. In P. C. Nystrom \& W. H. Starbuck (Eds.), Handbook of organizational design. London: Oxford University Press.

Stewart, D. W., \& Garson, G. D. (1983). Organizational Behavior and Public Management. New York: Marcel Dekker, Inc. 
Stone, D. L., Gueutal, H. G., \& McIntosh, B. (1984). The effects of feedback sequence and expertise of the rater on perceived feedback accuracy. Personnel Psychology, $37(3), 487-506$.

Stone, E.F., \& Stone, D. L. (1984). The effects of multiple sources of performance feedback and feedback favorability on self-perceived task competence and perceived feedback accuracy. Journal of Management, $10(3), 371-378$.

Taylor, W. (1984). Organizational culture and administrative leadership in universities. In $T$. J. Sergiovanni \& J. E. Corbally (Eds.), Leadership and organizational culture: New perspectives on administrative theory and practice. Urbana, IL: University of Illinois Press.

Thompson, J. D. (1967). Organizations in action. New York: McGraw Hill.

Tichy, N. M. (1983). Managing strategic change: Technical, political, and cultural dynamics. New York: John Wiley \& Sons.

Tichy, N. M., \& Devanna, M. A. (1986). The transformational leader. New York: John Wiley \& Sons.

Tichy, N. M., \& Ulrich, D. O. (1984). The leadership challenge- a call for the transformational leader. Sloan Management Review, 26, 59-68.

Townley, B. (1989). Selection and appraisal: Reconstituting social relations? In Storey, J. (ed.) New developments in human resource management. London, England: Routledge Publishers.

Van Maanen, J. (1975). Police socialization. Administrative Science Quarterly, 20, 207-228.

Van Maanen, J. (1976). Breaking in: Socialization to work. In R. Dubin (Ed.), Handbook of work, organization, and society. Chicago: Rand MCNally.

Van Maanen, J. (1983). People processing: Strategies of organizational socialization. In R. W. Allen \& L.W. Porter (Eds.), Organizational influence processes. Glenview, IL: Scott, Foresman and Company. 
Van Maanen, J., a Earkely, S. (1984). Occupational communities: Culture and control in organizations. In B. M. Staw and L. L. Cummings (Eds.), Research in organizational behavior (vol. 6). Greenwich, CT: JAI Press.

Varney, G. H. (1989). Building productive teams: An action guide and resource book. San Francisco, CA: Jossey-Bass Publishers.

Von Glinow, M. A. (1988). The new professionals: Managing today's high-tech employees. New York: Ballinger Publishing Company.

Walton, R. (1991). From control to commitment in the workplace. In Steers and Porter (eds.) (1991). Motivation and workplace behaviour. New York: McGrawHill.

Wanous, J. P. (1980) . Organizational entry: Recruitment, selection, and socialization of newcomers. Reading, MA: Addison-Wesley.

Weick, K. E. (1979). The social psychology of organizing (2nd ed.). Reading, MA: Addison-Wesley.

Whyte, W. H., Jr. (1956). The organization man. New York: Simon and Schuster.

Weiner, N. (1948). Cybernetics. Cambridge, MA: The M.I.T. Press.

Wiener, N. (1964). The human use of human beings. Boston: Houghton Mifflin.

Wilkins, A.L. (1983). Organizational stories as symbols which control the organization. In L. R. Pondy, P. J. Frost, G. Morgan \& T. C. Dandridge (Eds.), Organizational Symbolism. Greenwich, CT: JAI Press. 
Appendices 


\section{Appendix 1}

\section{Factor Analysis and the Construction of the PA Perception Scale}

After the pre-test of the survey instrument, which, ultimately, served the purpose of clarifying the language and validity of the statements, the questionnaire was distributed to the EA members as part of the overall study. Factor analysis was then performed in earnest following the receipt of the first one hundred and sixty cases. With a ratio of eight cases per variable, the results were credible and stable.

Principal-components factor analysis and maximum variance (varimax) rotation routine was conducted using the systat statistical package. Five factors (with eigenvalues of greater than one) loaded (see table A.1 on the next page). Nine items $(1,2,4,7,8,12,14,16$, and 18) loaded significantly on the first factor, three items (9, 11, and 19) loaded significantly on the second factor, two items (13 and 20) loaded significantly on the third factor, two items (5 and 10) loaded significantly on the fourth factor, and only one item (17) loaded significantly on the fifth factor. Items three and six loaded almost equally, but not significantly, on factors two and three. Item fifteen loaded, however insignificantly, on factor three.

The first factor actually represented most items intended to measure perceptions over Feedback and System 
Integrity. Part of the reason for such a result is that there is a high correlation between perceptions over Feedback and those over the integrity of the PA system. In other words, those respondents who perceived the PA system as providing them with feedback also perceived the system as legitimate and with integrity. Another factor

Table A.1 Rotated Loadings of the PA Perception Scale

\begin{tabular}{rrrrrr} 
& 1 & \multicolumn{1}{c}{2} & \multicolumn{1}{c}{3} & \multicolumn{1}{c}{4} & \multicolumn{1}{c}{5} \\
TWO & 0.761 & 0.052 & -0.002 & -0.076 & 0.090 \\
TWELVE & 0.756 & 0.182 & 0.213 & 0.085 & 0.103 \\
EIGHT & 0.732 & 0.145 & 0.333 & 0.161 & -0.117 \\
SIXTEEN & 0.697 & -0.015 & 0.314 & 0.155 & 0.079 \\
FOUR & 0.675 & 0.148 & 0.256 & 0.269 & 0.012 \\
ONE & 0.672 & 0.095 & 0.160 & 0.244 & -0.058 \\
FOURTEEN & 0.570 & 0.259 & 0.059 & -0.220 & 0.428 \\
SEVEN & -0.547 & -0.209 & 0.142 & -0.318 & -0.262 \\
EIGHTEEN & 0.510 & 0.372 & -0.045 & -0.237 & 0.126 \\
NINETEEN & 0.082 & 0.823 & 0.215 & 0.011 & -0.010 \\
ELEVEN & 0.144 & 0.816 & 0.104 & 0.042 & 0.041 \\
NINE & 0.198 & 0.739 & 0.016 & 0.067 & 0.032 \\
TWENTY & 0.127 & 0.100 & 0.836 & 0.100 & -0.018 \\
THIRTEEN & 0.229 & 0.153 & 0.810 & 0.102 & 0.084 \\
TEN & -0.249 & -0.075 & 0.025 & -0.818 & 0.025 \\
FIVE & -0.056 & -0.056 & -0.309 & -0.712 & -0.180 \\
SEVNTEEN & -0.030 & -0.004 & -0.074 & -0.160 & -0.805 \\
FIFTEEN & 0.254 & 0.107 & 0.478 & -0.075 & 0.383 \\
THREE & 0.057 & 0.496 & 0.424 & 0.290 & 0.185 \\
SIX & 0.440 & 0.381 & 0.445 & 0.114 & -0.100
\end{tabular}

VARIANCE EXPLAINED BY ROTATED COMPONENTS
$\frac{1}{4} .425$
2.671
2.492
1.730
5

PERCENT OF TOTAL VARIANCE EXPLAINED

1

22.124

13.355

2

3

4

5

8.649

5.954

analysis was performed with just those nine items. The 
results of that analysis are on table $A .2$ below.

Five items $(1,4,8,12$, and 16) loaded highly on one factor (Feedback), and four items (2, 7, 14 and 18) loaded on the second factor (System Integrity). Item seven, (The performance appraisal system we have here is not that important in the grand scheme of things) loaded highly, but

\section{Table A.2 Rotated Loadings of Factor 1 Items}

$\begin{array}{rcc} & 1 & 2 \\ \text { EIGHT } & 0.839 & 0.195 \\ \text { SIXTEEN } & 0.791 & 0.195 \\ \text { FOUR } & 0.771 & 0.236 \\ \text { TWELVE } & 0.742 & 0.374 \\ \text { ONE } & 0.693 & 0.248 \\ \text { FOURTEEN } & 0.235 & 0.758 \\ \text { EIGHTEEN } & 0.138 & 0.720 \\ \text { SEVEN } & -0.244 & -0.686 \\ \text { TWO } & 0.475 & 0.557\end{array}$

VARIANCE EXPLAINED BY ROTATED COMPONENTS

$\begin{array}{cc}1 & 2 \\ 3.313 & 2.207\end{array}$

PERCENT OE TOTAL VARIANCE EXPLAINED

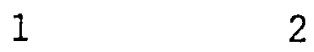

$36.808 \quad 24.519$

negatively, on the system integrity factor because of its negative orientation. In other words, those respondents who perceived the PA system to have integrity responded negatively (strongly disagree or somewhat disagree) with that statement.

Item seventeen, (I personally knov at least one person 
who is constantly a poor performer year after year, but was never disciplined loaded negatively to the fifth factor by itself. That statement was also designed to measure system Integrity, with the assumption that those respondents who perceive the $P A$ system as with integrity would respond negatively to that statement. Statement seventeen was then added to the system Integrity factor and assigned a negative coding along with item seven. A negative coding here means that the score the respondent assigns to an item is transformed during coding as follows: Four becomes a one, three becomes a two, two becomes a three, and one becomes a four. This assures that the scores on each factor remain consistent in measuring that factor.

Factor two items, (9, 11, and 19) were designed to measure perception over the coaching environment as defined by the relationship between a supervisor and his/her subordinate. Item three (I feel free to approach my supervisor with regard to any problem concerning my performance or my career with this organization) and item six (My supervisor is frank with me about my performance. $S /$ he lets me know what $I$ do well, and where $I$ need to improve in a none threatening way) were added to the Coaching factor although they both loaded insignificantly on it. Both items also loaded insignificantly on factor three (Fairness). In fact, item six had a slightly higher loading on the Fairness factor, .469, than the Coaching factor, .415. Loadings of within .05 are considered equal in factor 
analysis literature. The decision to assign items three and six to the Coaching factor was made primarily because that was the factor for which they were initially developed. Furthermore, respondents' perceptions over both Fairness and Coaching are not compromised since the Fairness factor already had stronger and more pointed loadings as discussed below.

Factor four was combined with factor three into one factor. Both factors were measuring Fairness perception. The positive items loaded on factor three and the negative items loaded on factor 4 . Negative items five (Performance appraisals make me nerrous because they are potentially unfair) and ten (I personally think performance appraisal is a waste of time, and most of my colleagues would agree with me) were assigned a negative coding. Item ten was originally developed to measure system integrity but it did not load signjficantly on that factor: -.196. Item fifteen loaded highest on the Fairness factor although that loading was also insignificant: .496 .

Each of the four PA scale dimensions had a score range of five to twenty. This was intended to be consistent with the OCTAPACE scale. See appendices $1 \mathrm{a}$ and $1 \mathrm{~b}$ for both the OCTAPACE and the PA perception questionnaires and their respective scoring sheets. 
Appendix 12

CASE\#

DIVISION

SECTION

\section{PERFORMANCE APHRAISAL PERCEPTION QUESTIONNAIRE}

Demographic Information:

I. Áre you represented by a union?

1. Yes

2. No

II. Gender:

1. M

2. F

III. Ethnicity:

1. White (non-hispanic)

2. Black (non-hispanic)

3. Hispanic

4. Asian

5. Some Graduate Studies

6. Other, Specify

IV. Highest Level of Education Attained:

1. Some High School

2. High School Graduate

3. Some College

4. College Graduate

5. Some Graduate Studies

6. Graduate Degree

V. How long have you worked for this organization?

1. Less than a year

2. More than a year, but less than two years

3. More than two years, but less than four years

4. More than four years

VI. When was your last performance appraisal review?

1. Less than a year ago

2. More than a year ago, but less than two years

3. More than two years ago, but less than four years

4. More than four years ago

5. Never been appraised

(Please Go To The Next Page) 
PA Perceplion Survey

For the staiements that follow, use the following key for your responses:

$$
\begin{aligned}
& 4=\text { Strongly Agree } \\
& 3=\text { Somewhat Agree } \\
& 2=\text { Somewhat Disagree } \\
& 1=\text { Strongly Disagree }
\end{aligned}
$$

Remember, there are no right or wrong answers- only honest and not-so-honest responses.

1. The performance appraisal system at this organization is a good educational tool for me in that it teaches me about what the organization values in my work.

2. Getting good performance appraisal revues is critical for advancement in this organization.

3. I feel free to approach my supervisor with regard to any problem concerning my performance or my career with this organization.

4. Each time I am appraised I learn new important information about my performance.

5. Performance appraisals make me nervous because they are potentially unfair.

6. My supervisor is frank with me about my performance. S/he lets me know what I do well, and where I need to improve in a none threatening way.

7. The performance appraisal system we have here is not that important in the grand scheme of things.

8. I personally feel I get helpful feedback about my performance through the performance appraisal process. 


$$
\begin{aligned}
& 4=\text { Strongly Agree } \\
& 3=\text { Somewhat Agree } \\
& 2=\text { Somewhat Disagree } \\
& 1=\text { Strongly Disagree }
\end{aligned}
$$

9. Throughout the year, my supervisor talks to me encouragingly about my performance goals.

10. I generally think performance appraisal is a waste of time, and most of my colleagues would agree with me.

1!. My supervisor is always finding ways to help me grow professionally.

12. Through the performance appraisal svstem I get pertinent information about what is considered essential for longtime success in this organization.

13. So far, I think my performance appraisals have been generally fair.

14. This organization takes the issue of performance appraisal very seriously.

15. When I talk with my colleagues about performance appraisal, most consider it to be fair.

16. Performance appraisals give me an idea of what is expected of me on the job, behavior wise.

17. I personally know at least one person who is constantly a poor performer year after year, but was never disciplined.

18. Supervisors frequently talk about the importance of performance appraisal reviews.

19. My supervisor encourages me to continually develop my skills in my job area.

20. I agree with the results of the last appraisal I had. 
Appendix 1a

PA PERCEPTION SCALE

\begin{tabular}{|c|c|c|c|c|c|}
\hline Case\# & \multicolumn{2}{|c|}{ Division } & \multicolumn{3}{|c|}{ Section } \\
\hline$\pi$ & II & III & IV & $\mathbf{V}$ & VI \\
\hline
\end{tabular}

FAIRNESS:

\section{COACHING:}

*5

*10

13

15

20

Total

SYSTEM INTEGRITY:

2

$\$ 7$

14

*17

18

Total
3

6

9

11

19

Total

\section{FEEDBACK:}

1

4

8

12

16

Total

* Denotes negative coding 


\section{ORGANIZATIONAL CULTURE SURVEY}

This survey is designed to solicit your individual views and/or perceptions with regard to your organizational value and belief system. There are no right or wrong responses, only honest and not so honest responses. In order to get a clear overall picture of how organizational members feel about their organization it is important that each member respond honestly. Individual responses will be kept in strict confidence. Only aggregate results will be reported.

\section{Instructions: Use the following key for your responses:}

$$
\begin{aligned}
& 4=\text { Very highly valued in the organization } \\
& 3=\text { Valued in the organization } \\
& 2=\text { Given rather low value in the organization } \\
& 1=\text { Not valued in the organization }
\end{aligned}
$$

1. Free interaction among employees, each respecting the feelings, competence, and judgement of others.

2. Facing problems, not shying away from them.

3. Offering moral support and help to employees and colieagues in crisis.

4. Congruity between feelings and expressed behavior.

5. Preventive action on most matters.

6. Employees' taking independent action relating to their jobs.

7. Teamwork and team spirit.

8. Employees trying out innovative ways of solving problems.

9. Genuine sharing of information, feelings, and thoughts in meetings.

10. Going deeper rather than doing surface-level analysis of interpersonal problems.

11. Interpersonal contact and support among employees.

12. Tactfulness, cleverness, and even a little manipulation to get things done. 


$$
\begin{aligned}
& 4=\text { Very highly valued in the organization } \\
& 3=\text { Valued in the organization } \\
& 2=\text { Given rather low value in the organization } \\
& 1=\text { Not valued in the organization }
\end{aligned}
$$

13. Supervisors' encouraging their subordinates to think about their development and take action in that direction.

14. Close supervision and direction of employees regarding action.

15. Accepting and appreciating help offered by others.

16. Encouraging employees to take a fresh look at how things are done.

17. Free discussion and communication between superiors and subordinates.

18. Facing challenges inherent in the work situation.

19. Confiding in superiors without fear that they will misuse the trust.

20. "Owning" mistakes made (No passing the buck).

21. Considering both positive and negative aspects before taking action.

22. Obeying and checking with superiors rather than acting on one's own.

23.Performing immediate tasks rather than being concerned about larger organizational goals.

24. Making genuine attempts to change behavior on the basis of feedback received.

New Instructions: Use the following key for the remainder of your responses:

$$
\begin{aligned}
& 4=\text { This belief is very widely shared in the organization } \\
& 3=\text { This belief is fairly well shared in the organization } \\
& 2=\text { Only some people in the organization share this belief } \\
& 1=\text { Few or no people in the organization share this belief }
\end{aligned}
$$

25. Effective managers suppress their feelings.

26. Pass the buck tactfully when there is a problem. 


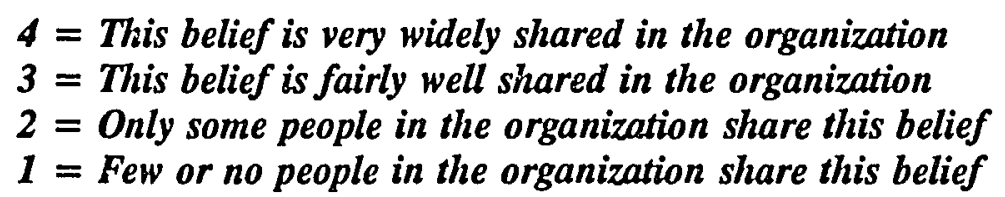

27. Trust begets trust.

28. Telling a polite lie is preferable to telling the unpleasant truth.

29. Prevention is better than cure.

30. Freedom for employees breeds lack of discipline.

31. Emphasis on teamwork dilutes individual accountability.

32. Thinking and doing new things tones up organizational vitality.

33. Free and candid communications between various levels helps in solving problems.

34. Surfacing problems is not enough; we should find solutions.

35. When the situation is urgent and has to be dealt with, you have to fend for yourself.

36. People are what they seem to be.

37. A stitch in time saves nine.

38. A good way to motivate employees is to give them autonomy to plan their work.

39. Employee involvement in developing the organization's mission and goals contributes to productivity.

40. In today's competitive situation, consolidation and stability are more important than experimentation. 
Appendix 1b

Case\#

OCTAPACE PROFLE SHEET

OPENNESS

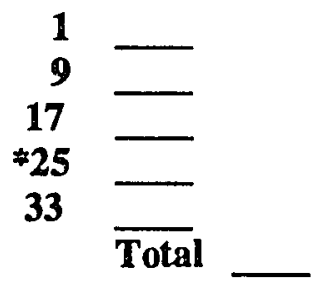

CONFRONTATION

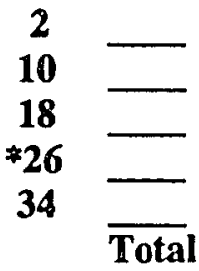

TRUST

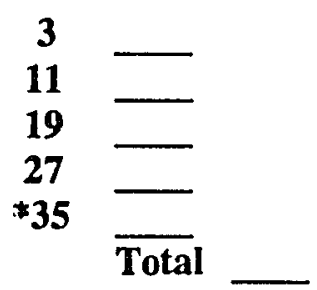

AUTHENTICITY

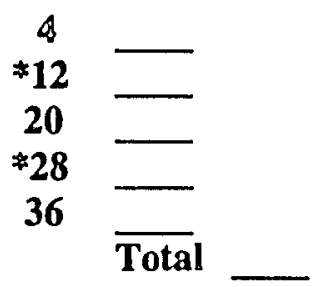

* Denotes negative coding
PROACTION

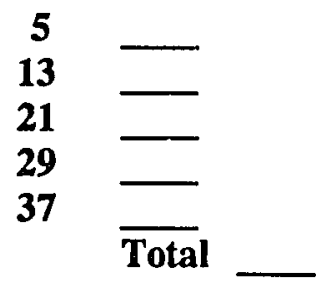

AUTONOMY

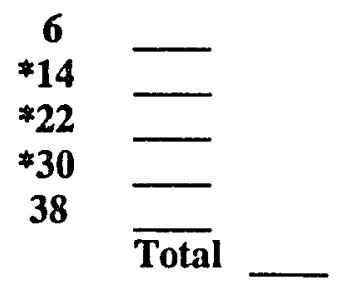

\section{COLLABORATION}

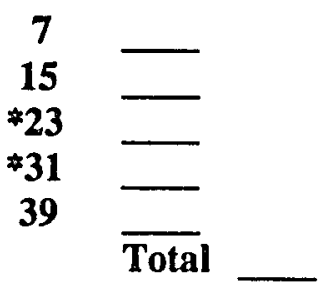

EXPERIMENTATION

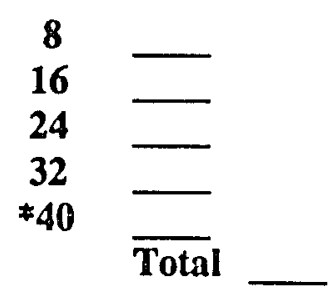




\title{
Appendix 1c
}

\author{
School of Urban and Public Affairs \\ C/O Office of the Dean \\ Portland State University \\ P.O. Box 751. Portland. OR 97207-0751
}

Dear EA member:

You might have learned through E-Mail that I would be conducting a perforanance appraisal (performance evaluation or performance review) and organizational culture (beliefs, values, and behaviors) study here at the EA This survey is designed to solicit your views with regard to those issues. Your participation is voluntary, of course. The survey results will be used in two ways:

1. A report will be compiled and given to the EA management. In that report, a summary of findings and, possibly, suggestions and/or recommendations in specific areas will be presented.

2. The results of this study will also be used in my doctoral dissertation entitled Performance Appraisal in Organizational Cultural Context. I am pursuing the degree through Portland State University's School of Urban and Public Affairs.

About responding in the survey: There are no right or wrong answers-- only honest and not-so-honest responses. Your responses will only be helpful, in the final analysis, if they are honest. Nobody will know how you, specifically, responded to each of the statements-- only group results will be reported. In your responses, think specifically about your own section. In statements that require you to respond to organizational values, think in terms of how you feel about the organization as a whole, and what you perceive to be the general feelings of those you interact with based on what you have heard them say about their experience in this organization. You will need ten to fifteen minutes to complete the survey. Please read and sign the "Informed Consent" statement that accompanies this note and survey. This is a Portland State University requirement.

A.fter you have completed the survey form, please take it to the reception desk where an envelop bas been provided for that purpose. Separate the "Informed Consent" form from the survey form and put it in another envelope (also provided for that purpose)- that way, it's not possible to link your name with your responses. Remember, don't write your name on the survey form. You are welcome to make additional comments on the form if you wish.

If you have any questions, call me at (503) 246-0654. If I am not there, which is normal, please leave a message and phone number where I can reach you and I will get back to you as soon as possible. I am hoping that you can complete the survey and turn it in by the end of business day on Friday, October 28. Thank you in advance for participating because this study cannot be adequately insightful without your input.

Sincerely,

Unoda C. Moyo 


\section{INFORMED CONSENT FORM}

I,

, agree to take part in this research project on Performance Appraisal in Organizational Cultural Context. I understand that the study involves voluntarily responding to the questions presented by the researcher in either questionnaire or interview format.

Unoda Moyo has told me that the purpose of the study is to learn if a relationship exists between organizational culture and its performance appraisal system.

I may not receive any direct benefit from taking part in this study. But the study may help to increase knowledge that may help others in the future.

Unoda Moyo has offered to answer any questions I have about the study and what I am expected to do.

He has promised that all information I give will be kept confidential to the extent of the law, and that the names of all people in the study will be kept confidential.

I understand that I do not have to take part in this study and may withdraw at anytime during the course of the study.

I have read and understand the above information and agree to take part in this study.

Date: Signature:

If you have any concerns or questions about this study, please contact the Chair of the Human Subjects Research Review Committee, Office of Grants and Contracts, 105 Neuberger Hall, Portland State University, 503/725-3417. 
Appendix 1d

Division Section

Interview Questions for Organizational Members:

(These questions were asked to both management and non-mangement and were adjusted accordingly from case to case).

1. In your opinion, how much has the culture at the EA changed since you have been here?

a What has specifically changed?

b. What hasn't changed?

2. How easily did those changes occur?

3. Do you feel the culture has either helped or hurt the overall performance of the EA?

4. What words or phrases best describe the organizational culture at $\mathbf{E A}$ in the last decade? If it has changed much in the last decade, describe what has changed and what has remained constant. 
5. How much has the culture at the EA valued employees?

6. Do you believe the way individual employees' performance is evaluated plays a role in the way they behave?

7. In organizational (and divisional) meetings, does the issue of performance appraisal surface often? How would you sum up the general managerial attitude towards performance appraisal?

8. Are you personally satisfied with the performance appraisal at the EA? Do you personally try to use the system as a coaching tool?

9. If it were all up to you, would you recommend the continuation of the formal performance appraisal process? Why or why not?

10. Do you believe the PA process, in its own way, communicates to the rest of organizational membership the values held by the EA leadership? 
11. How would you describe the EA's senior management style (team working together or individuals fighting turf battles)? Who do you see as the key players?

12. Do you believe senior management is supportive of what your section does? How do they convey this?

13. Generally speaking, do you think your section is successful in what it does? Why or why not?

14. What are the people like that work in your division? What distinguishes them from other divisions (different values, standards)?

15. Who would you say gets "ahead" in your division? In other words, what type of person (or function)? Do you see (managers only) opportunities for advancement for yourself?

16. What is communication (sideways and up and down) like in your division (informal, formal, non-existent)? Are there a lot of memos or verbal discussions. How much time is spent in meetings. 
17. How would you describe your own values and attitudes towards work? What do you believe in? Do others in your division share these values?

18. Is there something you can think of that you can share with me that is related to the EA culture and the performance appraisal system? 


\section{Appendix 2}

\section{Complete Ecology Agency Performance Appraisal System Dimensions With Brief Definitions '}

\section{Individual characteristics include:}

1. Effective judgement. This is where an individual is evaluated on his or her demonstrated ability to assess and judge a work problem or situation and solve the problem in the most productive manner, also, an individual has to demonstrate the ability to think on a long-term basis and an ability not to sacrifice good judgement or best solutions in exchange for avoiding conflicts.

2. Continuous improvement. This evaluates the individual's ability to improve job performance of self and work unit through training, and keeping abreast of changes and seeking opportunity for growth on job through assuming extra and/or special assignments.

3. Professionalism. This appraises the ability of the individual to conduct himself/herself, while representing the state or the Agency, in a manner that meets the standards of the work unit, organization, the state, and/or agency, the area of specialization and professional field.

4. Responsiveness. This evaluates the individual's ability to prioritize assignments and readiness to assimilate into own work priorities; and ability to respond to crises in an appropriate manner. Also, responsiveness characteristic enables the individual to identify conflicting priorities and effectively address them in reprioritization.

5. Creativity. This measures an individual's ability to go beyond normal range of solutions by finding ways to address issues from new and differing perspectives.

6. Decisiveness. This evaluates an individual's ability to make appropriate decisions in a timely manner.

7. Initiative. This measures the ability of the individual to be a self-starter in dealing with jobs or situations that need addressing.

\footnotetext{
${ }^{1}$ This information is taken from the Performance Management Manual. Some definitions have been paraphrased.
} 
8. Political awareness. This evaluates the individual's ability to understand the governmental, political and legislative process. This is understood by the individual's ability to work within that parameters of the process to forward the goals of the agency and the work unit. Also, a politically aware individual is sensitive to the possible internal and external perceptions of actions, and anticipates and plans for others' needs and reactions.

\section{Managerial Characteristics include:}

1. Planning and Organizing. This evaluates the individual's capabilities in developing practical plans and schedules for meeting goals, and his/her capabilities in considering alternatives and anticipating ramifications of decisions and barriers to getting the job done.

2. Strategic thinking. This evaluates the ability of the individual to accurately predict and forecast future needs and prepare strategies for dealing with them. This aspect also evaluates an individual's ability to develop contingency plans with staff to deal with the unexpected.

3. Tactical thinking. This evaluates an individual's ability to use resources in effectively implementing, monitoring, and maintaining strategic plans.

4. Problem solving. This aspect appraises the individual's resourcefulness in analyzing and solving problems related to meeting goals and achieving desired results.

5. Decision making. This evaluates an individual's ability to make appropriate decisions and taking responsibility for all those decisions.

6. Risk taking. This appraises an individual's ability to take appropriate calculated risks, where potential risk factors are properly analyzed.

7. Managing Change. This evaluates the manager's ability to create an environment that allows for change to happen in an efficient and effective manner by recognizing the need for change and setting up processes to accommodate change. 
8. Analytical skills. This aspect evaluates the individual's ability to make decisions or recommend actions that are based on careful analysis of available information, and the ability to recognize essential elements of a problem.

9. Delegation. This evaluates the manager's ability to appropriately assign work and projects ot the appropriate people at the appropriate level with consideration to priorities and workload.

\section{Interactive skills include:}

1. Team building. Evaluates ability to work well with others to accomplish team objectives both as a leader and member of the team.

2. Consensus building. Evaluates the ability to recognize situations needing consensus of decision, including appropriate members in decision making process, and effective leadership in groups to build that consensus.

3. Communication. Evaluates ability to share information by clearly expressing ideas and information verbally and in writing and giving clear instructions.

4. Networking. Evaluates the extent to which the individual establishes and maintains effective external relationships by developing an external base of knowledge and skill through other individuals within or outside the agency .

5. Liaison role. Evaluates ability to provide a liaison between groups and establishment, maintenance, and monitoring of communication between groups to ensure effective exchange of ideas, information, and policy.

6. Cooperation. Evaluates the ability to readily identify situations needing collaborative work effort and following through with teamwork with other parties.

7. Persuasion/Negotiation. Evaluates the ability to identify situations needing persuasion/negotiation and effectively reaching conclusions through persuasion and negotiation. 
8. Listening Ability. This evaluates an individual's ability to listen actively, to be accessible and approachable. This ability involves understanding issues brought forward, asking questions proactively about information being transmitted, clarifying issues, and ensuring mutual understanding of information being communicated.

9. Customer service. Evaluates the ability to provide customers with products, decisions, information, or assistance in a manner that is timely and meeting the needs of the customer.

\section{Leadership Characteristics include:}

1. Directing. his evaluates the ability of the manager to establish goals aligned with agency's priorities by clarifying roles and responsibility, and ensuring that work being conducted meets the organization's goals by continually establishing monitoring organizational priorities.

2. Motivating. This evaluates the manager's ability to create a climate that motivates employees to perform to their potential and eliciting enthusiastic cooperation and creative innovation from others.

3. Accepting responsibility. This evaluates the extent to which the manager accepts responsibility for the results achieved by the section or unit.

4. Accountability. This evaluates the manager's ability to ensure that work product accountability is established and work output is accomplished by those responsible, and the ability to identify both positive and nonproductive work outputs and appropriately rewarding success or modifying behavior to eliminate nonproductive outputs.

5. Role model. This evaluates the degree to which the manager sets an example by modeling agency values and leading by example.

6. Creative Environment. This evaluates the extent to which the manager creates an environment that allows for innovation and original ideas, and showing acceptance towards imagination and originality in thinking and encouraging the values of new ideas. 
7. Work habits. This evaluates the individual's work habits such as, maintaining an acceptable attendance pattern, being available when needed, effective use of time, using safe work habits, obeying all safety rules, and proactively looking to make the work safer.

8. Personal ownership. This evaluates the individual's ability to accept personal ownership for performance commitments and goals.

9. Integrity. This evaluates the manager's adherence to ethical standards, building trust, following through on commitments, accepting responsibility for failures as well as accomplishments, honestly portraying self and unit in all situations in all situations, and rigorously guarding confidentiality of information.

10. Continuous learning. This evaluates the individual's ability to keep up to date on job-related knowledge and skills.

11. Ethics. Like integrity, this aspect evaluates the individual's adherence to all ethical standards. In addition, this aspect evaluates the individual's ability not to compromise the ethics of the agency or the state by assessing each work situation to determine potential ethics issues involved, such as conflict of interest issues that can jeopardize public trust.

12. Involvement. This aspect evaluates the ability of the manager to ensure involvement of staff, customers, and clients in decisions affecting them or their work.

\section{Administration characteristics include:}

1. Systems administration. This evaluates the manager's ability to use systems/procedures/control systems to ensure state, federal, or other requirements are met, and the ability to identify problems and recommending and implementing their respective solutions.

2. Following business guidelines. This evaluates the manager's ability to apply and follow business-related guidelines/requirements.

3. Policy implementation. This evaluates the manager's ability to correctly implement state and agency policies and contracts by ensuring that implementation flows smoothly with all requirements met, and understanding the ramifications of policy and ensuring that negative consequences are addressed. 
4. Policy development. This evaluates the manager's ability to recognize the need for policy change or establishment and effectively developing policies, procedures, or controls necessary to carry out operations of the agency.

5. Fiscal Issues. This aspect evaluates the manager's understanding, promotions, and monitoring of budgetary controls to ensure responsible monetary expenditure by adhering to budgetary process and supporting the organization's budget, and staying within budgetary limitations.

\section{People Management characteristics include:}

1. Staff development. This evaluates the manager's ability to coach and mentor staff to develop and improve their performance by assisting in all areas of their development.

2. Performance management and performance management of subordinates. These aspects evaluate the manager's ability to actively ensure that the organization is moving towards the achievement of performance management and performance standards by setting performance measures for subordinates and providing timely feedback and conduction performance appraisals in a timely manner.

3. Selection. This aspect evaluates the manager's ability to select qualified, competent people to fill positions following established rules, regulations, laws, labor agreements, and policies, and taking proactive role in selection process.

4. Worker's compensation/return of injured workers, safety, and promoting wellness. These aspects evaluate the manager's ability to promote and ensure safe work environment, his/her realization of the costs associated with worker's compensation claims, his/her promotion of wellness programs in the workplace.

5. Affirmative action/EEO and Diversity. These aspects evaluates the manager's ability to promote a working environment that fosters a diverse workforce, and his/her ability to take a proactive role in achieving AA/EEO objectives and promoting a discrimination/harassment free workplace. 


\section{Job Rnowledge Characteristics include:}

1. Technical job knowledge. This aspect evaluates the individual's ability to understand the day to day knowledge needed to perform the job and applying the required technical knowledge.

2. Process literacy. This aspect evaluates the individual's knowledge of the work processes, procedures, laws, rules, regulations, and systems such that work output shows interrelationship between work assignment and organizational structure and the mission/goals of the agency.

8 Work Output is the only category that is unique for each individual as it is defined by the appraiser, based on the position description, for the incumbent/position being evaluated. The appraiser is required to describe the requirements of the position and the standards upon which these requirements will be evaluated at the beginning of the evaluation period. This information or requirements form the basis for each individual's work plan for the appraisal period. 